\title{
ఇUSGS
}

science for a changing world

Southwest Biological Science Center

\section{Mountain Lions of the Flagstaff Uplands 2003-2006 Progress Report}

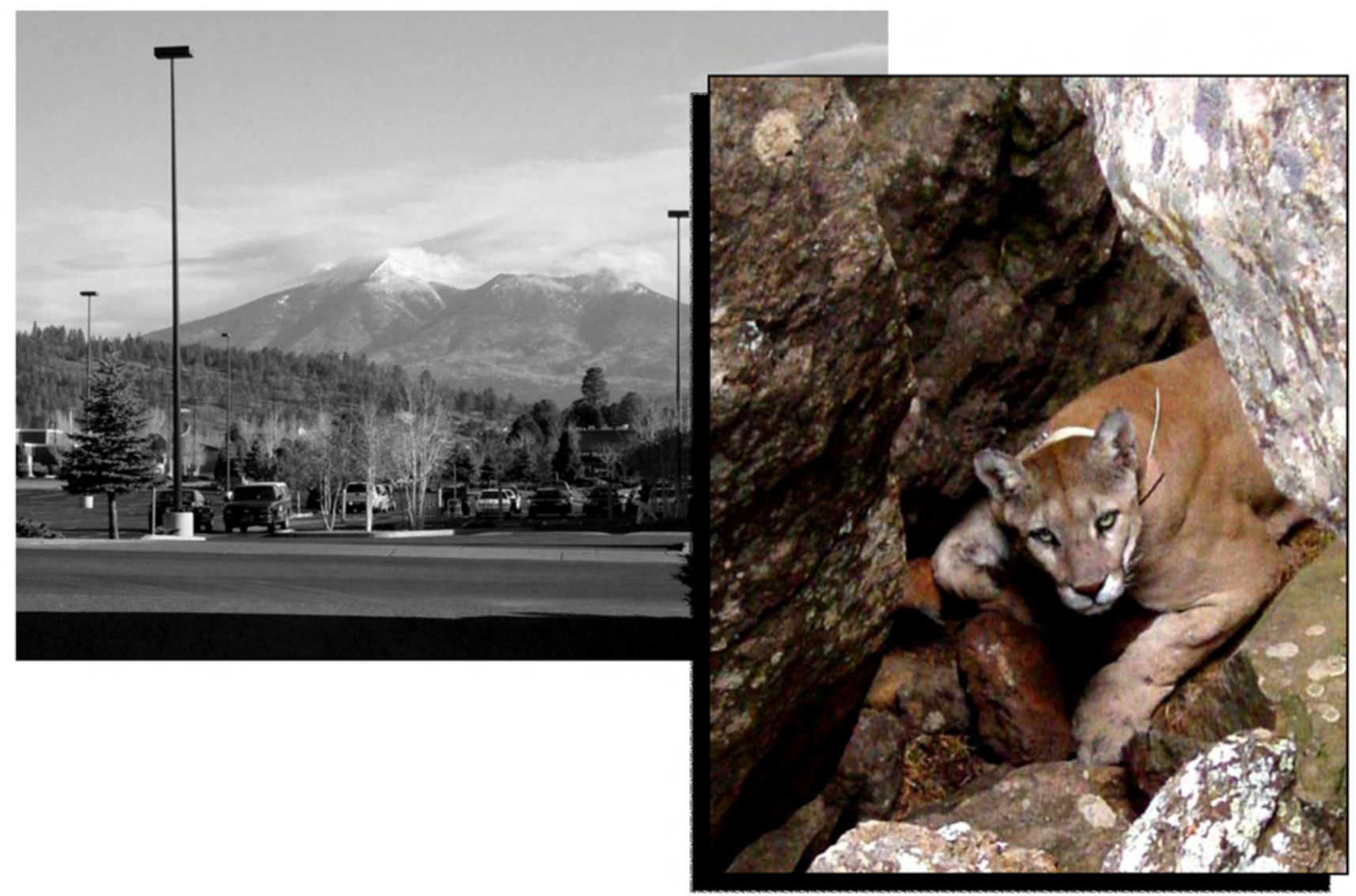

Open-File Report 2007-1062

2007

U.S. Department of the Interior

U.S. Geological Survey 


\section{Mountain Lions of the Flagstaff Uplands 2003-2006 Progress Report}

Edited by David J. Mattson

2007

Open-File Report 2007-1062

U.S. Department of the Interior

U.S. Geological Survey 


\section{Contents}

Executive Summary.

Page 5

Chapter 1. Background and Methods for Investigating Mountain Lions in the Flagstaff Uplands

Jan Hart, David Mattson, and Terence Arundel.

Page 6

Chapter 2. Movements and Habitat Selection by Mountain Lions in the Flagstaff Uplands

Terence Arundel, David Mattson, and Jan Hart.....

Page 17

Chapter 3. Predation and Other Behaviors of Mountain Lions in the Flagstaff Uplands

David Mattson, Jan Hart, Mike Miller, and Diane Miller....

Page 31

Chapter 4. Managing for Human Safety in Mountain Lion Range

David Mattson.

Page 43

References Cited.

Page 57

Acknowledgments

Page 63

Appendix 1. Summary of Outreach

Page 64 


\title{
U.S. Department of the Interior \\ DIRK KEMPTHORNE, Secretary
}

\author{
U.S. Geological Survey \\ Mark D. Myers, Director
}

U.S. Geological Survey, Reston, Virginia 2007

For product and ordering information:

World Wide Web: http://www.usgs.gov/pubprod

Telephone: 1-888-ASK-USGS

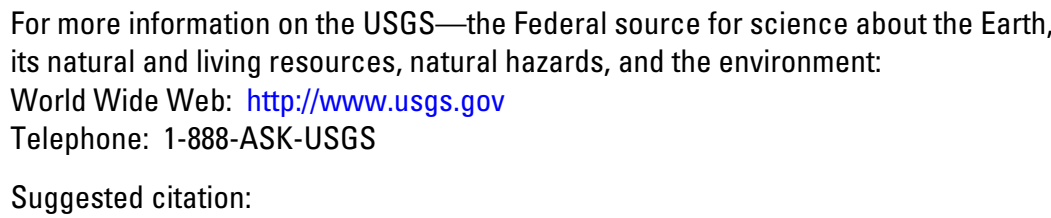

Cover: Background photo, San Francisco Peaks behind downtown Flagstaff, AZ, David Mattson, USGS Southwest Biological Science Center; inset photo, adult male mountain lion N6, Anderson Mesa, Jan Hart, USGS Colorado Plateau Research Station. 


\section{Executive Summary}

Stakeholders in management of mountain lions in the Flagstaff Uplands of northern Arizona have expressed increasing concern about both potential impacts of humans on lions and potential risks posed by lions to humans. A series of human-mountain lion encounters during 20002001 on Mt. Elden, immediately adjacent to Flagstaff, and similar incidents during 2004 near Tucson brought increased attention to management of human safety in mountain lion range. These human-centered concerns, together with longstanding questions about how the human infrastructure centered on Flagstaff might be affecting lion movements led us to initiate a mountain lion study in 2003 which we plan to continue through 2009. Our study focuses on movements and other behaviors of mountain lions, with the goal of providing information that can be used to increase human safety, decrease human impacts, and, overall, provide insight into the ecology of lions in this region. To serve this goal, we have focused on collecting data that will be the basis of explanatory models that can provide spatially-explicit predictions of mountain lion activity, specify the effects of human facilities, such as highways and urban areas, and provide insight into when, where, and how often different kinds of lions kill different kinds of prey.

During 2003-2006, we captured six female and five male mountain lions in the Flagstaff Uplands, 10 of which we fitted with collars that collected up to six high-precision GPS fixes per day, transmitted daily to our offices via Argos satellites. This timely delivery of data allowed us to visit kill sites and other foci of localized activity to collect detailed information on lion behavior. By June 2006 we had obtained 9357 GPS locations and visited 394 sites, at which we documented 218 kills, 165 of which were by five females and 53 by five males. These data were the basis for preliminary analyses presented in this report. All lions during all seasons exhibited a strong selection for rough terrain and forest or woodland cover. Females differed from males by selecting more strongly for intermediate, rather than extreme, levels of terrain roughness, by selecting more strongly for chaparral vegetation and related rocky areas during winter, and by not selecting as strongly for areas near water sources. Overall, lions collared during this study strongly avoided flat open areas in private ownership. Male but not female lions exhibited pronounced selection for National Park Service jurisdictions. Both males and females year-round avoided residential areas and a zone outward to about 1-3 km and, when within this zone, moved more slowly and with less change in direction compared to when farther away. Collared lions have so far rarely crossed paved highways of any description - orders of magnitude less often than expected by chance. We observed only 3 crossings of an interstate highway, all on I17 and none on I40.

Elk comprised the majority (52\%) of kills by lions in our study, followed by mule deer (46\%), and small mammals (15\%). Adults comprised most of the mule deer kills (68\%) and mesocarnivores, primarily coyotes $(n=21)$, comprised $73 \%$ of smaller prey. Calf and shortyearling elk comprised the largest single category of kills (29\%). In addition to kills, we documented seven instances of scavenging, involving four different lions. Females differed from males by killing more mule deer and virtually all of the mesocarnivores, and by killing fewer elk of all ages. Intervals between kills averaged between $144 \mathrm{hrs}$ (young females) to 221 hours (adult females), whereas average time spent on a kill ranged from $19 \mathrm{hrs}$ (adult males) to $40 \mathrm{hrs}$ (young males). Carcass mass had a strong effect on likelihood that a lion would bury or relocate a kill, the percentage of edibles consumed, and overall time spent feeding. Time spent feeding and likelihoods of carcass burial and relocation all peaked at intermediate carcass masses, suggesting an optimal mass in the range of 50-150 kg, likely dictated as much by handling efficiencies and competition from other scavengers as by a lion's shear ability to kill prey. Adult male lions exhibited a life strategy distinctly different from all other sex-age classes that entailed moving more rapidly over larger areas, and spending less time on kills in which they invested less energy handling, but from which they consumed tissue at a higher sustained rate. 


\title{
Chapter 1
}

\section{Background and Methods for Investigating Mountain Lions in the Flagstaff Uplands}

\author{
Jan Hart, David Mattson, and Terence Arundel
}

\section{Background}

\section{Trends and Conditions in the West}

Mountain lions (Puma concolor) are the most widespread large predator in the western United States, creating both opportunities and challenges for wildlife and public lands managers. Mountain lions are sufficiently abundant not only to directly and indirectly affect ecosystems, but also to pose a threat to humans. Human populations and related infrastructures in and near mountain lion range have, moreover, increased rapidly enough during the last three decades to exacerbate risks to humans and to impact mountain lion behaviors and populations (Torres et al. 1996). Wildlife and public land managers are confronted with somehow harmonizing the dual mandate of ensuring human safety while conserving ecologically functional mountain lion populations, often with little or no control over human behaviors and the pace and nature of infrastructure growth. Under such circumstances, detailed information about mountain lions and the effects of humans and human facilities is becoming ever more important to crafting integrated management strategies that create "win-win" solutions.

Threats posed to humans by mountain lions have commanded the attention of managers and the public since the 1980s. In large part this reflects a marked increase in well-publicized and welldocumented attacks on humans by mountain lions during the last 25 years (Etling 2001; see Chapter 4), mirrored in most western states by increases in documented non-injurious encounters with mountain lions that were deemed problematic by the involved humans. These trends have dominated public discourses, despite the fact that only 19 people have been killed by mountain lions in all of Canada and the U.S. since the 1890s, and despite attack rates that are small compared to rates of human injury and death caused by numerous other factors such as automobiles or even lightning
(Beier 1991; but see Chapter 4). The gruesome details of mountain lion attacks seem to fascinate and horrify many people who might not give a second thought to the equally gruesome prospects of a traffic accident.

At the same time that increasing numbers of people have felt threatened by mountain lions, increasing numbers have also valued lions for their aesthetics, naturalness, and role in ecosystems. This trend towards intrinsic valuation of mountain lions parallels a rapid emergence since the 1960s of ecologistic and scientific world views or value systems (Kellert 1996). In fact, a recent survey of Arizona residents revealed not only that a large majority valued having healthy populations of mountain lions, but also that the primary reason for this valuation was the belief that lions play an important ecological role - the essence of Kellert's ecologistic world view (Decision Research 2004). Sometimes heated exchanges between those who value the beauty and ecological role of mountain lions and those who either fear lions or value them for instrumental reasons (Kellert's dominionistic and utilitarian views) have increasingly typified public discourses that end up placing contradictory demands on management (Clark and Munno 1995).

Those who value mountain lions - including wildlife and public land managers with a conservation mandate - have been an increasingly vocal constituency for documenting and mitigating the impacts on lion populations of growing human populations and spreading human infrastructures. Residential areas and major highways potentially fragment and reduce mountain lion populations, not only by preventing lion movements, but also by increasing lion death rates resulting from collision with vehicles or conflict with humans. These kinds of impacts are particularly evident in places such as southern Florida, where vehicular collisions are a major cause of lion deaths (Maehr and Caddick 1995), and southern California, where lion range has shrunk to islands surrounded by a 
veritable sea of humanity (Beier 1993). Even in less urbanized regions of the interior West, heavily used interstate highways and spreading cities threaten to impact of mountain lion populations. Wildlife managers have perhaps most consistently given mountain lions their attention because of long-lasting concerns about impacts of lion predation on vulnerable ungulate populations or game species. In recent decades this concern has crystallized around widespread declines of mule deer (Odocoileus hemionus) and the precarious status or even extirpation of small and isolated bighorn sheep (Ovis canadensis) populations. Although a recent review of research regarding mule deer population declines concluded that mountain lions probably have had major impacts only where deer populations were severely reduced for other reasons (Ballard et al. 2001), and where lions have had significant numbers of alternate prey, an influential constituency still exists for widespread reduction of lion populations to increase densities of mule deer. Even greater support exists among hunters and wildlife managers for reducing or eliminating mountain lions in limited areas to help recover or re-establish bighorn sheep populations, supported by recent research showing that mountain lions were a significant factor in the loss or near loss of several populations of desert bighorn sheep (Hayes et al. 2000, Rominger et al. 2004).

\section{Arizona and the Flagstaff Uplands}

Even though mountain lions have injured only four people and killed none in Arizona since 1900, recorded conflict between humans and lions has increased especially since the early 1990s (Barber 2005). This conflict was epitomized by a series of incidents during the winter of 2000-2001 on Mt. Elden, immediately adjacent to Flagstaff, and a similar series of incidents during the winter of 2004 in Sabino Canyon, immediately adjacent to Tucson (Perry and DeVos 2005). In both cases, people reported what to them were threatening encounters with lions in popular hiking areas. On Mt. Elden, the encounters culminated in an attack by a lion on a dog accompanying a human. Mountain lions were killed or otherwise removed in both areas out of concern for human safety, but the publicity surrounding both cases was prolific, sometimes strongly expressed, and often focused on the performance of management agencies. Many participants emerged from these cases with a desire for standardized response protocols and more information about mountain lion behavior, especially pertaining to human safety.

Like other wildlife and public lands managers, National Park Service (NPS) managers on the Colorado Plateau have expressed increasing concern about mountain lions, focused on not only on human safety, but also on human impacts on lions and the ecological role of lions in park ecosystems. A 1999 survey of NPS units on the Colorado Plateau revealed that 11 parks (NPs) and monuments (NMs) considered mountain lions to be a management priority. Among these NPS units were Walnut Canyon and Wupatki NMs in the Flagstaff Uplands. These monuments, in particular, were concerned not only about human safety, but also about impacts of nearby Flagstaff residential areas and adjacent highways and railroads on mountain lion movements. Interstate Highway 40 (I40) and the paralleling Burlington Northern-Santa Fe (BNSF) railroad separate Walnut Canyon NM to the north from the two other Flagstaff area NMs (Sunset Crater Volcano and Wupatki), and I17 and the Flagstaff urban area lie astride potential wildlife movements routes to the west. Nearly 100 trains travel the BNSF railroad daily; I17 and I40 carry the bulk of traffic destined for Phoenix and the Los Angeles basin. Analysis of DNA from hunter-harvested mountain lions north and south of I40 and the railroad has shown a degree of genetic differentiation consistent with complete blockage of mountain lion movements by the interstate and railroad (McRae et al. 2005).

Arizona Game and Fish Department (AZGF) has had two priorities for mountain lion management in the Flagstaff Uplands: (1) insuring human safety; and (2) providing a quality sustainable hunt of mountain lions (AZGF 2001, 2005a). Concerns have also been expressed about potential impacts of lion predation on vulnerable pronghorn (Antilocapra americana) populations. The importance of human safety came into focus especially with the Mt. Elden incidents of winter 2000-2001, and was reason for AZGF holding one of three statewide workshops on management of mountain lion incidents in Flagstaff during the winter of 2004-2005. Concern about human safety has also precipitated a considerable increase in public outreach and education by AZGF, including presentations and the distribution of flyers and brochures (AZGF 2005a). Mountain lion hunting has always been a priority outcome for AZGF, but 
an increasingly controversial one in light of regulations that, until recently, did not expressly provide for area limits on number of kills or prohibit the killing of cubs or females with cubs (Schubert 2004). Concern on the part of animal rights advocates over these non-restrictive regulations has spilled over into debates about how to manage for human safety, and the relative merits of lethal versus non-lethal measures (Clark and Munno 2005, Perry and DeVos 2005).

Although pronghorn are generally not considered to be mountain lion prey, primarily because of their fleetness and open habitats, some pronghorn kills by lions have been documented (Ockenfels 1994). Several comparatively small and vulnerable populations of pronghorn in the Flagstaff Uplands spend much of their time in semi-isolated grasslands surrounded and encroached upon by ponderosa pine (Pinus ponderosa) forests and pinyon (Pinus edulis) and juniper (Juniperus utahensis and J. monosperma) woodlands. This nearness and comparative commonness of potential ambush cover has been thought to increase mountain lion predation on these pronghorn populations, compounding the impacts of cattle grazing on pronghorn habitat and coyote (Canis latrans) predation on fawns (Barrett et al. 1984). Even so, little is known about the extent of lion predation on pronghorns, factors driving it, and whether many lions or few are responsible.

\section{This Study}

This study was designed to address a broad range of questions arising from issues articulated in the preceding section, focused on mountain lion behavior in areas surrounding Flagstaff and nearby NPS NMs. Our focal questions pertain to mountain lions movements, habitat selection, and predatory behaviors, as follow:

(1) What are seasonal mountain lion range sizes and rates of movement, by gender and ageclass, and the locations of ranges relative to
Flagstaff residential areas, NPS NMs, and heavilytrafficked highways or railroads?

(2) How often do lions cross roads of different types, and is this rate different from what would be expected at random?

(3) What are diagnostic features of places where mountain lions do cross heavily-trafficked highways or railroads?

(4) What are seasonally diagnostic features of habitats heavily used by mountain lions, by gender and age-class, and where are these heavily-used seasonal habitats located relative to Flagstaff residential areas, NPS NMs, heavily-trafficked highways or railroads, and areas regularly used by pronghorn?

(5) What are the diel patterns of kills and movements by mountain lions when near humans versus far away?

(6) How often and what do mountain lions kill, by season, by species and estimated mass of prey, and by gender and age-class of lion?

(7) How long do mountain lions stay with kills and what behaviors do they exhibit while there, by species and estimated mass of prey, and by gender and age-class of lion?

(8) What are seasonally diagnostic features of sites where mountain lions make kills, and where are these types of sites located relative to Flagstaff residential areas, NPS NMs, and areas regularly used by pronghorn?

In more concrete terms, this study is designed to produce information that will allow managers to assess temporal and spatial dimensions of risk to humans, impacts of humans on mountain lions, and impacts of mountain lion predation on prey species. To serve this end, key products will be:

(1) Explanatory models of mountain lion habitat selection that can be used to generate maps of high versus low levels of predicted mountain lion activity;

(2) Explanatory models of kill site selection by mountain lions that can be used to generate maps of high versus low predicted levels of predatory activity; and 

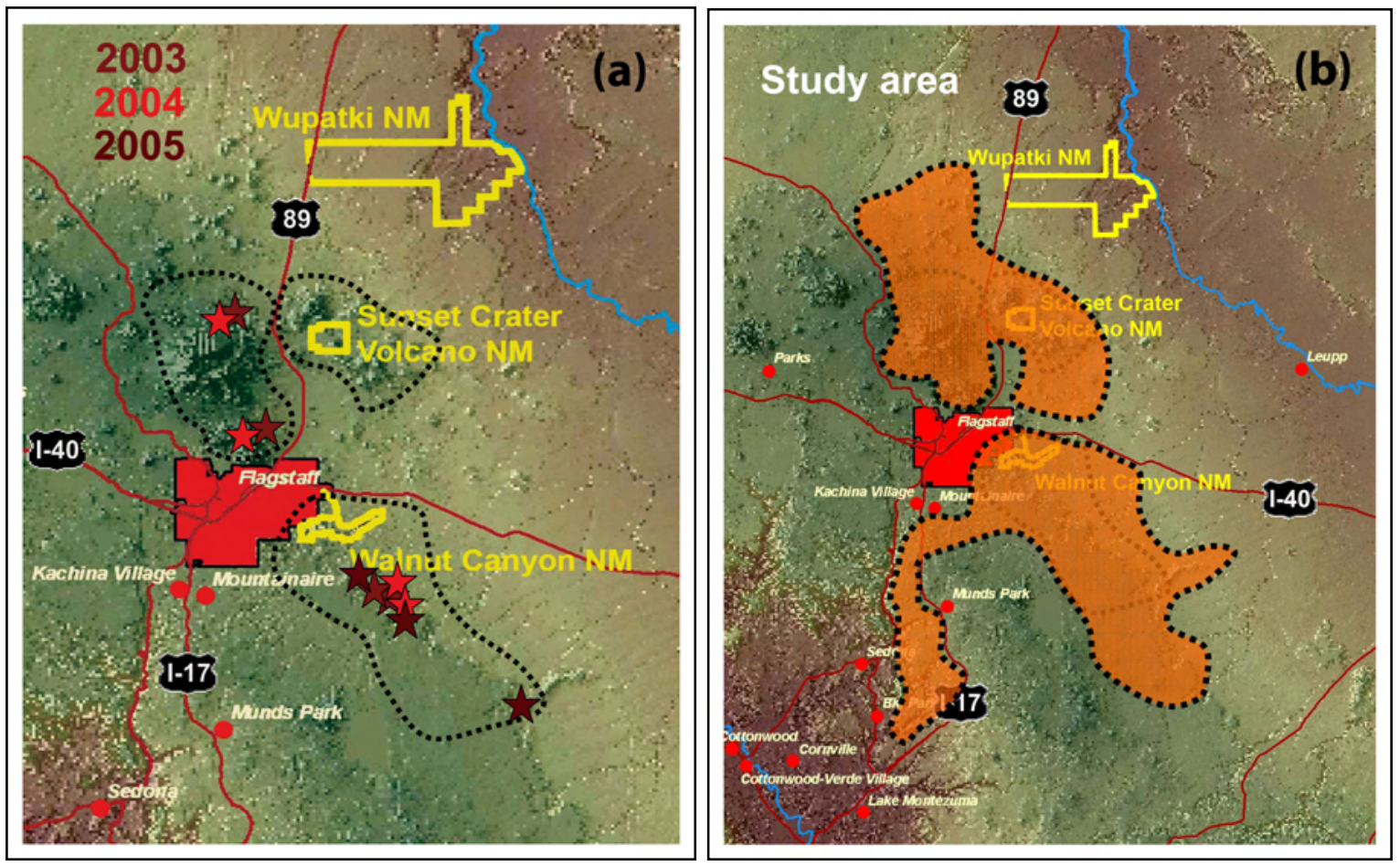

Figure 1.1. The Flagstaff Uplands with the Flagstaff incorporated area and major highways in red, and National Monuments in yellow. (a) Capture areas are delineated by dashed black lines and locations of mountain lion captures are denoted by stars of different colors corresponding to different years, as indicated by years given on the map. (b) The study area, as denoted by the orange area bounded by a dashed black line is defined by the extent of current movements by captured lions.

(3) Explanatory models of predatory behavior that will provide insight into when, where, and how often different kinds of mountain lions kill different kinds of prey.

Proposals to initiate this study were written in 2002, at a time when there were no investigations in Arizona or neighboring interior western states focused on human safety or mountain lions using the urban-wildland interface, and after other management agencies expressed little interest in pursuing such a study after being approached by this study's investigators. The impetus for our work arose from NPS concerns and initial funding came from the USGS Park-Oriented Biological Support (POBS) Program. Subsequent funded proposals broadened the topical and geographic scope of our investigations and were supported by the USGS Southwest Biological Science Center, the Summerlee Foundation, the NPS Cooperative Conservation Initiative, the USGS Fire Research Program, the USGS Colorado Plateau Research Station, the Wilburforce Foundation, and the Johnson Family Foundation.

\section{Study Area}

Our study area is centered on Flagstaff, Arizona, at approximately $35^{\circ} 10^{\prime} \mathrm{N}$ latitude and $111^{\circ} 35^{\prime}$ W longitude. The study area boundary continues to evolve with documented movements of marked animals, and was initially determined by capture areas delineated to radio-mark animals that would be exposed to NPS units and important human features of the Flagstaff Uplands (Figures 1.1a and 1.1b). We established capture areas north and south of I40, containing Walnut Canyon (south) and Sunset Crater Volcano (north) NMs, with the intention of marking animals that potentially used these NPS units and also had opportunity to cross I40 and, to the north, U.S. Highway 89. We also established a capture area immediately north of Flagstaff, on Mt. Elden and the San Francisco Peaks, to mark animals that would likely use the urban-wildlife interface, including the problematic south-face of Mt. Elden (see Background), and also have the opportunity to cross U.S. Highway 89 in areas farther from Flagstaff. 
The current study area ranges from grassland and juniper woodland at 1,600 m elevation up to alpine at 3,850 m on the top of Mt. Humphreys, the highest point in Arizona. Most of the study area is between 1,980 and 2,290 m elevation and consists of plateaus and other comparatively flat topography incised by shallow canyons. Aside from the San Francisco Peaks massif, most mountainous topography consists of cinder cones and other volcanic features, primarily to the north of Flagstaff, and the scarps of plateaus, primarily to the south. Natural surface water is uniformly scarce because typically porous substrates allow for rapid drainage of precipitation, even in comparatively well-watered areas. Humans have compensated by building a network of numerous well-distributed artificial devices to provision livestock and water-dependent wildlife with water.

The climate is sunny and temperate to warm and semi-arid. On average, Flagstaff has 209 days with minimum temperatures below $0^{\circ} \mathrm{C}$, three days with maximum temperatures above $32^{\circ} \mathrm{C}$, a January mean of $-1.8^{\circ} \mathrm{C}$, and a July mean of $19.1^{\circ} \mathrm{C}$. Flagstaff's $58 \mathrm{~cm}$ of precipitation is moreor-less uniformly distributed throughout the year, with the exception of a strong spring drought that lasts roughly from mid-April to the first week in July. Monsoonal precipitation, primarily from thunderstorms, breaks the drought, and typically lasts until mid-September. Snowfall around Flagstaff averages $245 \mathrm{~cm}$. To the east, and lower in elevation, annual precipitation declines to about $20 \mathrm{~cm}$ and mean summer temperatures increase by about $6^{\circ} \mathrm{C}$. To the south temperatures increase, although monsoonal precipitation also increases, resulting in an elevational depression of vegetation zones.

Pinyon-juniper woodlands and ponderosa pine forests cover most of the study area, grading to sparse grass and low shrubs at lower elevations to the north and east, and dense chaparral-like shrublands on south-facing slopes at mid- and lower-elevations near Flagstaff and south. This chaparral is typified by oaks (Quercus spp.), mountain mahogany (Cercocarpus montanus), cliffrose (Purshia stansburiana), and Fremont mahonia (Mahonia fremontii). At higher elevations of the San Francisco Peaks ponderosa pine forests are progressively replaced upward in elevation by aspen (Populus tremuloides) and mixed conifers (typified by white fir [Abies concolor] and southwestern white pine [Pinus strobiformis]), by subalpine fir (Abies lasiocarpa) and bristlecone pine (Pinus aristata), and finally by alpine fellfields and tundra.

There are no reliable estimates for populations of potential mountain lion prey in our study area, although there are substantial numbers of mule deer and elk (Cervus elaphus), blacktail jackrabbit (Lepus californicus) and desert cottontail (Sylvilagus auduboni), and coyotes, bobcats (Lynx rufus), and badgers (Taxidea taxus). Whitetail deer (O. virginianus) are rare and javelina (Pecari angulatus) are present but not abundant.

Pronghorn are present and seasonally semi-isolated in grasslands scattered throughout the predominantly forested study area. At mid- to high-elevations, mule deer tend to concentrate on southerly slopes during the winter, especially where oaks, cliffrose, and mountain mahogany are abundant. Elk tend to be more widely dispersed, especially during milder winters.

Humans in our study area are concentrated in and near Flagstaff, primarily because most lands outside the Flagstaff corporate boundary are publicly owned and managed by the U.S. Forest Service. Current populations of Flagstaff and the broader study area are roughly 60,000 and 100,000 , respectively, with Flagstaff's population roughly six-times larger now compared to in the 1950s. Interstate Highways 17 and 40 (I17 and I40) were constructed through the study area during the 1970s and 1980s, and both currently are traveled by $>20,000$ vehicle per day. The Burlington Northern Santa-Fe railroad parallels I40 and is traveled by roughly 100 trains per day. Other paved roads in the study area include U.S. Highways 180 and 89, which connect Flagstaff to Grand Canyon NP and Page, AZ, respectively, and Lake Mary Road, which is a comparatively littleused county road.

\section{Methods}

\section{Field Methods}

We contracted with USDA Wildlife Services for pursuit and capture of mountain lions for our study. We used snares and hounds to restrain or bay lions and either Telazol ${ }^{\circledR}$ or KetasetRompun ${ }^{\circledR}$ (with Yohimbine antagonist) for subsequent sedation and anesthetization. In all but one instance we fitted cougars with 880g-weight Telonics ${ }^{\circledR}$ TGW-3580 collars fitted with a VHF beacon, GPS locational device, and Argos satellite transmitter (Figure 2.1). We fitted one mountain 


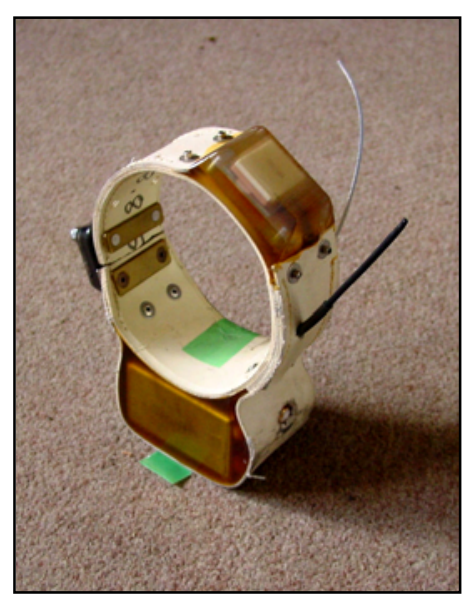

Figure 2.1. Telonics GPS/Argos collar with automatic release mechanism. The VHF and Argos antennas can be seen on the top right, and the release mechanism on the lower left.

lion with a VHF-only collar, and do not include data from this animal in our analyses. Our collars were programmed to attempt a 2-20-m accuracy GPS location once every four hours. Collars were also programmed to attempt transmission of the most recent six GPS fixes via Argos satellites once daily, for most collars during a four-hour evening window. Successfully transmitted data were relayed through Argos Inc. to us within 12 hours, embedded in an email message. We converted these data into decimal degree fixes and plotted them on USGS 1:24,000 topographic maps for assistance in field investigations.

We identified all clusters of $\geq 2$ GPS locations $<200 \mathrm{~m}$ apart as candidate for investigation (Anderson and Lindzey 2003). These clusters represented, at a minimum, four hours of mountain lion activity within a localized area. We attempted to visit clusters within 10 days of when lions had departed. We were not able to visit all such clusters because data transmission failures did not allow us to identify some in a timely manner and, more commonly, because of lack of time and personnel. Under such circumstances we prioritized visiting clusters of $\geq 4$ locations, representing a minimum of 12 hours of localized activity. We did not visit even some of these longer-duration clusters within 10 days of a focal animal's departure, primarily because of data transmission failures. However, we did visit all such clusters once a collar had been retrieved, the complete collection of data downloaded, and clusters comprehensively identified. Under these circumstances field visits occurred between one and 18 months after they had occurred.

We investigated the vicinity of GPS location clusters to document site characteristics, mountain lion activity, and characteristics of prey, if present. We used a Magellan handheld GPS unit with up to 3-m accuracy to navigate to clusters. Of relevance to this analysis, we determined a kill based on the presence of animal remains, diagnostic physical trauma, and/or evidence of a struggle (e.g., blood, torn ground, broken branches, snagged hair). We determined scavenging in instances where we found animal remains, but together with often substantial sign of especially avian scavengers and no evidence of a struggle. We mapped and measured distances (in $\mathrm{m}$ ) between activity features, including kill site, burials, latrines, and bed sites. We paced drag trails to estimate total distances and measured length and width of burials (in $\mathrm{dm}$ ). Where possible, we identified prey to species and, for ungulates, aged animals on the basis of tooth wear and eruption (Anderson 1981, Bubenik 1982). We determined gender on the basis of remaining genitalia and, for ungulates, presence and development of antlers or horns. We could rarely determine species of Leporids, much less age and gender, because remains almost always consisted solely of hair. Remains of animals as large as adult deer also on rare occasions consisted of no more than hair and bone chips, even when sites were visited within 24 hours of abandonment by a mountain lion. Under such circumstances we judged age-class (fawn or yearling versus adult) on the basis of volumes of hair and sizes of burials.

\section{Analysis Methods}

\section{Predation}

We comprehensively documented clusters for individual animals using locational data downloaded from retrieved collars. All clusters of $\geq 2$ points $<200 \mathrm{~m}$ apart were distinguished, assigned a unique identifier, and ascribed a starting time and duration (in hours). Where field data were available, each cluster was also identified as being with or without a kill, and where a kill was present, identified with the prey type (by species, age class, and gender). Starting time was defined as that of the GPS fix initiating the sequence minus half the interval between the initiating fix and the fix immediately prior. Duration was defined as starting with the temporal midpoint between the 
initiating GPS fix and the fix immediately prior and ending with the temporal midpoint between the terminating GPS fix and the fix immediately following. We excluded long-distance (>400 m) excursions of $\geq 4$ hours duration.

Because we did not visit all clusters to determine presence of a kill and prey type, we were faced with probabilistically assigning this information to unvisited clusters, especially where we were interested in determining kill rates. For purposes of this analysis we differentiated three states: no kill, kill of small-bodied prey, and kill of large-bodied prey. We defined small-bodied prey as being between 2 and $30 \mathrm{~kg}$ wet weight, including fawns, porcupines (Erethizon dorsatum), and all mesocarnivores. Very small prey, $<2 \mathrm{~kg}$ in size, largely went undetected by our protocols for investigating GPS clusters at our employed temporal resolution. Large prey included all adult ungulates plus elk calves. We used logistic regression to specify relations between the log odds of each state and cluster duration (Anderson and Lindzey 2003). Of relevance to the explanatory power of cluster duration, we found little difference in the duration of time spent on kills of larger prey, including both deer kills (45-80 kg wet weight) and elk kills (100-400 kg; see Chapter 3).

We used our logistic regression models and data from visited clusters to assign kill states to unvisited clusters. Each unvisited cluster was assigned a probability of being associated with no kill, a small kill, and a large kill based on logistic regression models developed from visited clusters for each state. Models for probability of no kill and a small kill both included time-of-day as a predictor, in addition to cluster duration (see Chapter 3). Unvisited clusters were then assigned a state based on which had the highest predicted probability. Once all clusters were comprehensively assigned, we then calculated for each animal hourly intervals between all kills, large kills only, and between time of departure from a kill site and next kill (basically, duration of time without feeding).

In addition to calculating kill rates, time spent on kills, and intervals without feeding, we also estimated biomass of kills, and from that, total amount of biomass consumed per kill and hourly rates of consumption. For animals $<30 \mathrm{~kg}$ wet weight, we assigned a mass based on weights given in Burt and Grossenheider (1976). For mule deer and elk, we assigned weights given by
Anderson (1981) and Bubenik (1982), respectively, differentiating adults from calves or fawns and adult males from adult females and, additionally for elk, yearlings from older animals. These assigned masses were obviously only approximations, but nonetheless usefully partitioned a range of masses spanning $<1 \mathrm{~kg}$ to $400 \mathrm{~kg}$ for insight through analysis. When multiplied by field estimates of the percentage of total edibles consumed by lions from a kill, we were able to estimate total biomass consumed which, when divided by hours spent on a kill, also allowed us to estimate hourly rates of consumption reckoned for the duration of a cluster.

For purposes of this report, we undertook preliminary explanatory analyses that considered a range of potential causal factors. We treated mountain lion sex and age-class and seasons defined by climate and mating activity as class variables. We considered pre-reproductive lions to be "young" and reproductive lions to be "mature." We defined three climate-based seasons: (1) fallwinter, lasting from mid-September through the end of April; (2) spring drought, lasting from the beginning of May through mid-July; and (3) monsoons, lasting from mid-July through midSeptember. We defined two mating-related seasons based on observed births in two previous comprehensive studies; one in New Mexico (Logan and Sweanor 2001) and the other in Alberta (Ross and Jalkotzy 1992). We back-dated births by a 90-dy gestation period (Anderson 1983, Beier and Barrett 1993, Logan and Sweanor 2001) to establish probable months of conception, and from that defined a season of peak mating activity (February-August) and a season of ebb mating activity (the remainder of the year). We also considered continuous variables such as prey mass, precipitation, maximum and minimum ambient temperatures, site slope, aspect (degrees from due south), and elevation, and percent coverages of trees, shrubs, herbaceous vegetation, and rocks. We determined temperatures and precipitation from daily records at Flagstaff's Pulliam Airport and adjusted temperatures for effects of elevation by applying a standard adiabatic lapse rate $\left(9.8^{\circ} \mathrm{C} / 1000 \mathrm{~m}\right)$ to the elevational difference between the kill site of interest and Pulliam Airport.

For continuous response measures such as time spent on kills and kill intervals, we developed general linear models (GLM). For binary categorical responses, such as likelihood of a kill 
being buried or drug, we used logistic regression analysis and related categorical models. We judged the explanatory performance of GLMs by $R^{2}$ and $P$ values, but, for lack of experimental control, without taking $p$-values as literally representing the probability of committing type I errors. We judged the explanatory and predictive power of our logistic regression models by area under the Receiver Operating Characteristic (ROC) curve and $R_{\mathrm{L}}{ }^{2}$ (Hosmer and Lemeshow 2000). We determined probabilities ( $p$ values) by backtransforming the modeled logits.

\section{Movements}

We high-graded locational data down-loaded from retrieved collars for use in analysis of movements and habitat selection, retaining only those locations rated as "good" by the on-collar GPS software and eliminating obvious erroneous locations identified by visually examining $x-y$ plots. We calculated straight-line distance (m) and turn angle $\left({ }^{\circ}\right)$ between subsequent locations, which were also attributed with time interval (hrs). We used the HRT home range analysis extension for ArcGIS (Rodgers et al. 2005) to estimate 95\% home ranges for each animal using fixed kernels determined by least-squares cross validation (LSCV).

We used logistic regression to develop seasonal models of habitat selection for each animal. Conceptually, we discriminated between observed locations and locations expected if animals were moving within their ranges randomly (Keating and Cherry 2004). We paired random locations with observed locations, constraining random points to fall within a buffer centered on the paired lion location (discrete choice; (Cooper and Millspaugh 1999). Radii for buffers were specific to each animal, and were equal to the $99^{\text {th }}$ percentile of observed straight-line distances between sequential locations obtained at 4-hr intervals. We adopted the $99^{\text {th }}$ percentile after determining that random points generated within a buffer of this radius provided consistently better discrimination compared to using buffer radii based on $50^{\text {th }}, 67^{\text {th }}, 75^{\text {th }}$ or $95^{\text {th }}$ distance percentiles.

We stratified our analyses of habitat selection by sex and by season and considered a number of continuous and categorical explanatory variables. We used three seasons based on climate (fallwinter, spring drought, and monsoons), described under methods pertaining to predation. As explanatory variables, we considered an index of terrain roughness (TRI), elevation, distance to nearest paved highway (differentiated by highway ID), distance to nearest human residential area, distance to nearest known source of free water, jurisdiction (private and leased state lands, NPS, public but non-NPS), and habitat type. We calculated TRI as the sum change in elevation between focal 10-m resolution grid cells and all 8 neighboring grid cells, using standard USGS digital elevation maps (DEMs; Riley et al. 1999). We specified habitat types based on GAP maps available for our study area (http://gapanalysis. nbii.gov/xml/th_landcover_az_1.htm), consolidating the more numerous GAP types into the following nine general types: urban, desert grass and low shrubland, montane grassland and open areas, rock and cliff, chaparral, pinyonjuniper forest and woodland, ponderosa pine forest, mesic high-elevation forest, and subalpine forest.

We also considered effects of roads in terms of whether observed road crossings were different from those expected with random movement. To achieve this, we selected mountain lion locations that were within range of potential movement across a paved highway based on the $99^{\text {th }}$ percentile of observed 4-hr straight-line movements. We connected the selected lion locations by vectors with observed locations next in time sequence and with random points generated within the $99^{\text {th }}$ percentile buffer. We then counted how many times mountain lions actually crossed a highway compared to the times they would have crossed if connecting to a random point, and tested to determine whether observed frequencies differed from frequencies expected with random movements.

\section{Mountain Lion Captures and Collar Performance}

\section{Captures and Collaring}

Between March 2003 and June 2005 we conducted 12 captures of 11 mountain lions (six females and five males) in the Flagstaff Uplands and fitted them with radio-telemetry collars. We fitted the first lion captured (C1) with a standard Telonics ${ }^{\circledR}$ VHF-only radio collar. We fitted all other captured lions (C2 through C11) with Telonics ${ }^{\circledR}$ TGW-3580 GPS-Argos collars. We captured 9 of the lions (five females, four males) using hounds and we snared two others (one male, 
one female). We captured four lions in each year (2003-2005), although one in 2005 was a recapture. At the time of this report (June 2006) our study lions had accumulated a total of 2365 collar-days (one collar day = one lion wearing a collar for one day).

We used two sizes of collars: small (with an inner circumference of 30.5-40.5 cm [12-16 inches]), intended for females, and large (33.0-43.0 cm [13-17 inches]), intended for males. Proper fit is important when sizing these collars to ensure that the GPS antenna block is in the correct position on the back of the neck. However, the correct collar size was sometimes unavailable when a capture occurred, requiring modification of the available collar though shortening (cutting) or lengthening (adding a spacer).

The approximate life expectancy for the Argos/GPS battery system is one year given our programmed parameters (six fixes attempted/day with four hours of attempted satellite uplink each evening). We typically programmed collar release for one year after deployment, or slightly less if the collar had been active for some time prior to deployment. To save power, the GPS system was set to time-out if a successful fix had not been obtained within three minutes. The VHF beacon in each collar had a separate battery and was programmed to function somewhat longer than the Argos-GPS systems to aid in collar recovery after release from collared animals. All data collected during deployment were stored in non-volatile memory that did not require battery power.

\section{Collar Performance}

To date, ten lions fitted with GPS-Argos collars averaged 237 collar-days each and collected a total of 9357 high-precision GPS fixes, for an average of 4.3 fixes per day out of six possible. Of 11 collars deployed, six performed as expected in theory, one experienced a failure of the GPS system, two experienced failures of the Argos system, and two experienced failures of the VHF beacon. User errors caused one collar to release prior to the expected date and one collar to experience poor Argos uplink success (see below).

We assessed performance of collar components in two ways: 1) the percentage of all possible GPS fixes that were successfully obtained, and 2) the percentage of all possible uplinks to Argos satellites that delivered data of any quality. The first of these measures can only be determined from stored data once a collar has been recovered. By contrast, successful uplinks to Argos satellites can provide an ongoing measure of performance for the Argos feature, in addition to providing near real-time locational data.

\section{GPS Fix Success Rates}

We found both similarities and differences between sexes in performance of GPS systems on deployed collars (Table 1a). Collars on female lions collected successful GPS fixes at a higher rate than did collars on male lions (76\% and 64\%, respectively), with the proviso that data shown in Table 1a are not corrected for collar malfunctions, of which there were several (see Table $1 \mathrm{~b}$ for comments). At the high-performance extreme, collars on two females with $>100$ collar-days each (C4 and C7) had GPS fix rates around 90\%, as did one collar on a male (C5). At the low performance end of the spectrum, female C2's collar acquired successful GPS fixes at the lowest rate of all lions (53\%), followed closely by male C10's 56\%. It is worth noting, however, that the GPS in C10's collar, which accounted for $42 \%$ of all male collardays, began to malfunction at 255 days, and provided little additional data before failing completely at 302 days. Considering only the first 254 days, C10's collar successfully collected GPS locations at a rate of $77 \%$. If we do not consider data from after when C10's collar began to malfunction, then overall rate of successful GPS fixes on male-deployed collars increased to $76 \%$, which is virtually identical to the rate we observed for collars on females.

\section{Argos Satellite Uplink Rates}

Percentages of successful Argos uplinks also differed between collars deployed on females versus males. On average, collars worn by females successfully uplinked $70 \%$ of the time, whereas collars worn by males successfully uplinked only $48 \%$ of the time. However, malfunctions of the Argos system on two collars (one for each sex), and an unsuccessful user attempt to "refine" the Argos uplink window on a second male collar, affected these rates as well. Three females with $>100$ collar-days each achieved well-above average uplink success (around 80\%), whereas the most successful male collar (C11's) managed only $58 \%$ of possible uplinks.

The Argos system on female C8's collar functioned with some regularity for just 64 days, 
during which time the uplink rate was only $27 \%$. During the next 106 days, successful uplinks declined to only $10 \%$ of all possible (Table $1 \mathrm{a}$, see C8-A). On Day 171, C8 was recaptured and fitted with a replacement collar that she wore for an additional 362 days (Table 1, C8-B). If we ignore the 106 potential uplinks to C8-A's collar that occurred after the apparent malfunction of the Argos feature, overall success rate for Argos uplinks from female collars increased to $76 \%$. We experienced two different problems that affected Argos uplinks from male collars. C6's Argos system failed after 217 days, and we lost all ability to track the collar at approximately Day 310 when the VHF beacon also failed. For two weeks before the collar was programmed to release we conducted an intensive hunt to capture C6 and retrieve his collar, but these efforts proved unsuccessful and the collar and its data were temporarily lost. However, the intensive effort to locate C6 led to the capture and collaring of C9, C10, and C11. Because we do not yet have the comprehensive data set from C6's collar, we only included potential uplinks in our analysis from before Argos failure. Analysis of GPS performance for this collar will need to await retrieval of the data.

The second problem we experienced with Argos uplink on male collars was one of our own making. In an attempt to improve uplink success after the first year of data collection, we decided to split the usual 4-hour uplink window (1700 to 2100 MST) into two 2-hour segments (1630 to 1830 and 0330 to $0530 \mathrm{MST}$ ). Our intent was to increase odds that a lion would be out in the open, where its collar would more likely uplink with an Argos satellite during two periods of good satellite coverage instead of one. We modified the uplink programming on two collars and deployed one of these on male C5. As male uplink success was already lagging behind that for females, we were optimistic about prospects for this modification. Unfortunately, the success rate for C5 (26\%) was half that of other males. We returned the second collar to its original uplink schedule before deployment. However, even if we were to omit C5's uplink data from our assessment, the overall success rate for uplinks from collars deployed on males would only improve slightly (from $48 \%$ to $51 \%$ ) and would still be substantially less than what we observed for females.

\section{Discussion of Collar Performance}

We suspect that differences in rates of successful GPS fixes between collars deployed on the two sexes were partly because males spent more time in rugged terrain than did females (see Chapter 2). Rugged terrain is known to reduce rates at which GPS locations are successfully acquired (D'Eon et al. 2002, Frair et al. 2004, Cain et al. 2005), and also very likely reduces the odds of successfully uplinking to Argos satellites. If true, then one would expect that differences between the sexes in successful uplinks to Argos satellites would be greater than differences in successful acquisitions of GPS fixes, primarily because south-north transiting Argos satellites should be more difficult to contact than geostationary GPS satellites. In fact, this is the effect observed, which adds weight to our speculation that selection by males for rough terrain, at least during the daily period when uplinks to Argos satellites were attempted, hindered communication with Argos satellites.

Another factor that could have contributed to observed differences in collar performance was collar fit and related position of GPS and Argos elements on the animal (D'Eon and Delparte 2005). As previously mentioned, the correct collar size was sometimes not available at captures, requiring that we modify length of the available collar. This happened with five of 11 captures. Three females received large collars that had to be cut down and two males received small collars that had to be extended (Table 1b). We observed no consistent effect of modifying length for the large collars shortened for deployment on females. On one collar the VHF battery failed and GPS performance was poor - but performance of the Argos system was good. A second collar's Argos system failed, but GPS performance was average. The third cut-down collar had the highest GPS success rate and second highest Argos success rate of any collar. Results from the two small collars extended to fit on males were similarly ambiguous. One collar had average GPS performance and above average Argos performance, while the other collar experienced Argos and VHF failures. It does not appear that collar fit, at least to date, had any major effect on collar performance. 
Table 1a. Summary of capture and collaring information for 10 mountain lions caught near Flagstaff, Arizona in 2003-2005 and fitted with GPS-Argos telemetry collars. Collar performance, including GPS position fix and Argos uplink success rates is shown for each collar. Color-shaded cells indicate noteworthy results discussed below.

\begin{tabular}{|c|c|c|c|c|c|c|c|c|c|c|c|}
\hline $\begin{array}{l}\text { Animal } \\
\text { ID }\end{array}$ & Sex & Age & $\begin{array}{l}\text { Date } \\
\text { Collared }\end{array}$ & Collar Released & $\begin{array}{l}\text { Days } \\
\text { On }\end{array}$ & $\begin{array}{l}\text { Possible } \\
\text { Fixes (\#) }\end{array}$ & $\begin{array}{l}\text { Successful } \\
\text { Fixes (\#) }\end{array}$ & $\begin{array}{l}\text { Successful } \\
\text { Fixes (\%) }\end{array}$ & $\begin{array}{l}\text { Possible } \\
\text { Uplinks (\#) }\end{array}$ & $\begin{array}{l}\text { Successful } \\
\text { Uplinks (\#) }\end{array}$ & $\begin{array}{l}\text { Successful } \\
\text { Uplinks (\%) }\end{array}$ \\
\hline C2 & $\mathrm{F}$ & $A$ & 14-Jul-03 & 15-Jun-04 & 338 & 2022 & 1075 & 53 & 337 & 253 & 75 \\
\hline C4 & $\mathrm{F}$ & $J-A$ & 4-Aug-03 & 15-Jun-04 & 317 & 1902 & 1682 & 88 & 316 & 246 & 78 \\
\hline C7 & $\mathrm{F}$ & $A$ & 14-Dec-04 & died with collar & 204 & 1224 & 1122 & 92 & 203 & 160 & 79 \\
\hline C8-A & $\mathrm{F}$ & $A$ & 15-Dec-04 & 4-Jun-05 & 170 & 1020 & 715 & 70 & 169 & 17 & 10 \\
\hline C8-B & $\mathrm{F}$ & $A$ & 4-Jun-05 & 1-Jun-06 & 362 & 2172 & 1681 & 77 & 361 & 297 & 82 \\
\hline C9 & $\mathrm{F}$ & $\mathrm{J}$ & 16-May-05 & died with collar & 138 & 828 & 706 & 85 & 137 & 100 & 73 \\
\hline \multicolumn{5}{|c|}{ Totals for females } & 1529 & 9168 & 6981 & 76.1 & 1523 & 1073 & 70.5 \\
\hline C3 & M & A & 3-Aug-03 & 15-Dec-03 & 134 & 804 & 504 & 63 & 133 & 70 & 53 \\
\hline C5 & $\mathrm{M}$ & $J-A$ & 19-Aug-04 & died with collar & 110 & 660 & 571 & 87 & 109 & 28 & 26 \\
\hline C6 & $\mathrm{M}$ & A & 17-Aug-04 & not recovered & $>217$ & unknown & unknown & unknown & 217 & 112 & 52 \\
\hline C10 & $\mathrm{M}$ & A & 25-May-05 & 15-May-06 & 355 & 2130 & 1196 & 56 & 354 & 179 & 51 \\
\hline C11 & $\mathrm{M}$ & $\mathrm{J}$ & 13-Jun-05 & died with collar & 20 & 120 & 105 & 88 & 19 & 11 & 58 \\
\hline \multicolumn{5}{|c|}{ Totals for males } & $>836$ & 3714 & 2376 & 64.0 & 832 & 400 & 48.1 \\
\hline \multicolumn{5}{|c|}{ Overall totals for both sexes } & $>2365$ & 12,882 & 9357 & 72.6 & 2249 & 1473 & 65.5 \\
\hline
\end{tabular}

Table 1b. Additional information regarding collar fit and performance for 10 mountain lions caught near Flagstaff, Arizona in $2003-2005$ and fitted with GPS-Argos telemetry collars. Collar modifications are noted and the fate of each lion/collar is briefly described. Color-shaded cells indicate noteworthy results discussed below.

\begin{tabular}{|llllcl|l|}
\hline $\begin{array}{l}\text { Animal } \\
\text { ID }\end{array}$ & Sex & Age & $\begin{array}{c}\text { Correct collar sizel } \\
\text { size used }\end{array}$ & $\begin{array}{c}\text { Collar } \\
\text { Modified? }\end{array}$ & Comments \\
\hline C2 & F & A & small/large & cut & VHF battery failed after 330 days; Argos continued to relay collar's position; low GPS fix rate \\
C4 & F & J-A & small/small & no & Greatest number of successful GPS-fixes; wildfire consumed much of C4's home range \\
C7 & F & A & small/large & cut & Lion hunted-collar returned; C7 had highest percentage of successful GPS-fixes \\
C8-A & F & A & small/large & cut & Argos failed after 64 days--uplink rate only 27\%; recapture on Day 171 \& new collar (C8-B) \\
C8-B & F & A & small/small & no & Replacement collar (C8-B) worked very well; highest percentage of successful Argos uplinks \\
C9 & F & J & small/small & no & Lion hunted-collar returned; C9 migrated soon after collaring to form a new home range \\
C3 & M & A & large/small & spacer & Collar released prematurely (user error); C3 was often located in Walnut Canyon NM \\
C5 & M & J-A & large/large & no & Lion hunted-collar returned; came from Grand Canyon NP; ineffective Argos uplink window \\
C6 & M & A & large/small & spacer & Argos failed after 217 days; VHF also failed before scheduled release; collar not recovered \\
C10 & M & A & large/large & no & GPS began failing at 255 days and failed at 302 days; Argos continued to function \\
C11 & M & J & small/small & no & Lion killed-head trauma, apparently caused by an elk; collar retrieved; high GPS fix rate \\
& & & & & \\
\hline
\end{tabular}




\title{
Chapter 2
}

\section{Movements and Habitat Selection by Mountain Lions in the Flagstaff Uplands}

\author{
Terence Arundel, David Mattson, and Jan Hart
}

\section{Introduction}

Movements and habitat selection by mountain lions (Puma concolor) are of interest to managers and the public for several reasons. Insight into habitat selection is germane to assessing and managing risks posed to humans by lions - by allowing researchers and managers to, ideally, explain and map distributions of lion activity, potentially at the level of different behaviors, of which predation is the most relevant to human safety. Such information allows managers to identify high-risk areas for ameliorative management, and to better understand what measures, when, will most likely yield desired results. Insights into movements and habitat selection also provide a basis for assessing impacts of humans on mountain lion populations and individuals, both to judge impairments of natural dynamics and behaviors and to design mitigations. Finally, information on movements and habitat use are a basis for insight into the comparative ecology of this species, and potentially a compelling part of public education about mountain lions.

Other than standard calculations of home range size, which date back to the onset of radiotelemetry investigations in the 1960s and early 1970s (e.g., Seidensticker et al. 1973), investigations of especially habitat selection have a comparatively recent pedigree in mountain lion research. Only within the last decade have analyses of habitat use and selection included multi-variable explanatory models employing methods such as logistic regression (Dickson and Beier 2002, Dickson et al. 2005), allowed principally by recent developments in modeling methods (Burnham and Anderson 1998, Hosmer and Lemeshow 2000). More commonly, habitat selection has focused on rejection of null hypotheses pertaining to landscape classifications that do not encompass questions of nearness, as to water or human facilities, or questions pertaining to continuous landscape measures (e.g., Logan and Irwin 1985, Williams et al. 1995, Katnick and Wielgus 2005). With the development of genetic methods, mountain lion research has also only recently broached very broad-scale, populationlevel questions of movements, signaled by patterns of genetic similarity (Sinclair et al. 2001, McRae et al. 2005). By contrast, the tradition of investigating fine-scale movements, associated with behaviors such as predation, bedding, or roadcrossing, is long-standing and based on diverse methods that include intensive ground-telemetry (e.g., Hornocker 1970, Laundré and Hernández 2003, Dickson et al. 2005) and fixed track or camera stations (Clevenger and Waltho 2000, 2005; Gloyne and Clevenger 2001).

Regardless of the scale, previous research on habitat use has shown that mountain lions select for rugged terrain with forested or woody cover and are averse to crossing or otherwise using flat open areas (e.g., Logan and Irwin 1985, Koehler and Hornocker 1991, Laing and Lindzey 1993, Williams et al. 1995, Riley and Malecki 2001). McRae et al. (2005) speculated that expansive open areas impeded lion movements to such an extent that it explained genetic differentiation among lion populations at the regional scale. Even at a micro-scale, lions select for cover, whether greater forest cover, nearby rockiness, and even more confined highway underpasses (Akenson et al. 2003; Laundré and Hernández 2003; Clevenger and Waltho 2000, 2005). Mountain lions also tend to select for ecotone edges (Laing and Lindzey 1993, Akenson et al. 2003, Laundré and Hernández 2003), and areas with abundant browse of their favored prey (Logan and Irwin 1985, Laing and Lindzey 1993).

Insofar as human features are concerned, mountain lions tend to avoid residential areas (Beier 1995, Dickson et al. 2005) and areas with on-going or recent timber harvest (Van Dyke et al. 1986, Meinke et al. 2004). Ernest et al. (2003) associated broad-scale genetic differentiation 
among mountain lions in California with limited movements not only across open areas, as speculated by McRae et al. (2005) for lions in the interior Southwest, but also population-level impediments posed by broad areas of human developments. At a finer scale, lions avoid crossing heavily trafficked paved highways (Alexander and Waters 2000, Dickson et al. 2005) and areas with high densities of secondary roads (Van Dyck et al. 1986), but show little aversion to, or even potentially favor traveling on, lightly trafficked unpaved roads (Dickson et al. 2005). In spite of some degree of aversion by lions to most human-related landscape features, mountain lion populations nonetheless have been relatively resilient to humans and their activities, especially compared to other large carnivores such as grizzly bears (Ursus arctos) and wolves (Canis lupus; Laliberte and Ripple 2004, Riley et al. 2004).

Of the analyses of habitat selection done to date, comparatively few have produced robust models with wide applicability and non-monotonic parameters that have been used to address spatially-explicit management questions. The coarse-grained broad-scale model developed by Riley and Makecki (2001) has been given spatially-explicit application to the state of Montana, as has a similar model to Utah. At a much finer scale, Dickson et al. (2005) used an analysis of movements at 15-minute intervals to parameterize an agent-based model for identifying likely movement corridors. At a similar resolution, Clevenger and Waltho (2005) applied models to identify locales and other features of road-crossing structures that favored movements of lions. To our knowledge, no models have been used to map probability of mountain lion activity as an aid to managing human exposure to lions (see Chapter 4). Other models have merely specified directions of relations, without elucidating important features such as asymptotes or optima that can only be captured by gathering data over a broad range of landscape conditions. Without such critical nuances, models can suggest, for example, an unconditional affinity for rugged terrain which produces improbable results such as shear canyon walls in Zion National Park, Utah, being rated as prime mountain lion habitat. Clearly, opportunities exist to improve habitat selection models for mountain lions, and find applications that provide insight and highlight opportunities for managers.

\section{The Flagstaff Uplands}

Human safety, human impacts, and public education are all issues for stakeholders of mountain lion management in the Flagstaff Uplands. A series of high-profile incidents during the winter of 2000-2001 on Mt. Elden, a mountain massif popular for hiking and adjacent to residential areas, brought the potential for lion attacks on humans sharply into focus, along with the related need for additional information to manage human risk. There has also been on-going concern among local wildlife and public lands managers about potential impacts of the considerable human infrastructure in the Flagstaff Uplands on mountain lion movements and populations. Two major interstate highways (Interstate Highways 40 and 17 [I40 and I17]), one twined federal highway (US 89), and a major railroad (Burlington Northern-Santa Fe [BNSF]) transect the region and converge on the city of Flagstaff's urbanized areas. Although localized impacts have not been documented, McRae et al. (2005) speculated on the basis of broad-scale north-south genetic differences that the BNSF railroad, since perhaps it construction in 1884, together with the paralleling U.S. 66, then I40, were major filters or even barriers to lion movements. Information on mountain lion movements, analyses of effects of especially transportation routes, and related products such as maps of predicted lion activity are clearly germane to concerns regarding mountain lions in the Flagstaff Uplands.

We initiated a study in 2003 that included investigations of mountain lion movements and habitat selection in the Flagstaff Uplands. Our goal was to provide information that would help managers and other stakeholders assess impacts of human facilities on mountain lions and manage exposure of humans to risk of mountain lion attacks (Chapter 1 ). The primary products in service of such goals are seasonal maps of predicted mountain lion activities and analyses of movements and habitat selection that include candidate effects of human facilities. To achieve these ends we continue to deploy GPS/satellite collars (see Chapter 1) that collect highly accurate locations at four-hour intervals round-the-clock. We used these time-specific locational data to determine the effects of highways on movements, including turn angles and crossings. We also used these data to parameterize preliminary multi- 
variable models of habitat selection for radiocollared mountain lions, which we then used to develop preliminary seasonal maps of predicted lion activity, which we present in this chapter. Like previous researchers, we considered the effects of terrain roughness, woody cover, and nearness to roads and human residential areas on selection. Unlike previous studies, we also considered effects of jurisdiction, nearness to open water, and distance to the centroid of the lion's GPS locations, as surrogate for an individual lion's attraction to familiar areas. We considered terrain roughness and woody cover to be surrogates for ambush advantage and also for concentration of prey, terrain roughness especially for mule deer during winter and woody cover for elk year-round. We also considered elevation and nearness to water as surrogates for prey distribution, water especially for elk.

This preliminary analysis is for data collected during July 2003-June 2006. We expect to present a final analysis after 2009, when field work will be completed. At that time we will consider additional explanatory variables, including local monthly temperatures and precipitation, incident radiation, satellite-derived wetness and greenness, and, where available, forest cover and stem density. These additional variables will provide additional surrogate measures for prey distribution and, in the case of forest measures, direct links to management for forest health.

\section{Notes on Methods}

We describe methods for the analysis presented here in Chapter 1. However, a few issues warrant discussion; in particular, autocorrelation and bias in GPS locations, and our future plans for addressing these potential problems. The likelihood that a collar-mounted GPS unit will obtain a location has been shown to be lower in forested steep terrain compared to flat open areas (D'Eon et al. 2002, Frair et al. 2004, Cain et al. 2005); a bias which can be mitigated by applying correction factors (Frair et al. 2004). We have designed but not yet implemented a study to develop correction factors which we plan to use in future analyses of habitat selection. For lack of such correction factors now, results presented here likely under-estimate the degree of selections both for rough forested terrain and against grasslands and low shrub-lands.
Spatial and temporal autocorrelation can bias especially estimates of parameter variances, and taint judgments regarding the performance of related models. In future analyses of movements using multiple regression, we plan to assess autocorrelation bias in estimates of coefficients and variances by incorporating lag terms, not only for dependent variables (previous turn angle or distance moved), but also for independent variables (e.g., terrain roughness at prior locations; Weisberg 1985). We will also account in some measure for non-independence and related autocorrelation by eliminating locations that are $<100 \mathrm{~m}$ away from the prior location, which signify instances where a lion effectively exercised no choice independent of prior choices regarding use of a site. Even with these measures, estimates of coefficient variance will likely be underestimated, leading to inflated judgments of model performance (Nielson et al. 2002), which we plan to address by using measures accepted at the time for adjusting variances and related judgments of "significance" to additionally account for autocorrelation.

\section{Results}

Natural and human features, as well as the identities of monitored animals, had major apparent effects on habitat use and movements by mountain lions in the Flagstaff Uplands during 2003-2006 (Table 2.1). Of the independent variables we considered, all were in at least one explanatory model. The models themselves exhibited varying degrees of sufficiency reckoned in terms of predictive capabilities (e.g., area under the Receiver Operating Characteristic [ROC] curve) or explanation of data variance (e.g., $R^{2}$ or $R_{\mathrm{L}}^{2}$ ), but none were likely to have been specified by chance alone (i.e., $p$-values were all $<0.0001$; Table 2.1). We specified models for only two seasons, fall-winter and spring drought-monsoons (or "summer"), after preliminary analyses showed surprisingly little difference between models for the summer months. We present the following results by whether they pertain to natural features, the animals themselves, or human-made features, integrating among models specific to different sexes, seasons, and response variables. We include water sources in "natural" features, realizing that most in our study area were created and are maintained by humans to provision livestock and wildlife species such as elk with water. 
Table 2.1. Parameters for models of habitat selection and movement (turn angle and distance between successive locations) for mountain lions in the Flagstaff Uplands, 2003-2006, including score $x^{2}$ or parametric $F$ values, degrees of freedom, and $p$-values for tests of model type I errors, $R^{2}$ or $R_{L}^{2}$ values for explained variance, and area under the ROC curve for logistic regression models. Values in the table body are, to the right of the slash, $\triangle \mathrm{AIC}$ (Akaike Information Criterion), which signifies the comparative weight of the corresponding variable in the model (Burnham and Anderson 1998) and, to the left of the slash, the direction of the relation between continuous explanatory variables and likelihood of a mountain lion location versus a paired random point; 'na' signifies "not applicable" for class variables. Comments in parentheses identify an interaction effect.

\begin{tabular}{|c|c|c|c|c|c|c|}
\hline \multirow[b]{2}{*}{ Explanatory variable } & \multicolumn{6}{|c|}{ Model } \\
\hline & $\begin{array}{l}\text { Male } \\
\text { habitat } \\
\text { selection } \\
\text { (Fall- } \\
\text { winter) }\end{array}$ & $\begin{array}{l}\text { Male } \\
\text { habitat } \\
\text { selection } \\
\text { (Spring } \\
\text { drought- } \\
\text { monsoon) }\end{array}$ & $\begin{array}{l}\text { Female } \\
\text { habitat } \\
\text { selection } \\
\text { (Fall- } \\
\text { winter) }\end{array}$ & $\begin{array}{l}\text { Female } \\
\text { habitat } \\
\text { selection } \\
\text { (Spring } \\
\text { drought- } \\
\text { monsoon) }\end{array}$ & $\begin{array}{l}\text { Distance } \\
\text { moved } \\
\text { between } \\
\text { successive } \\
\text { locations } \\
\text { (Step } \\
\text { length, m) }\end{array}$ & $\begin{array}{l}\text { Turn angle } \\
\text { between } \\
\text { successive } \\
\text { movements } \\
\left(^{\circ}\right)\end{array}$ \\
\hline Terrain roughness (index) & $+/ 325.0$ & $+/ 166.0$ & $+/ 269.1$ & $+/ 73.6$ & $-/ 10.7$ & - \\
\hline Terrain roughness polynomial & - & - & $-/ 9.0$ & $-/ 70.1$ & - & - \\
\hline $\begin{array}{l}\text { Vegetation cover type (consolidated } \\
\text { GAP types) }\end{array}$ & na / 74.9 & na / 31.2 & na / 223.2 & na / 62.1 & na / 18.8 & - \\
\hline Distance to nearest free water (m) & $-/ 4.0$ & $-/ 12.1$ & - & $-/ 5.1$ & - & - \\
\hline $\begin{array}{l}\text { Season (winter-fall versus spring } \\
\text { drought-monsoons) }\end{array}$ & - & - & - & - & na / 47.0 & - \\
\hline Diel time period & - & - & - & - & na / 436.8 & - \\
\hline $\begin{array}{l}\text { Distance from centroid of an individual } \\
\text { animal's locations (m) }\end{array}$ & - & $-/ 4.1$ & $-/ 36.5$ & $-/ 4.2$ & - & $\begin{array}{l}+/ 22.5 \\
\text { (by sex) }\end{array}$ \\
\hline $\begin{array}{l}\text { Time interval between successive } \\
\text { locations (hr) }\end{array}$ & - & - & - & - & $+/ 23.2$ & - \\
\hline $\begin{array}{l}\text { Modeled probability }(p) \text { of a male } \\
\text { mountain lion being present }\end{array}$ & - & - & - & $-/ 10.6$ & - & - \\
\hline Ownership/jurisdiction & na / 8.7 & na / 27.6 & na / 62.3 & na / 43.5 & na / 8.8 & - \\
\hline Distance to nearest paved highway (m) & - & - & $\begin{array}{c}\text { + / } 64.0 \\
\text { (by hiway } \\
\text { type) }\end{array}$ & $\begin{array}{c}+/ 29.9 \\
\text { (by hiway } \\
\text { type) }\end{array}$ & $\begin{array}{c}+/ 9.3 \\
\text { (by sex) }\end{array}$ & - \\
\hline Distance to nearest urban area (m) & $+/ 23.8$ & $+/ 25.8$ & $+/ 31.0$ & $+/ 33.3$ & $\begin{array}{r}+/ 37.4 \\
\text { (by sex) }\end{array}$ & $\begin{array}{r}+/ 44.0 \\
\text { (by sex) }\end{array}$ \\
\hline Score $\chi^{2}$ or $F$ statistic & 558.3 & 288.3 & 976.3 & 424.8 & 62.1 & 12.3 \\
\hline df (numerator/denominator) & 15 & 14 & 17 & 19 & 28/9274 & 11/9292 \\
\hline$P$-value & $<0.0001$ & $<0.0001$ & $<0.0001$ & $<0.0001$ & $<0.0001$ & $<0.0001$ \\
\hline$R^{2}$ or $R_{\mathrm{L}}^{2}$ & 0.249 & 0.233 & 0.156 & 0.115 & 0.158 & 0.014 \\
\hline Area under ROC curve & 0.751 & 0.744 & 0.682 & 0.656 & - & - \\
\hline
\end{tabular}

\section{Effects of Natural Features}

Terrain roughness had a major, if not dominant, effect in all models of habitat selection, regardless of season or sex, and was also included in the model explaining distance moved between successive locations (i.e., step length; Table 1). It was excluded only from the model explaining turn angle. Lions strongly positively selected for terrain roughness, males more-so than females. Unlike males, female selection exhibited inflections during both fall-winter and spring drought-monsoons that denoted optima at intermediate levels of roughness (Figure 2.1). In general, both males and females more strongly selected for rough terrain during fall-winter compared to summer. They also tended to travel 


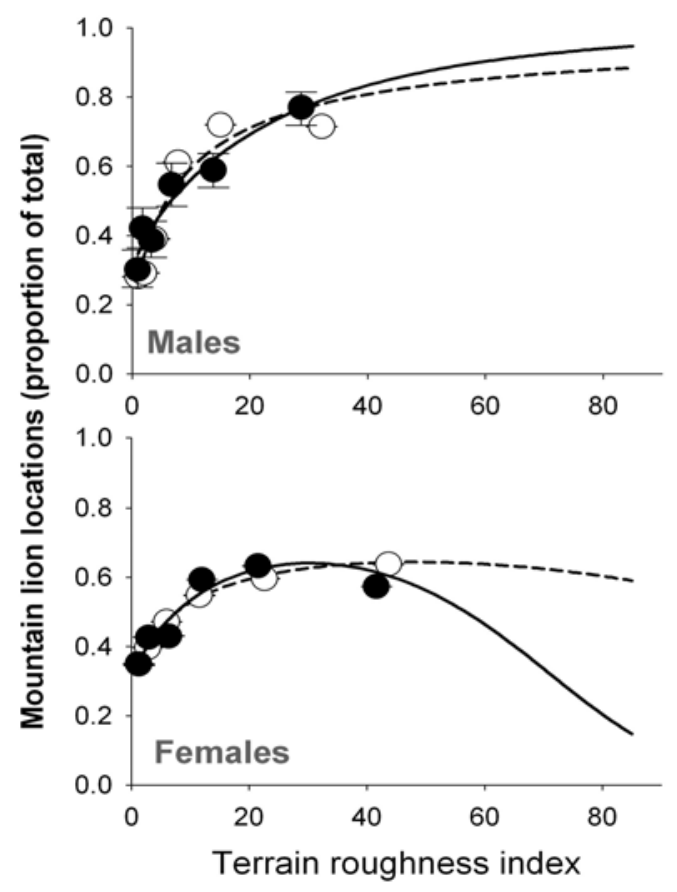

Figure 2.1. Relations between probability of a mountain lion location versus a random point and index of terrain roughness, for mountain lions in the Flagstaff Uplands, 2003-2006. Lines show modeled relations and circles are proportions and associated $95 \%$ confidence intervals for septiles of the data, shown to illustrate goodness-of-fit. Open circles and dashed lines are for fall-winter; filled circles and solid lines are for summer, for males at top and females at bottom.

shorter distances between successive locations as terrain roughness increased (Table 2.1).

Mountain lions in our study have so far exhibited pronounced patterns of selection for different vegetation cover types during both summer and fall-winter (Figure 2.2). Overall, they used urban areas and desert grass- and shrublands much less than expected by chance. They also tended to under-use montane grasslands and other higher-elevation open areas. By contrast, piñonjuniper woodlands and ponderosa pine forest were consistently used more than expected, although not by much. Male and female mountain lions differed most in their use of chaparral and rock and cliff, with males registering ambivalence and females strongly selecting for both types, especially during fall-winter. In large measure consistent with patterns of selection, monitored lions tended to move most rapidly through urban areas, subalpine forest, rock and cliff, and desert grass- and shrubland, and slowest through chaparral (Figure2.2).
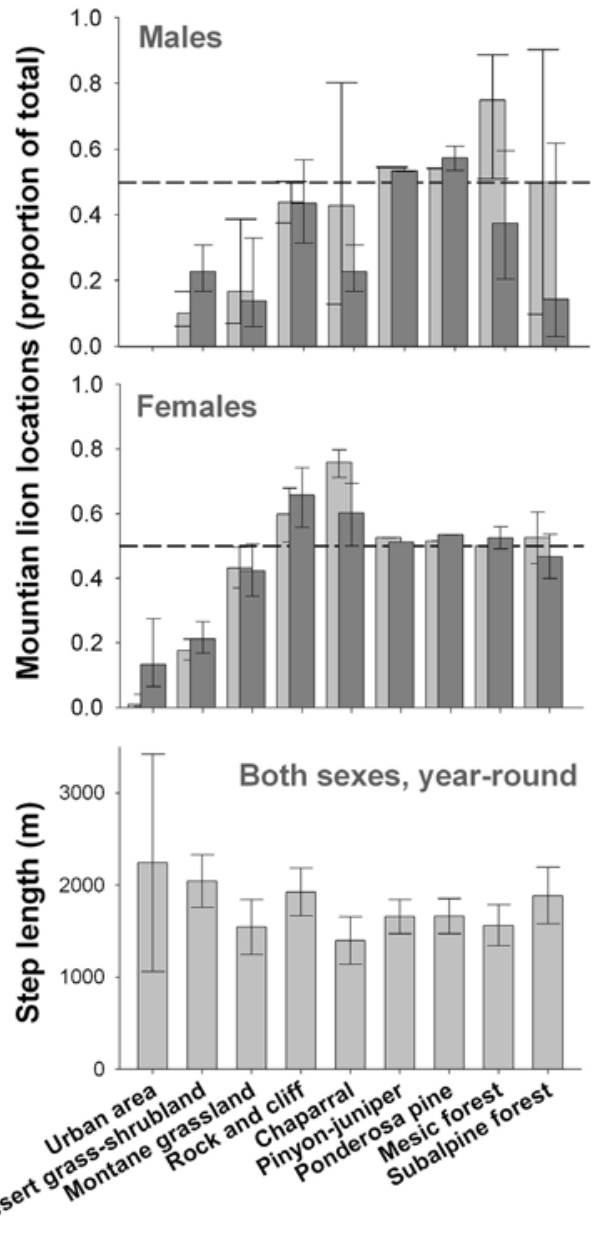

Figure 2.2. Relations between vegetation cover types and probability of a mountain lion location versus a random point, for males (top) and females (middle), as well as mean distance moved between successive locations (step length, bottom), for mountain lions in the Flagstaff Uplands, 2003-2006. Error bars show 95\% confidence intervals. Light gray bars, top and middle, are for winter-fall, whereas dark gray bars are for summer.

Insofar as other natural factors were concerned, mountain lions of both sexes selected for areas near water sources compared to farther away, more-so during summer compared to fallwinter, and more consistently for males than for females (Table 2.1). Males exhibited an affinity for water sources during both fall-winter and summer whereas females did so only during summer. We also introduced the distribution of males as a candidate for explaining, in part, the distribution of females. We did this by first developing models of habitat selection for males, which we then used to assign probabilities of habitat use by this sex to locations and paired random points for females. On this basis, females 

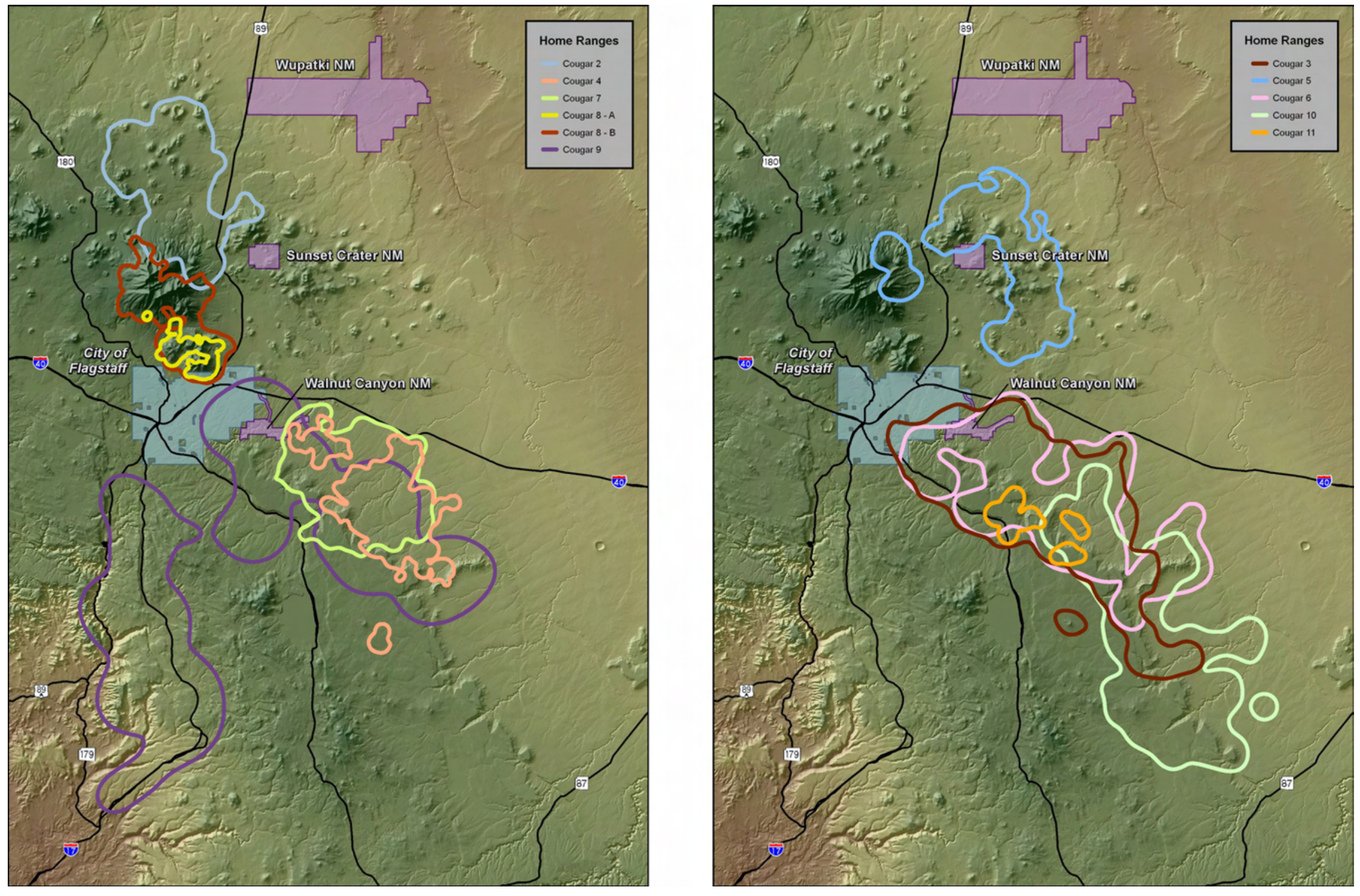

Figure 2.3. Home ranges of female (left) and male (right) mountain lions in the Flagstaff Uplands, 2003-2006. 


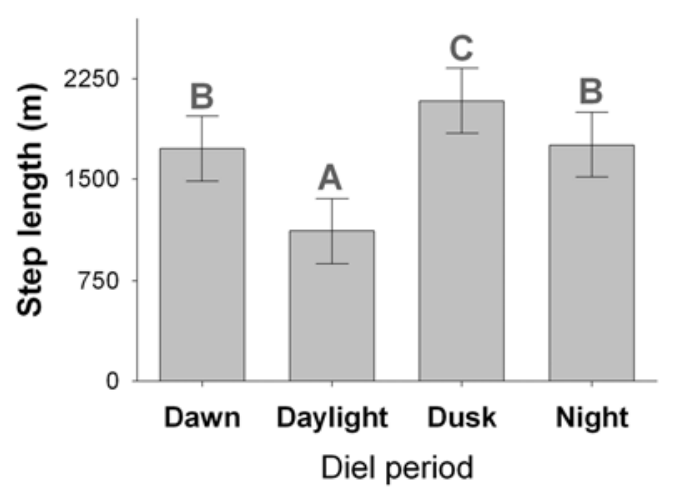

Figure 2.4. Mean distance moved between successive locations (step length ) by mountain lions in the Flagstaff Uplands, 2003-2006, relative to diel period. Means were calculated by marginal least squares and error bars show 95\% confidence intervals. Letters above bars denote means not equal at $\alpha=0.05$ using the Tukey-Kramer test for multiple comparisons.

appeared to select for areas not likely used by males during summer (Table 2.1).

Movements differed by several time-related factors, in addition to sex and age of the animal. Annual ranges of males averaged $488 \mathrm{~km}^{2}$ (Range $=281-606 \mathrm{~km}^{2}$ ), much larger than the average 165 $\mathrm{km}^{2}$ (111-262 $\mathrm{km}^{2}$ ) observed for females (see Figure 2.3 for range locales). Outliers include 47 $\mathrm{km}^{2}$ for the one-month range of a young male, 30 $\mathrm{km}^{2}$ for the two-month range of an adult female, and $432 \mathrm{~km}^{2}$ for a dispersing young female. On average, lions moved longest distances during dusk, shortest distances during daylight, and intermediate distances at night and dawn (Figure 2.4). They also averaged longer movements during fall-winter (least squares marginal mean $=$ $1895 \mathrm{~m}, 95 \% \mathrm{CI}=1657-2133 \mathrm{~m}$ ) compared to summer (1642 m [1408-1877]). Adult males consistently averaged longer movements and greater turn angles compared to any other sex or age class, regardless of climatic or mating season (Figure 2.5). By contrast, young males averaged movements longer than those of both young and mature females during ebb mating season, but not during peak mating season, when length of movements by young males lessened (Figure 2.5).

\section{Effects of Human Features}

Locations of mountain lions in our study area were affected by several human-related features, including nearness to paved highways and urban areas and occurrence in different jurisdictions or land ownerships. Controlling for the effects of temporal factors and other natural and human features, males and females consistently selected against areas in private ownership, including leased Arizona state lands (Figure 2.6). Males differed from females in use of National Park Service (NPS) jurisdictions by selecting for these areas, especially during fall-winter, in contrast to a tendency towards under-use by females yearround. Lions of both sexes moved longer average distances when in Park Service or Arizona Wildlife Management areas, in contrast to shorter distances

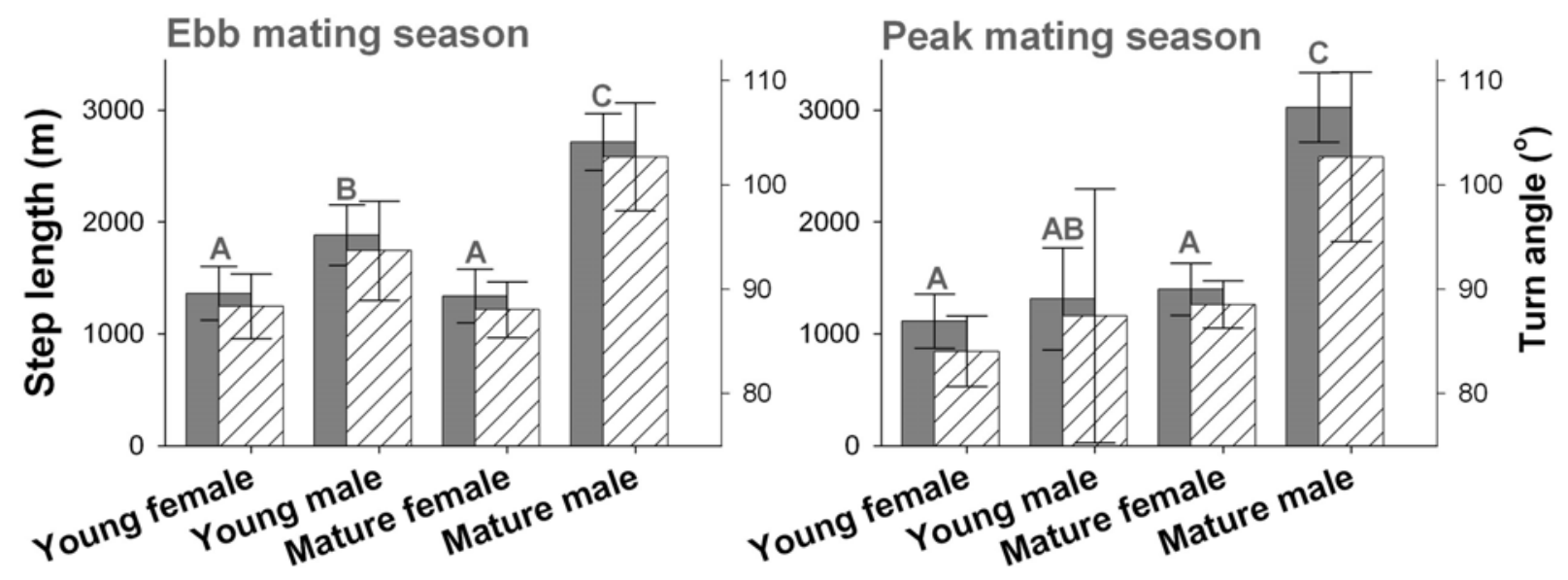

Figure 2.5. Relations between sex-age class and mean distance moved (step length; dark bars behind) and turn angle (cross-hatched bars in front) between successive locations, by ebb (left) versus peak (right) mating seasons, for mountain lions in the Flagstaff Uplands, 2003-2006. Means were calculated by marginal least squares and error bars show $95 \%$ confidence intervals. Letters above bars denote means not equal at $\alpha=0.05$ using the Tukey-Kramer test for multiple comparisons. 

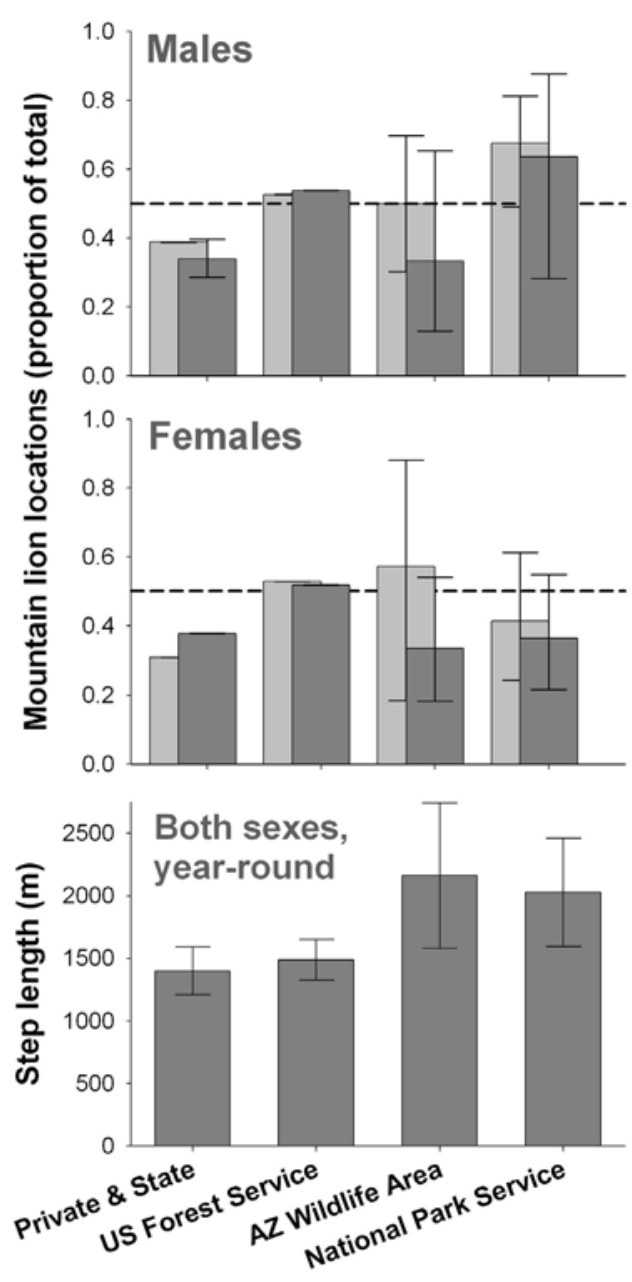

Figure 2.6. Relations between land ownership or jurisdiction and proportions of mountain lion locations versus a random points, by jurisdiction, for males (top) and females (middle), as well as mean distance moved between successive locations (step length, bottom), for mountain lions in the Flagstaff Uplands, 2003-2006. Light gray bars, top and middle, are for winter-fall, whereas dark gray bars are for summer. Mean step length was calculated by marginal least squares and error bars show $95 \%$ confidence intervals. The dashed line, top and middle, denotes non-selective use (prop. $=0.5$ ).

when on U.S. Forest Service lands or private and leased state lands (Figure 2.6). Of all humanrelated features, mountain lions of both sexes exhibited consistently strongest responses to nearness to urban areas, principally Flagstaff's incorporated jurisdiction (Table 2.1). Males exhibited a broader zone of avoidance compared to females, pronounced out to roughly 1.5 to $3 \mathrm{~km}$, depending on season, in contrast to roughly $1 \mathrm{~km}$ for females year-round (Figure 2.7). Males also differed somewhat from females in their movements when near urban areas. Both turn

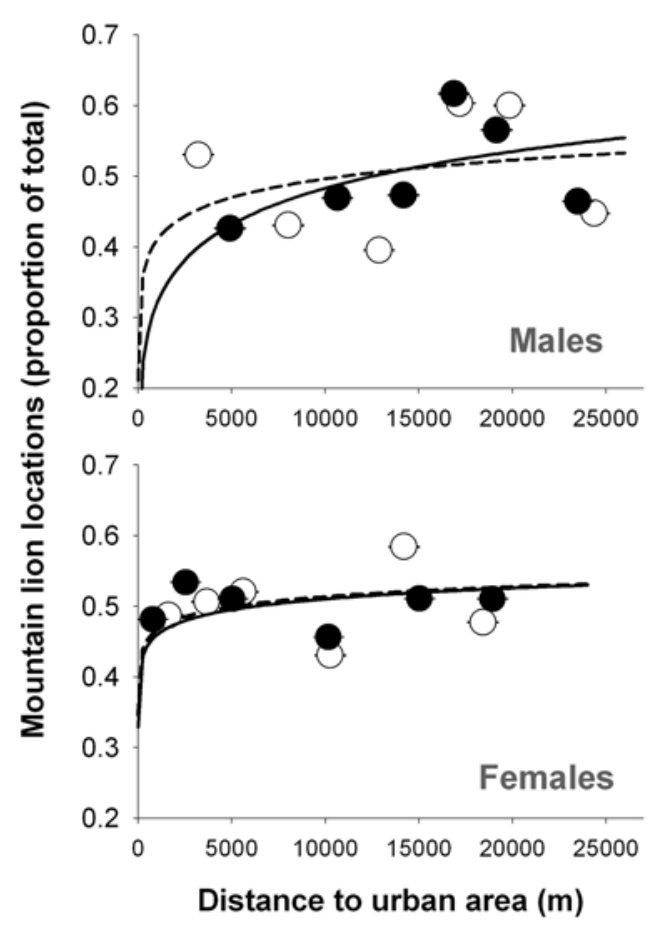

Figure 2.7. Relations between probability of a mountain lion location versus a random point and distance to urban area, for mountain lions in the Flagstaff Uplands, 2003-2006. Lines show modeled relations and circles are proportions and associated $95 \%$ confidence intervals for septiles of the data, shown to illustrate goodness-of-fit. Open circles and dashed lines are for fall-winter; filled circles and solid lines are for summer, for males at top and females at bottom.

angles and movement distances declined for males and females when near urban areas, but more-so for females, evident out to a greater distance (Figure 2.8). Females moved shorter distances, with less angular deviation, out to as much as 3-5 $\mathrm{km}$ away from urban areas, whereas the same was true for males out only to $1-2 \mathrm{~km}$, depending on whether the measure was step length or turn angle.

Females exhibited comparatively strong responses to nearness of paved highways, in contrast to males, which did not (Table 2.1). Females consistently selected against areas near highways, but to varying degrees depending on season and type of highway (Figure 2.8). Female response was greatest during fall-winter, and least reactive to highways with low traffic volumes ( $<4,000$ vehicles/day) and most reactive to interstate highways and highways with high traffic volumes (>6,000 vehicles per day; Figure 2.8). By contrast, during summer, when responses were somewhat weaker, females tended to be least reactive to nearness of interstates and most reactive 


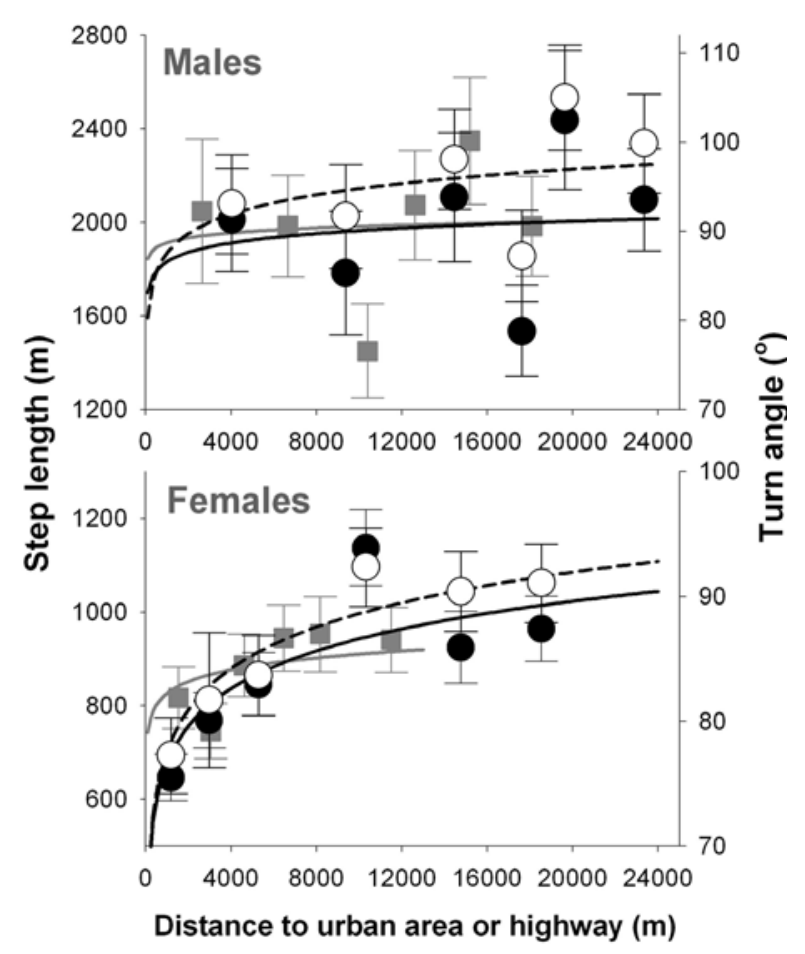

Figure 2.8. Relations between distance to urban area or paved highway and distance moved (solid lines and filled circles or squares) and turn angle (dashed lines and open circles) between successive locations, for mountain lions in the Flagstaff Uplands, 2003-2006, by sex. Lines show modeled relations and circles are means and associated 95\% confidence intervals for septiles of the data, shown to illustrate goodness-of-fit. Squares denote highways and circles denote urban

to nearness of highways with low traffic volumes. When near highways, females moved shorter average distances compared to when farther away, and to a greater extent compared to males (Table 2.1; Figure 2.8).

To date, perhaps the most dramatic effect of a human feature on mountain lion behavior was evident in the probability that a lion would cross a paved highway. Mountain lions tracked so far in our study were much less likely to cross a paved road of any type compared to crossings expected with random movements (Likelihood Ratio $\chi^{2}=$ 713.8, $\mathrm{df}=3, p<0.0001$ ). Between 16 and $20 \%$ of random movements originating at a lion location within range of a paved highway crossed the highway (Figure 2.9). By contrast, only 0.4 to $2 \%$ of observed mountain lion movements did so. Even so, lions were more likely to cross a paved road with low traffic volumes compared to especially an interstate highway (Figure 2.10). To date, we have observed 20 crossings of little-used

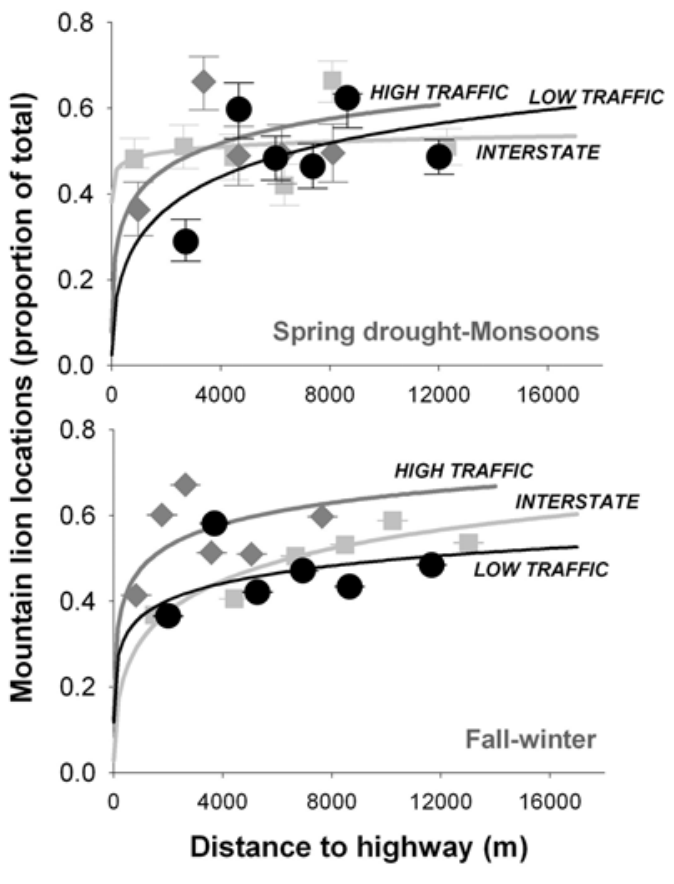

Figure 2.9. Relations between probability of a mountain lion location versus a random point and distance to paved highway, for mountain lions in the Flagstaff Uplands, 2003-2006, by season. Lines show modeled relations and circles are proportions and associated 95\% confidence intervals for septiles of the data, shown to illustrate goodnessof-fit. Black circles and lines are for paved roads with low traffic volumes; dark gray diamonds and lines are for paved roads with high traffic volumes; and light gray boxes and lines are interstate highways.

paved highways, primarily Lake Mary Road, only three crossings of I17, and none of I40.

\section{Mapped Application to the Flagstaff Uplands}

We used preliminary models of habitat selection presented here for male and female mountain lions to map seasonal probability of lion activity in the Flagstaff Uplands (Figures 2.112.12, following pages). Our intent was not to produce a definitive product, but rather to illustrate potential application of this information to management and planning, and to also provide a spatially explicit picture of what seemingly abstract relations look like applied to real and potentially familiar places. We included the spatially-explicit effects of all explanatory variables, with the exception of distance to centroid of locations for individual animals. This 


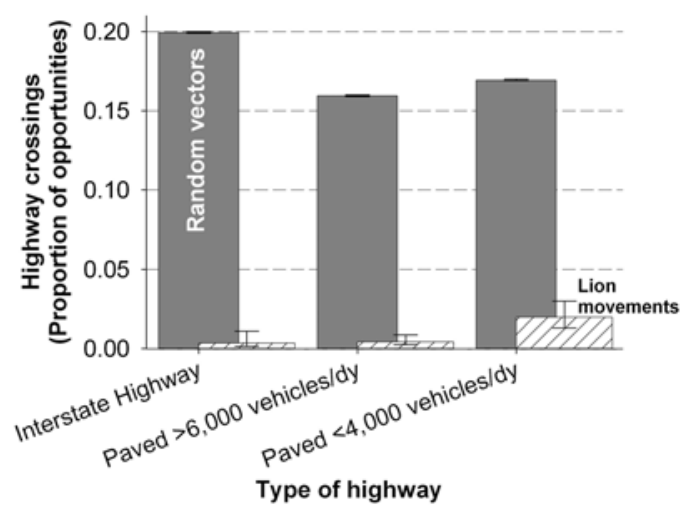

Figure 2.10. Proportion of instances when a mountain lion location was within range of potential movement across a highway that a random vector crossed the road (dark bars behind) versus an observed lion movement (open bar with crosshatching in front), for mountain lions in the Flagstaff Uplands, 2003-2006, by highway type and traffic volume.

measure is specific to a given animal and period of time, and so has no stable spatial frame. We controlled for this effect by subsuming into the intercepts of relevant models.

Hotspots of potential mountain lion activity stand out in the Flagstaff Uplands, denoted in our maps as shades of red. Throughout the year, areas of greater topographic relief or terrain roughness stand out, specifically Mt. Elden and slopes of the San Francisco Peaks, Walnut Canyon, cinder cones north and east of Flagstaff and Doney Park, and scarps of Observatory Mesa. Predicted activity is decidedly low (shades of blue) in flatter areas without forest cover, especially to the north and east where piñon-juniper woodland grades to desert grass- and low shrubland, largely on private and leased state lands.

\section{Discussion}

We are not yet in a position to reach definitive conclusions regarding movements and habitat selection by mountain lions in the Flagstaff Uplands. Although our sample of telemetry locations is large by any standard, our basis for inference is compromised by, as yet, the small sample of individuals and the study's relatively short duration. Even so, we found comparatively strong signals from the data revealing not only expected patterns, but also suggestive patterns that raise questions rather than provide answers. In what follows, we note similarities with previous research, offer what seem to be plausible explanations for novel patterns, and identify results that, as yet, defy ready explanation.

\section{Selection of Natural Features}

Our results are consistent with previous more-or-less universally observed affinities of mountain lions for rugged terrain and woody vegetation in the western United States (Logan and Irwin 1985, Koehler and Hornocker 1991, Laing and Lindzey 1993, Williams et al. 1995, Riley and Malecki 2001). As others have previously remarked, anyone who has spent time tracking mountain lions already knows that lions prefer wooded rough terrain. However, results such as the ones presented here allow for specific quantitative comparisons, as well as explicit application to landscapes to produce maps of mountain lion activity. The main argument for spatially and temporally explicit quantitative representations is that they provide stakeholders with an inter-subjective basis for communication, management, and planning. Of course, a key requirement for these kinds of applications is that spatial frames and related landscape metrics be stable for the areas of intended application.

Although broadly consistent with previous research elsewhere, our results did reveal novel patterns relevant to understanding and representing mountain lion behavior. For one, female lions clearly expressed selection for an intermediate range of terrain roughness, most evident during summer. Such a pattern is consistent with our prior expectation that lions probably do not prefer, despite occasionally using, extreme topography such as shear cliffs. Even so, unlike the females, male lions did not express selection for a midrange of terrain roughness and, instead, exhibited monotonic relations to this variable. We suspect that this failure to detect a mid-range optimum for males was related to at least two factors. For one, the males were not as exposed as the females were to the roughest terrain in our study area, concentrated primarily around the San Francisco Peaks and cinder cones north of I40. For another, the males did, in fact, orient more strongly towards rough terrain compared to females.

We observed other differences in habitat selection by males and females, with potential 

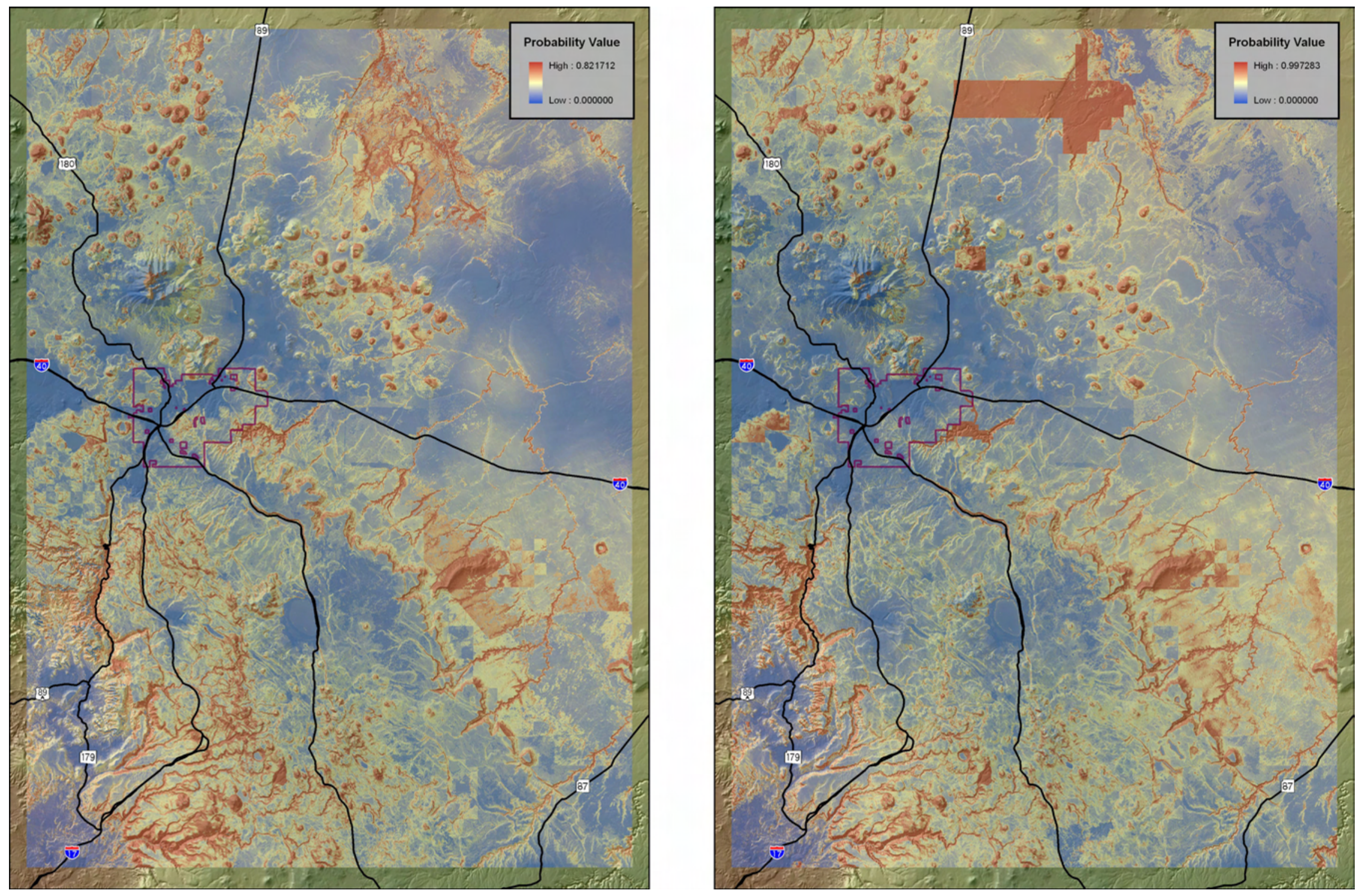

Figure 2.11. Predicted probabilities of female (left) and male (right) mountain lion activity in the Flagstaff Uplands during Spring drought-Monsoons, based on preliminary models of habitat selection from data collected during 2003-2006. 

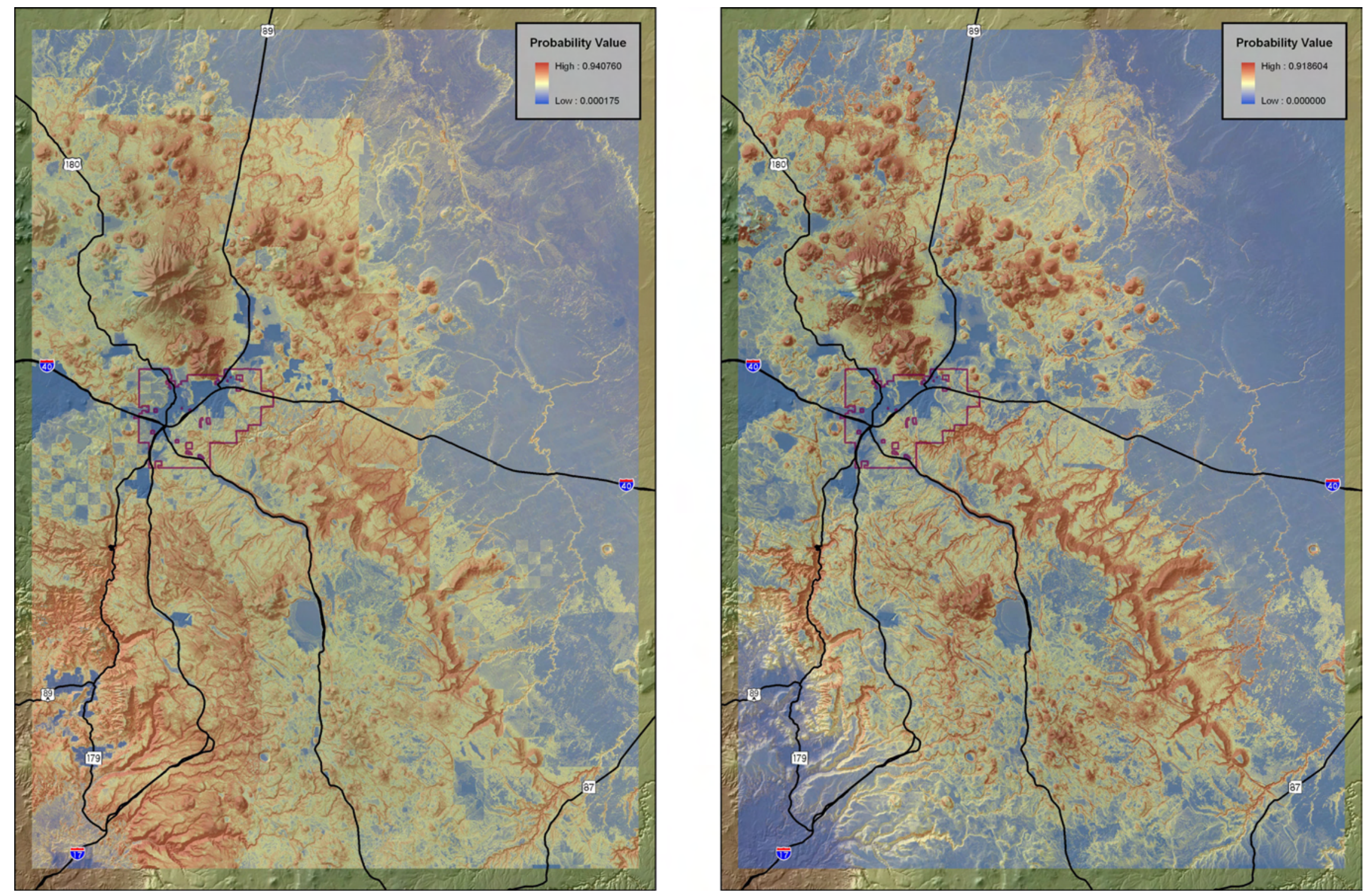

Figure 2.12. Predicted probabilities of female (left) and male (right) mountain lion activity in the Flagstaff Uplands during Fall-Winter, based on preliminary models of habitat selection from data collected during 2003-2006. 
implications to explaining composition of kills. Especially during fall-winter, females more strongly selected for chaparral and bare rock, which roughly equated with south-facing slopes of Mt. Elden and the Dry Lake Hills near Flagstaff, and with south-facing scarps of the Mogollon Rim at the southern end of our current study area. These areas of chaparral often contained abundant oaks, cliffrose, and mountain mahogany, and were heavily used by mule deer, especially during winter. This potential juxtaposition of female lions, deer, and chaparral plausibly explains both the much greater incidence of mule deer killing by females compared to males, as well as the association of mule deer kill sites with presence of cliffrose and mountain mahogany (Chapter 3). In contrast to the pattern with chaparral, males yearround more strongly oriented toward water sources than did females. Again, this sex-based difference in habitat selection was plausibly associated with sex-based differences in kills. Unlike mule deer, elk are among the heaviest users of free water in our study area (B. Holton, personal communication). Thus, the much higher incidence of elk kills by male lions (Chapter 3 ) is plausibly associated with male lions having spent more time near water sources.

\section{Movements by Time Period}

Mountain lions tracked so far in the Flagstaff Uplands moved at different rates depending on season and time of day. Movements were much longer during fall-winter, which is consistent with longer intervals between kills and meals also evident during this season, especially in contrast to during the spring drought (Chapter 3). Together with the results of our analysis of foraging behavior, this result suggests that fall-winter was energetically perhaps the most stressful season for lions in our study area, a result of expending greater energy for movement, while obtaining less energy from fewer kills. We were surprised by this pattern because we expected fall-winter to be a season that favored lions, primarily because their prey tended to be concentrated on winter ranges, in somewhat poorer condition, especially during late winter and early spring. It may be that sport hunting of mountain lions by humans provides some explanation for this pattern, given that most successful sport hunts in Arizona occur during winter, when snowfall facilitates tracking (Schubert 2004). A plausible hypothesis is that lions accelerate their movements to avoid or otherwise in response to hunters.

The relation between diel pattern of movements and kills by mountain lions in our study area contrasted with relations between seasonal movements and kill rates. Whereas lower kill rates were associated with more extensive movements seasonally, the opposite was true on a daily basis. The dusk peak in movements by lions corresponded with a dusk peak in numbers of kills of large prey (Chapter 3). Likewise, the dawn peak in initiation of 8-12 hr inactive periods (Chapter 3), not surprisingly, corresponded with a nadir in movements. This diel pattern suggests that the higher incidence of kills at dusk was not fortuitous, or driven strictly by prey vulnerability, but, rather, partly the result of lions employing a strategy that entailed greater activity.

\section{Effects of Roads, Urban Areas, and Jurisdiction}

Consistent with results of previous research elsewhere (Beier 1995, Alexander and Waters 2000, Dickson et al. 2005), mountain lions in our study area were clearly affected by paved highways and human residential areas or, more plausibly, by human activities associated with these features. These effects were evident in under-use of areas near roads and urban areas, dramatic under-use of urban areas themselves, changes in lion movements when near human features, and failure to cross paved roads, even when nearby. With one proviso, movements by lions decelerated and became less angular when they were in areas that they otherwise avoided near highways and urban areas. This raises the intriguing possibility that slower and less angular movements typify cautious behavior by mountain lions. That said, once a lion was in a mapped residential area, movements tended to accelerate, which could signify flight behavior.

Effects of one sort or another extended out between 0.5 and $5 \mathrm{~km}$ from highways and urban areas, but with intriguing differences between male and female mountain lions. In contrast to females, males more evidently avoided urban areas, but modified their movements less when nearby. On the other hand, females avoided areas near paved highways, which had no apparent effect on males. We have no highly plausible explanation for these differences except that the intrinsically longer movements of males could explain, in part, the 
greater spatial extent of their avoidance of urban areas. The $75^{\text {th }}$ percentile for movements during four hour intervals was around 2-4 km for males, in contrast to $0.5-2 \mathrm{~km}$ for females, which would be consistent with observed differences in the spatial extent of avoidance.

Paved highways of all sorts were clearly a barrier to movements of mountain lions tracked so far in the Flagstaff Uplands. Numbers of observed highway crossings were orders of magnitude less than expected if highways were not a "presence" for lions. This applied not only to the interstate highways, which we expected, but also to comparatively little-used highways such as Lake Mary Road and U.S. Highway 180, which surprised us. Lions have so far crossed minor highways more often than interstates, but this difference among types of highways pales in comparison to the rate at which lions failed to cross highways of all sorts. Our failure to detect any crossings of I40 and the paralleling BNSF railroad tracks is consistent with speculation by McRae et al. (2005) that these transportation features have functioned as a near impermeable barrier to lions for a non-trivial period of time, for the BNSF since 1884. Overall, our results suggest the potential extent to which major transportation features can function as strong filters or even barriers in study areas, such as ours, comprised largely of wildlands.

Controlling for other human and natural features, jurisdiction, per se, had a surprising degree of influence on habitat selection by mountain lions monitored to date. All lions avoided privately owned and associated intermingled state lands. Males, on the other hand, tended to select for National Park Service (NPS) jurisdictions, which did not allow hunting. In this light, the exhibited female tendency towards ambivalence or even avoidance of NPS lands is intriguing. However, if females seasonally tended to avoid adult males (see the next section), then they may have avoided the quite small NPS units typical of the Flagstaff Uplands more as an expression of avoiding males than avoiding this jurisdiction, as such.

\section{Effects of Lions on Each Other}

We found evidence that especially adult male mountain lions were affecting habitat selection and movements by other lions. As noted previously, selection of NPS jurisdictions by males could explain ambivalence towards or even avoidance of these areas by females. More directly, modeled probability of male activity explained some measure of habitat selection by females during summer (May through mid-September). Assuming that patterns of parturition were the same in our study area as in southwestern Alberta (Ross and Jalkotzy 1992) and the San Andres Mountains of New Mexico (Logan and Sweanor 2001), "summer," as defined for this analysis, would also have been time of peak parturition and denning. Females were presumably most risk averse during this period, especially when venturing out with cubs (Logan and Sweanor 2001). Male lions, which do kill cubs, would have probably constituted a non-trivial part of this risk (e.g., Logan and Sweanor 2001). We can only speculate whether females in our study area were avoiding males as a strategy for reducing risk to cubs. However, such a strategy would be consistent with what we know of mountain lion biology (Logan and Sweanor 2000).

As in every other study area where mountain lion movements have been studied (e.g., Seidensticker et al. 1973, Logan and Sweanor 2001, Dickson and Beier 2002), adult males in our study area moved more extensively over larger areas compared to non-dispersal movements of all other sex and age classes. This held for both peak and ebb mating seasons, which suggests that the drop in kill rate by adult males during peak mating season (Chapter 3) was not a function of lessened movements but rather a reflection of adult males shifting their focus from predation to reproductive opportunities. Interestingly, young males were the only sex-age class to exhibit a difference in movements between peak and ebb mating seasons, with shorter movements and less acute changes in direction evident during the peak season. This pattern is similar to that of movements by all lions when near highways or urban areas. If our earlier speculation is correct, that shorter more linear movements betoken more cautious behavior, then young males may have likewise been more cautious during peak mating season, but generalized to their entire range. This would be consistent with heightened intolerance of young males by adult males during peak mating activity (Logan and Sweanor 2001). 


\title{
Chapter 3
}

\section{Predation and Other Behaviors of Mountain Lions in the Flagstaff Uplands}

\author{
David Mattson, Jan Hart, Mike Miller, and Diane Miller
}

\section{Introduction}

Information on mountain lion (Puma concolor) predation is potentially germane to a number of management issues. Times and locales preferred for hunting are clearly relevant to assessing and managing the risks to humans that are increasingly of concern to managers. Under certain circumstances, mountain lion predation can limit bighorn sheep (Ovis canadensis), have potentially deleterious impacts on vulnerable pronghorn (Antilocapra americana), and potentially regulate mule deer (Odocoileus hemionus) and other ungulate populations (Ockenfels 1994, Hayes et al. 2000, Logan and Sweanor 2001, Robinson et al. 2002, Rominger et al. 2004). These direct effects on populations of herbivores potentially translate into indirect effects on vegetation structure and composition (Ripple and Beschta 2006). Indirect effects could also be engendered by mountain lion predation on mesocarnivores such as coyotes (Canis latrans; Boyd and O’Gara 1985).

However, despite this multitude of potential effects and the fact that mountain lions are the most abundant of large predators in the western United States, we know comparatively little about mountain lion predation and its impacts on ecosystems (Logan and Sweanor 2000). Some of this dearth is attributable to lack of attention and resources, but most is attributable to the difficulty of studying this cryptic low-density species.

Methods for studying mountain lion diet and predation have steadily improved since the 1940s. Early studies relied primarily on anecdote, the analysis of opportunistically collected feces, or contents of stomachs from hunter-killed animals (e.g., Robinette et al. 1959, Spalding and Lesowski 1971). Beginning in the 1960s, researchers began using ground-based radiotelemetry, often in combination with snow tracking, to systematically study kills and kill sites (e.g., Hornocker 1970). These methods were pushed to their limits by researchers in southern California, southern New Mexico, Alberta, northwestern Montana and the Yellowstone ecosystem (Murphy et al. 1992, Beier et al. 1995, Ross and Jalkotzy 1996, Kunkel et al. 1999, Logan and Sweanor 2001, Ruth 2004). Even so, these more recent intensive and often grueling studies yielded only partial pictures of predation behavior. Kill rates, diel timing of kills, time spent consuming kills, and differences among sex and age classes remained only sparsely sampled or reliably known from only one or two study areas. The recent incorporation of GPS technology into telemetry collars introduced the potential for comprehensive year-long round-the-clock records of mountain lion movements which have so far been demonstrated in one study reported from Wyoming (Anderson and Lindzey 2003).

There are a number of issues involving mountain lions in the Flagstaff Uplands of northcentral Arizona, including threats to human safety, impacts of humans and human infra-structure on movements, effects of different management regimes (e.g., National Park versus non-park) on populations, and effects of predation, especially on several small semi-isolated populations of pronghorn. Information on predation is obviously germane to understanding impacts on prey in this region, and also relevant to managing for human safety. Moreover, the natural history of mountain lion predation is a potentially compelling centerpiece for public outreach designed to educate and raise awareness. We deployed newly-developed technology on mountain lions in the Flagstaff Uplands that coupled satellite delivery of data with GPS-based telemetry, allowing us to document round-the-clock movements and collect detailed information on predation (see Chapter 1). Our primary goals for investigation of predation were to determine: (1) diel timing of kills; (2) kill rates, durations of consumption, and prey composition 
by mountain lion sex and age class; (3) the likelihood that kills were of small (2-30 kg wet weight) and large ( $>30 \mathrm{~kg}$ ) prey as a function of durations of localized movements; (4) diagnostic features of kill sites; and (5) other details of mountain lion predatory behavior. In this chapter we present a preliminary analysis of predation in our study area using data collected during July 2003-May 2006. A complete analysis will be presented after conclusion of scheduled field work in late 2009. We describe methods for this analysis in Chapter 1.

\section{Results}

\section{Activities by Type and Time of Day}

Between July 2003 and May 2006 we visited 394 clusters of GPS locations (see Methods in Chapter 1), at which we documented 218 kills, 165 of which were attributable to five female mountain lions and 53 attributable to five males. A kill of large prey (logit $\left.\left[p_{\text {large prey }}\right]\right)$ was strongly positively related to duration (Dura; in hrs) of the associated cluster of GPS locations (Figure 3.1; area under the ROC curve $[c]=0.90$; Goodness-of-fit [Hosmer and Lemeshow] $X^{2}=1.77, \mathrm{df}=7, p=0.98$ ):

$$
\operatorname{logit}\left[p_{\text {large prey }}\right]=-8.30+2.38 \ln (\text { Dura }+1) \text {. }
$$

A cluster without any kill (logit $\left.\left[p_{\text {no kill }}\right]\right)$ was strongly negative related to duration and associated with time-of-day partitioned into six equal periods $\left(\right.$ Time $\left._{\mathrm{x}}\right)\left(c=0.92\right.$, Goodness-of-fit $X^{2}=11.56, \mathrm{df}=$ $8, p=0.17)$ :

$$
\begin{aligned}
& \operatorname{logit}\left[p_{\text {no kill }}\right]=3.54-0.42(\ln [\text { Dura }+1])^{2}+ \\
& \text { Time } \\
& \text {; }
\end{aligned}
$$

where Time $e_{2}=-0.36$, Time $_{6}=1.21$, Time $_{10}=$ 0.06, Time $_{14}=0.56$, Time $_{18}=-0.87$, and Time $22=$ -0.61 . A kill of small ( $<30 \mathrm{~kg}$ wet weight) prey was also related to time-of-day, as well as to a polynomial of cluster duration $(c=0.75$, Goodness-of-fit $X^{2}=11.21$, df $=8, p=0.19$ ):

$$
\begin{aligned}
& \operatorname{logit}\left[p_{\text {small prey }}\right]=0.48+1.42(\ln [\text { Dura }+1])^{2}- \\
& 3.34 \operatorname{sqrt}(\text { Dura }+0.5)+\text { Time }_{\mathrm{x}} ;
\end{aligned}
$$

where Time $2=-0.06$, Time $_{6}=-0.99$, Time $_{10}=$ 0.03, Time $14=0.07$, Time $_{18}=0.07$, and Time $22=$ 0.87 .

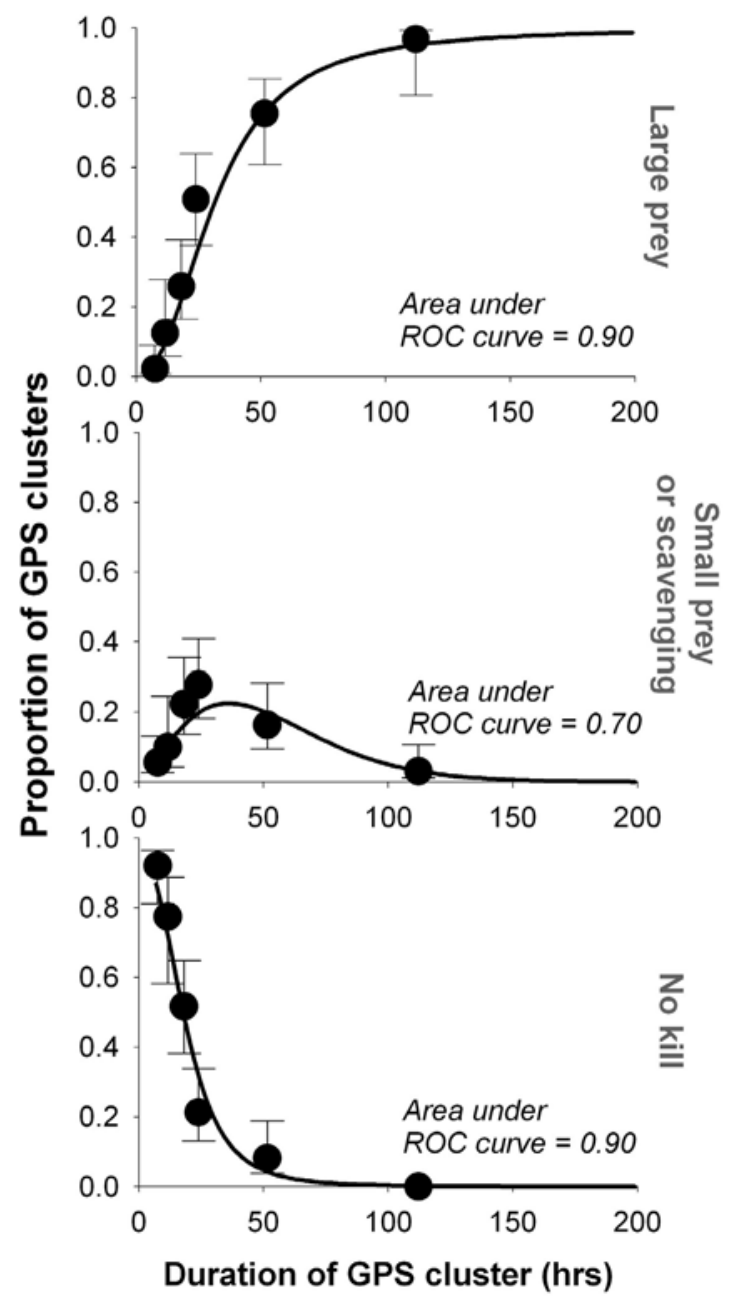

Figure 3.1. Relations between duration of GPS clusters (in hrs) and the probability that (top) a kill of large prey had occurred, (middle) a kill of small ( $<30 \mathrm{~kg}$ wet weight) prey had occurred, and (bottom) no kill had occurred. Probability of a small kill peaked at roughly 40-hr duration, which is about the same duration when $p$ exceeded 0.5 for a kill of large prey. Dots and associated 95\% Cls are for septiles of the data and shown to illustrate goodnessof-fit.

Of the visited clusters, we found kills of large prey at 146, kills of small prey (2-30 kg wet weight) at 49 , and no kills at 150 . Applying our predictive equations to unvisited clusters, kills of large prey totaled 207, kills of small prey totaled 54 , and clusters with no kills totaled 568, suggesting that we had documented $70 \%$ of the large kills, $91 \%$ of the small kills, and $26 \%$ of the sites where marked animals were inactive, but not because of a kill.

When partitioned among diel time periods, kills of large prey, kills of small prey, and periods of inactivity for other reasons exhibited markedly different distributions (Figure 3.2). Most kills of 

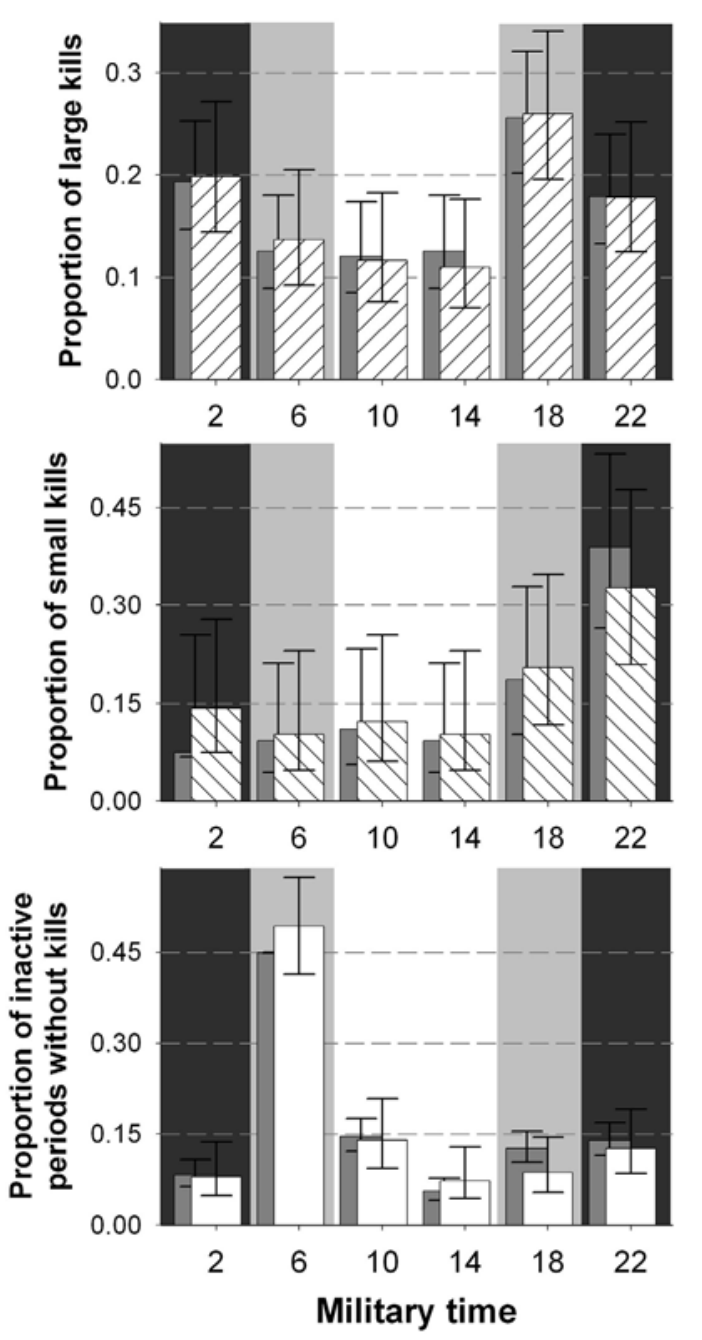

Figure 3.2. Proportional distributions of kills of large prey (top), kills of small prey (middle), and initiation of periods of inactivity (bottom), by six diel periods indicated by the median hour in military time. Lighter open or diagonally striped bars are for visited clusters only; dark bars behind include predicted activities; error bars are for $95 \%$ Cls.

large prey (62-64\%, the range depending upon whether predicted events were included) occurred during night-time or crepuscular hours, with a peak (26\%) at dusk. A similar majority of kills of small prey (67-70\%) occurred during dark or near-dark, but with a peak (32-39\%) at night. By contrast, periods of inactivity not associated with kills, and typically of 10-12 hr duration, were commonly initiated at dawn (45-49\%), and a majority (65$71 \%$ ) during dawn or daylight hours.

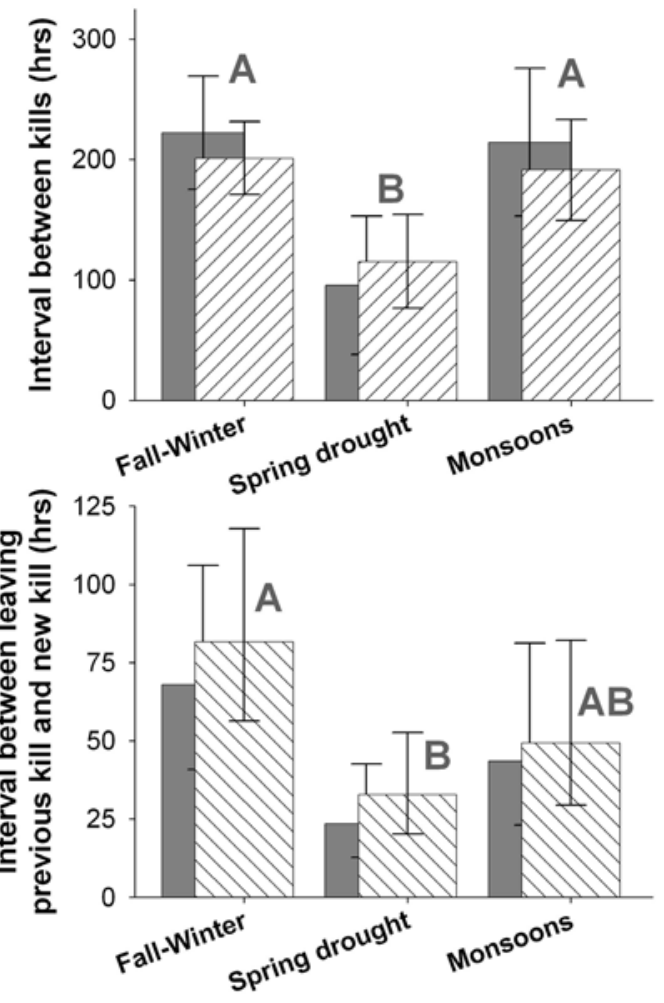

Figure 3.3. Mean intervals (with $95 \% \mathrm{Cls}$ ) between kills (top) and without eating (bottom), in hours, relative to three climatic seasons. Letters in dark gray are for results of multiple comparisons of means. Means with the same letter are not different at $\alpha=$ 0.05. Darker bars behind are for kills of large prey only.

\section{Interval between Kills}

Intervals between observed and predicted kills of large prey varied among sex-age classes ( $F$ $=3.5$, $\mathrm{df}=3 / 269, p=0.016)$ and averaged 221 hours $(95 \% \mathrm{CI}=191-252)$ for mature females, 177 hrs (143-211) for mature males, 144 hrs (106-181) for young females, and 191 hrs (104-277) for young males. Intervals between kills and intervals between departure from a kill site and the next kill (roughly, time between feedings) were strongly related to climatic season (fall-winter, spring drought and monsoons; Figure 3.3) and an interaction between mating season (peak versus ebb) and sex-age class (male or female by prereproductive [young] or mature; Figure 3.4). Model type I error probabilities were quite low and $R^{2}$ values modest, considering kill intervals for large prey only $(F=5.59$, $\mathrm{df}=9 / 263, p<0.0001$; $\left.R^{2}=0.16\right)$ and for prey of all sizes $(F=5.73, \mathrm{df}=$ 9/312, $p<0.0001 ; R^{2}=0.14$ ); or time without 

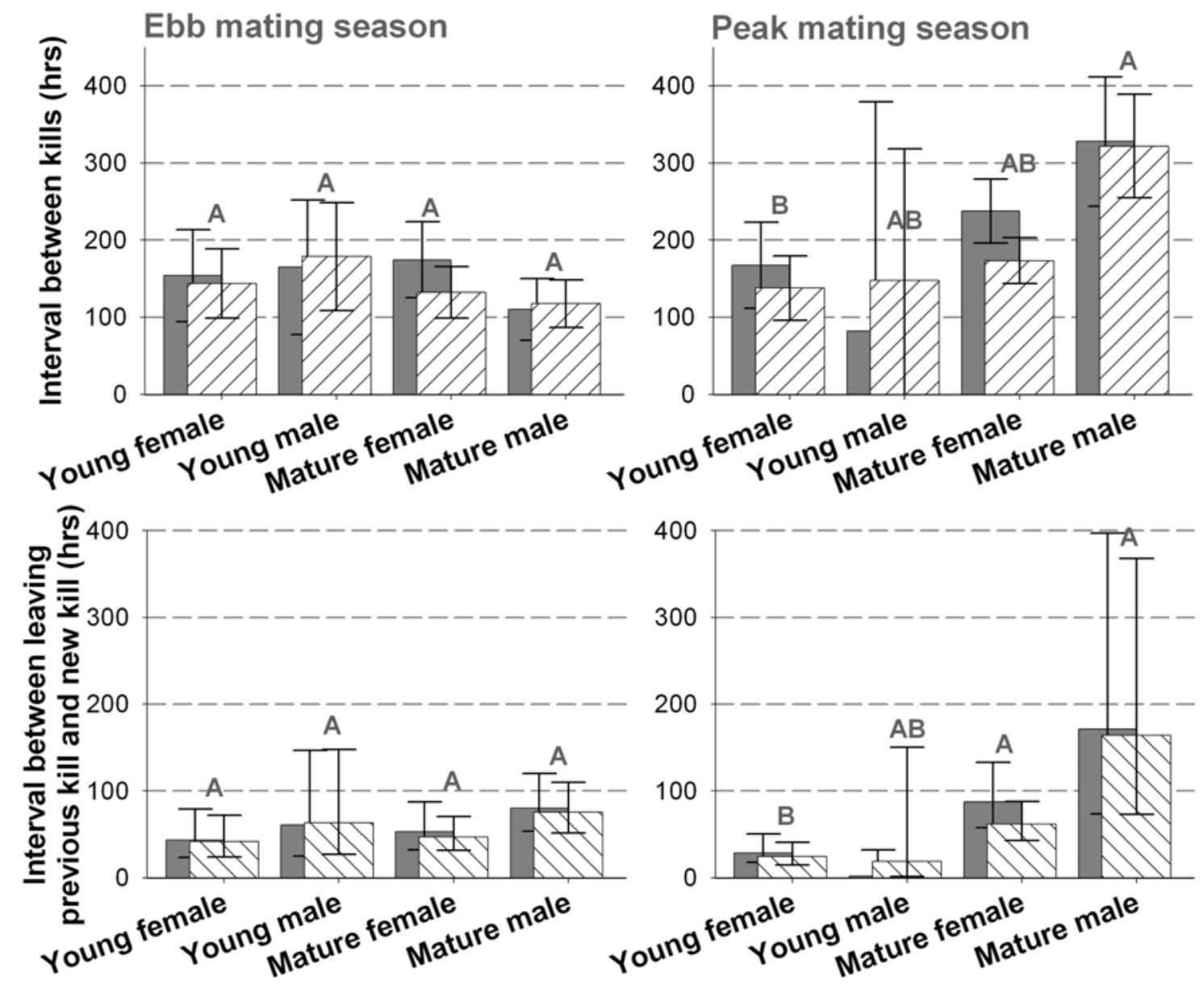

Figure 3.4. Mean Intervals (with $95 \%$ Cls) between kills (top) and without eating (bottom), in hours, for sexage classes relative to ebb mating season (left) and peak mating season (right). Letters in dark gray are for results of multiple comparisons of means. Means with the same letter are not different at $\alpha=0.05$. Dark bars behind are for kills of large prey only.

feeding for large prey only $(F=7.09, \mathrm{df}=9 / 263, p$ $\left.<0.0001 ; R^{2}=0.20\right)$ and for prey of all sizes $(F=$ 7.14 , df $\left.=9 / 312, p<0.0001 ; R^{2}=0.17\right)$. Type III sums of squares tended to be higher for the mating season by sex-age class interaction in all models, although climatic season also was consistently a strong effect.

We used least squares marginal means and the Tukey-Kramer method of controlling for type I error rate $(\alpha=0.05)$ to test for differences in mean kill intervals and mean intervals without feeding among climatic seasons and mating season $\times$ sexage class categories. Intervals of both types were longer during fall-winter compared to spring drought (Figure 3.3). Kill intervals, but not intervals without feeding, were also longer during the monsoons compared to the spring drought. Kill intervals and intervals without feeding did not differ among sex-age classes for the ebb mating season (Figure 3.4). However, during the peak mating season, kill intervals and intervals between feeding were longest for mature males, especially compared to pre-reproductive females. Both types of intervals also tended to be longer for mature females, again, especially when compared to young animals of the same sex.

\section{Kill Composition}

Of the 218 kills or instances of scavenging documented at the time of this report, the majority (52\%) were elk (Table 3.1). Small prey comprised $15 \%$ and mule deer $46 \%$ of all kills. Total percent is $>100$ because $>1$ kill was recorded at some sites. Reckoned in terms of finer categories, females 
Table 3.1. Numbers of kills or carcasses scavenged by mountain lions in the Flagstaff Uplands during 20032006, total $(n=218)$ and differentiating female from male mountain lions.

\begin{tabular}{|c|c|c|c|}
\hline Type of kill or scavenging & Total & Females & Males \\
\hline \multicolumn{4}{|l|}{ Mule deer (Odocoileus hemionus) } \\
\hline Sex and age not specified & 3 & 3 & 0 \\
\hline Adult (sex not specified) & 20 & 19 & 1 \\
\hline Adult female & 25 & 24 & 1 \\
\hline Adult male & 12 & 7 & 5 \\
\hline Yearling & 10 & 8 & 2 \\
\hline Fawn ( $<1$ yr old $)$ & 14 & 12 & 2 \\
\hline \multicolumn{4}{|l|}{ Whitetail deer (Odocoileus virginianus) } \\
\hline Adult male & 1 & 0 & 1 \\
\hline \multicolumn{4}{|l|}{ Elk (Cervus elaphus) } \\
\hline Sex and age not specified & 1 & 1 & 0 \\
\hline Adult (sex not specified) & 3 & 2 & 1 \\
\hline Adult female & 12 & 4 & 8 \\
\hline Adult male & 5 & 5 & 0 \\
\hline Yearling male & 3 & 1 & 2 \\
\hline Calf 6-12 months old & 11 & 6 & 5 \\
\hline Calf $<6$ months old & 53 & 34 & 19 \\
\hline Scavenged adult female & 5 & 3 & 2 \\
\hline Scavenged adult male & 2 & 1 & 1 \\
\hline \multicolumn{4}{|l|}{ Pronghorn (Antilocapra americana) } \\
\hline Adult male & 1 & 1 & 0 \\
\hline \multicolumn{4}{|l|}{ Small (c. 2-30 kg wet weight) prey } \\
\hline \multicolumn{4}{|l|}{ Mesocarnivores } \\
\hline Coyote (Canis latrans) & 21 & 21 & 0 \\
\hline Bobcat (Lynx rufus) & 2 & 2 & 0 \\
\hline Badger (Taxidea taxus) & 2 & 2 & 0 \\
\hline Grey fox (Urocyon cinereoargenteus) & 1 & 1 & 0 \\
\hline Raccoon (Procyon lotor) & 1 & 0 & 1 \\
\hline \multicolumn{4}{|l|}{ Other } \\
\hline Rabbit (Leporidae) & 7 & 5 & 2 \\
\hline Porcupine (Erithizon dorsatum) & 1 & 1 & 0 \\
\hline Owl & 2 & 2 & 0 \\
\hline
\end{tabular}

comprised $68 \%$ of all sexed adult mule deer kills. Adult mule deer, in turn, comprised 26\% of all kills, and $68 \%$ of all deer kills. Among documented kills of small prey, $73 \%$ were of mesocarnivores, of which $78 \%(n=21)$ were coyotes. Seven of the remaining 10 documented small kills were lagomorphs. Of the elk, 21\% were adults that had been killed and 7\% $(n=7)$ were adults that had been scavenged. Elk $<1$-yr old comprised the largest single category of fully identified kills, accounting for $67 \%$ of all elk carcasses, and $29 \%$ of all kills or scavenging.

Male and female mountain lions tended to kill different prey (Table 3.1). Elk comprised 72\% of all documented male kills or instances of scavenging compared to $34 \%$ for females. Of elk prey (not including scavenging), 31\% of male kills and $21 \%$ of female kills were adults. Females killed virtually all (96\%) of the mesocarnivores and the large majority (87\%) of mule deer. Logistic regression models discriminating mesocarnivores, mule deer, and elk <1-yr-old from other kills all included an effect of mountain lion sex-age class. The model for mesocarnivores included sex-age class and elevation (negative effect) as explanatory variables and provided good discrimination $(c=0.80)$ and adequate fit (Hosemer and Lemeshow goodness-of-fit, $X^{2}=$ $10.48, \mathrm{df}=7, p=0.16$ ). Differences among sexage classes were wholly attributable to a lack of mesocarnivore kills by mature males (Figure 3.5). The model for mule deer kills included mountain lion sex-age class, climatic season, elevation (a positive effect), and kill site abundances of 


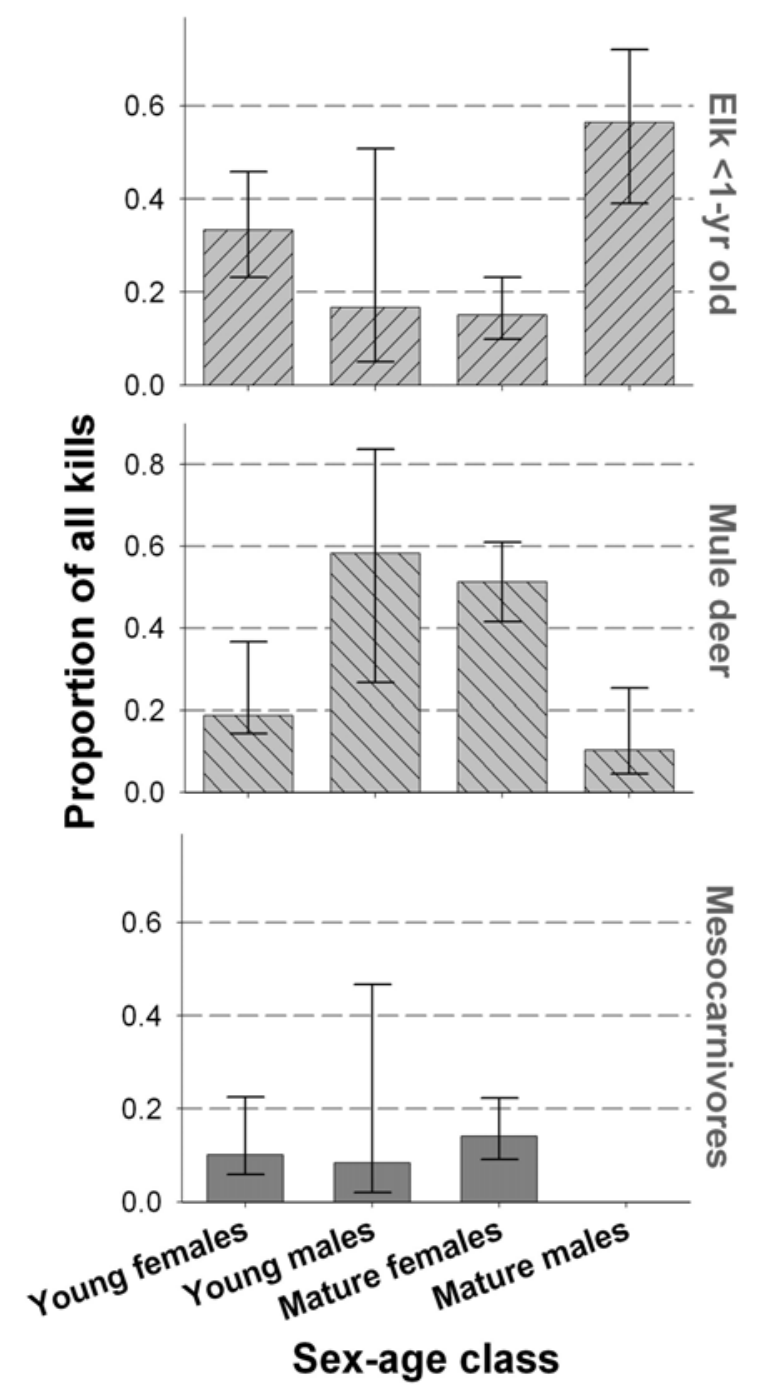

Figure 3.5. Proportional kills (with $95 \% \mathrm{Cls}$ ) of elk $<1$ yr-old (top), mule deer of all classes (middle), and mesocarnivores (bottom) by different sex-age classes of mountain lions in the Flagstaff Uplands.

cliffrose and mountain mahogany (both positive), and also provided good discrimination $(c=0.82)$ and good fit $\left(X^{2}=6.04, \mathrm{df}=8, p=0.64\right)$. Mule deer kills were much more common during fallwinter (Figure 3.6) and more common by mature females and young males compared to mature males and young females (Figure 3.5). Finally, the model for kills of elk <1-yr-old included sex-age class, a polynomial of days since onset of elk calving season (mid-May), and elk calf crop year (3 years treated categorically), and provided good discrimination ( $c=0.83$ ) but poor fit $\left(X^{2}=44.2\right.$, df $=8, p<0.0001)$. Differences among sex-age classes were largely attributable to proportionately more kills by mature males (Figure 3.5).

Otherwise, kills of elk calves peaked at roughly 70 dys after mid-May and in association with the calf

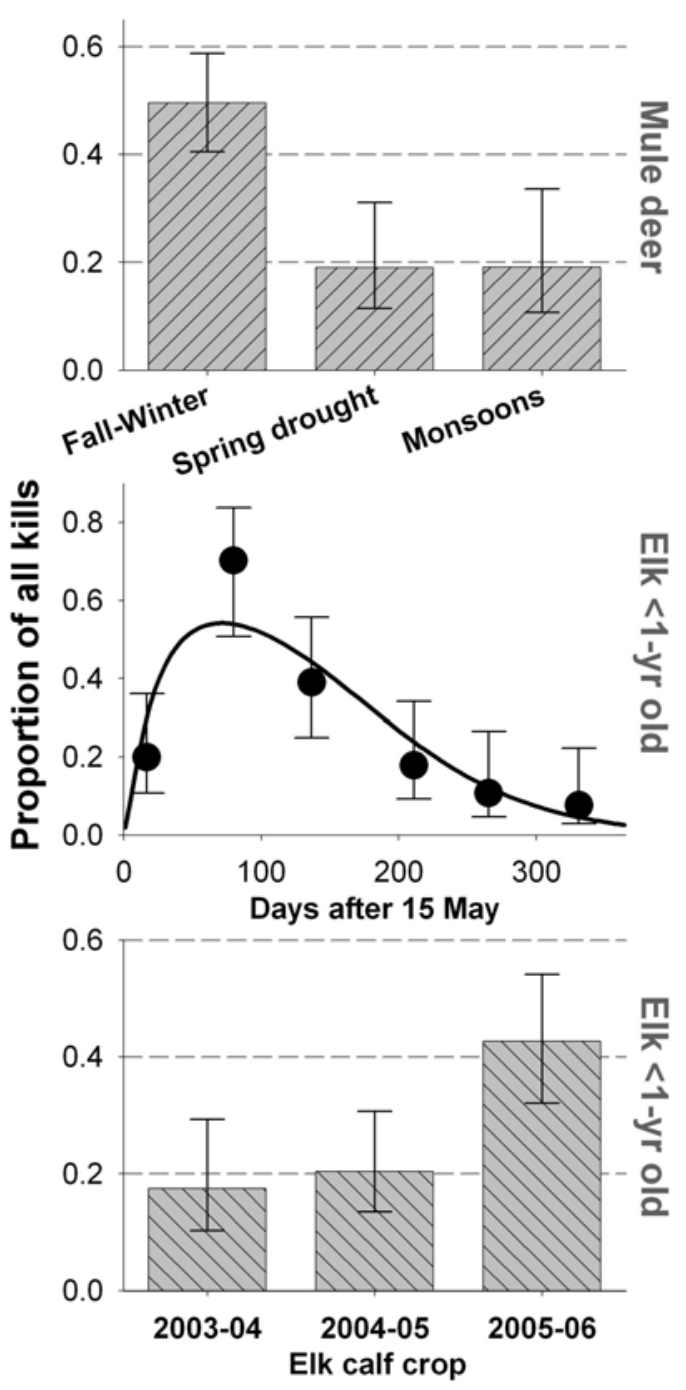

Figure 3.6. Proportion of mountain lion kills in the Flagstaff Uplands (with 95\% Cls) of mule deer by season (top), and of elk <1-yr-old by days after the advent of calving season (middle) and by elk calf crop year (bottom).

crop produced during May and June of 2005 (Figure 3.6).

\section{Behavior at Kills}

\section{Time Spent at Kills and Percent of Kills Consumed}

Time spent at documented kills (in hrs) was related to nine independent variables that explained $41 \%$ of total variance and were part of a model that was almost certainly not attributable to chance ( $F=4.5$, $\mathrm{df}=11 / 193, p<0.0001)$. Time spent increased with amount of precipitation at the time of feeding and with length of time spent at the previous kill, and decreased with increasing elevation and when a lion was scavenging. Otherwise, time spent at a 

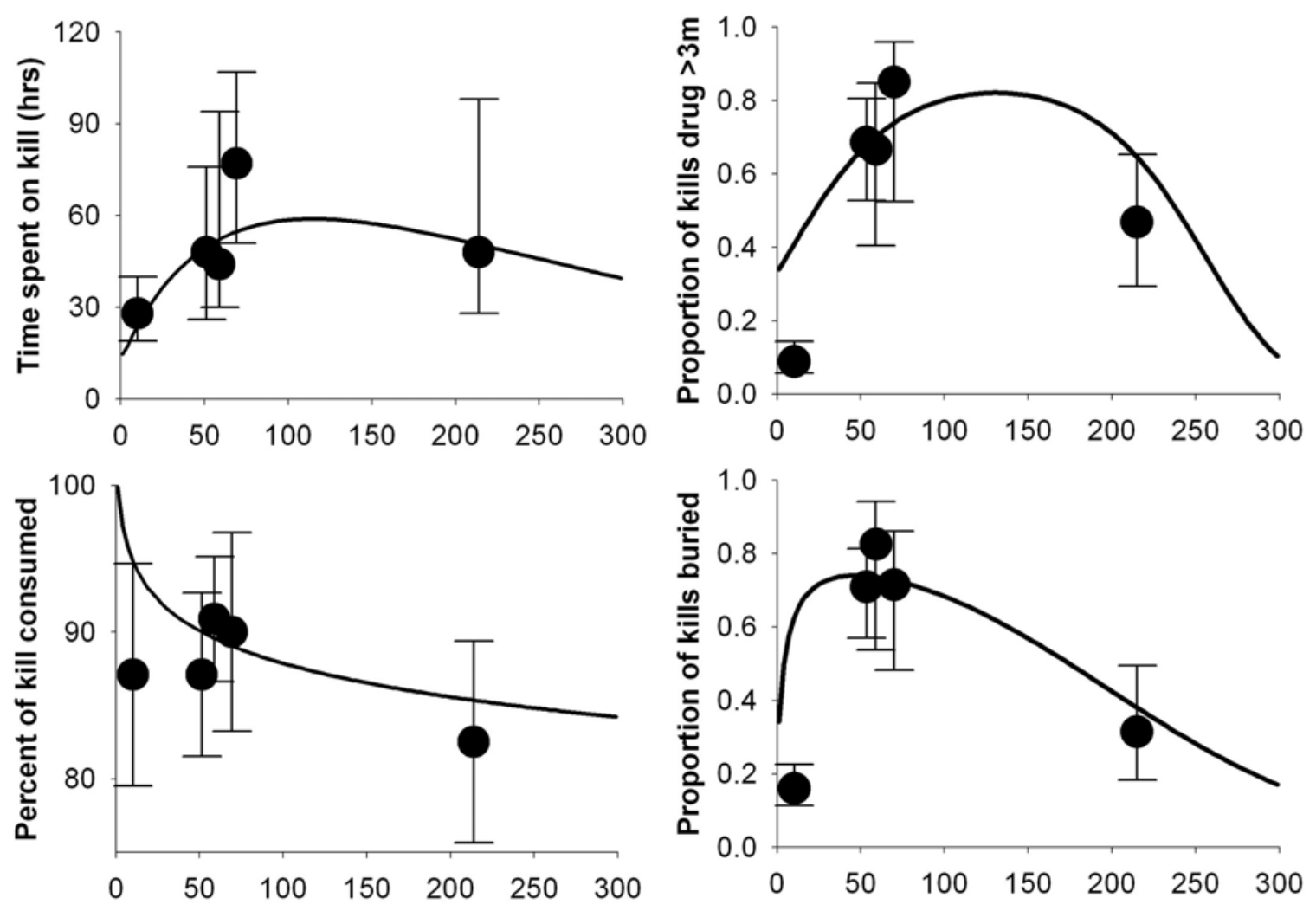

\section{Approximate mass of kill $(\mathbf{k g})$}

Figure 3.7. Effects of prey mass on mountain lion behaviors at kills, including total time spent at the kill site (top left), percent of edibles consumed from the carcass (bottom left), proportion of kills that a lion drug $>3 \mathrm{~m}$ (top right), and proportion of kills that a lion buried (bottom right). Univariate relations are shown by solid lines and dots with $95 \% \mathrm{Cls}$ are for means of quintiles of the data, shown to illustrate goodness-of-fit.

kill was related to sex-age class and polynomials of maximum ambient temperature and carcass mass. Duration peaked at prey mass $\approx 114 \mathrm{~kg}(251 \mathrm{lbs}$; Figure 3.7) and at ambient temperature $\approx 15^{\circ} \mathrm{C}$ $\left(59^{\circ} \mathrm{F}\right)$. Strongest effects were attributable to precipitation, prey mass, and sex-age class. Compared to all other classes, mature males averaged the least time at a kill $(19.1$ [95\% CI = 13.4-28.1] hrs, compared to 33.7 [25.3-44.7] hrs for mature females, 37.7 [27.4-51.6] hrs for young females, and 39.6 [25.7-60.8] hrs for young males; Figure 3.8).

Estimated percentage of total edibles consumed from a carcass was related to seven independent variables that explained $40 \%$ of total variance and were also part of a model that was almost certainly not attributable to chance $(F=$ 11.26, $\mathrm{df}=9 / 150, p<0.0001)$. Percentage consumed was positively related to elapsed time (in days) between the kill and our site investigation, elevation, and whether the lion drug the carcass $>3 \mathrm{~m}$ or not, and negatively related to prey mass (Figure 3.7) and percent forest and shrub cover at the site. Percentages consumed were also related to lion sex-age class, with percentages averaging least for mature males and greatest for young females (Figure 3.8). Overall, strongest effects were attributable to time interval between the kill and site investigation, elevation, prey mass, and sex-age class.

\section{Handling of Kills}

The probability that a lion had drug a carcass $>3 \mathrm{~m}$, versus not, was related to five variables that were part of a logistic regression model that provided adequate discrimination (area under the ROC curve $[c]=0.75$ ) and good fit to the data 


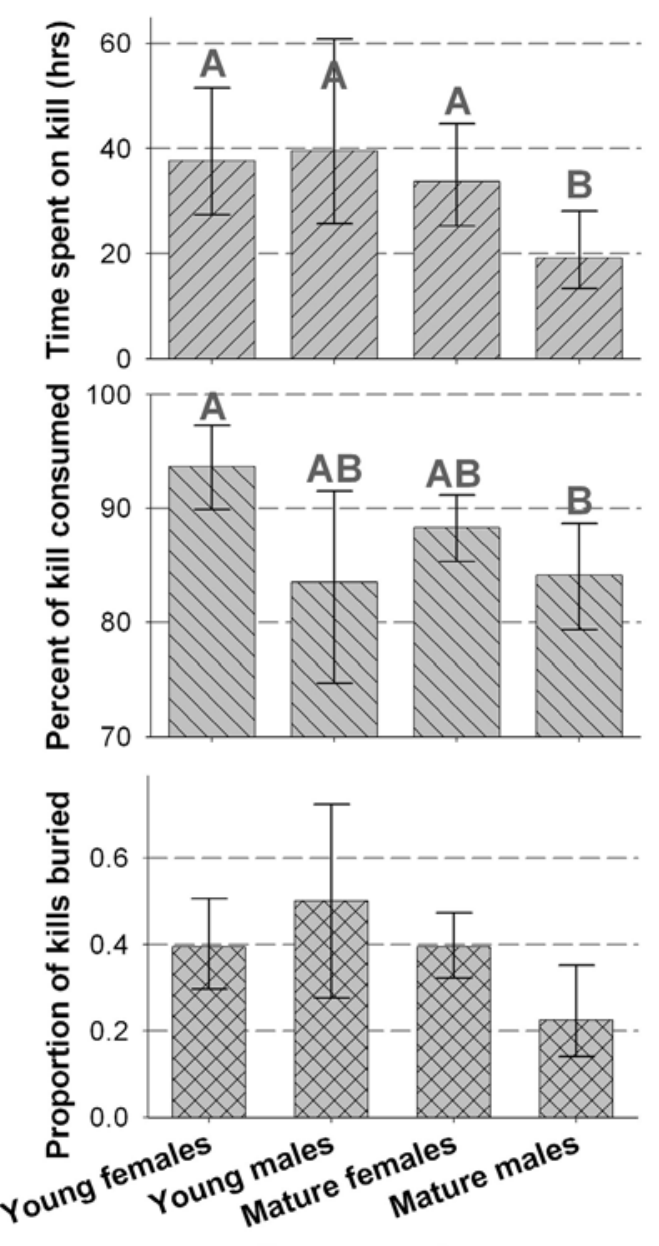

Figure 3.8. Effects of sex-age class on behavior of mountain lions at kills, including time spent at the kill site (top), percent of edibles consumed from the carcass (middle), and proportion of kills that a lion buried (bottom). Error bars are 95\% Cls and bars topped by the same letters denote means that are not significantly different.

(Hosmer-Lemeshow goodness-of-fit, $X^{2}=10.63$, $\mathrm{df}=8, p=0.22$ ). Probability of dragging increased with increasing cover of herbaceous vegetation and with increasing southerly orientation at the site, and decreased with increasing elevation. Probability of dragging was also related to a polynomial of prey mass (Figure 3.7 ) and peaked at a mass $\approx 131 \mathrm{~kg}$ (289 lbs.). Overall, prey mass had the strongest effect on probability of dragging in this model.

The probability that a lion had buried a carcass, versus not, was related to six variables that were part of a model that also provided adequate discrimination $(c=0.76)$ and good fit to the data $\left(X^{2}=7.94, \mathrm{df}=8, p=0.44\right)$. Probability of burial increased with increasing forest cover and ambient

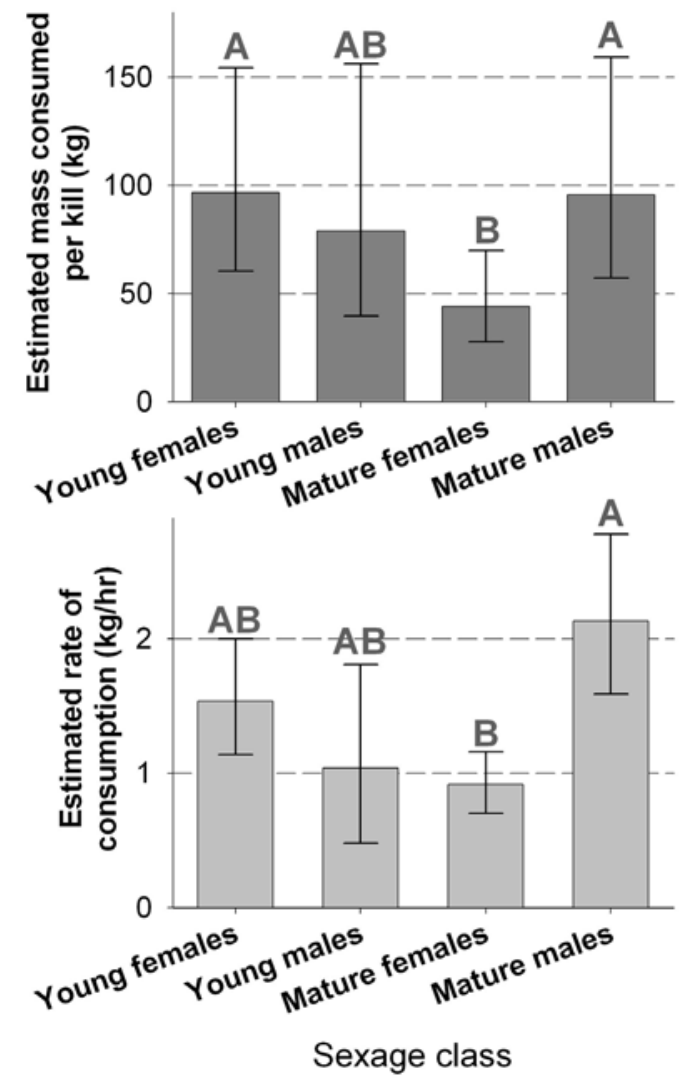

Figure 3.9. Effects of sex-age class on estimated total biomass consumed (top) and rate of consumption (bottom) by mountain lions at kills in the Flagstaff Uplands. Error bars are $95 \% \mathrm{Cls}$ and bars topped by the same letters denote means that are not significantly different.

decreased with increasing elevation. Also like dragging, probability of burial was related to a polynomial of prey mass (Figure 3.7), but peaked at a much lesser mass, $\approx 47 \mathrm{~kg}$ (104 lbs.).

Probability of burial was related to sex-age class, and was lowest for mature males compared to all other classes of mountain lion (Figure 3.8). As with probability of dragging, carcass mass had the strongest effect of any explanatory variable on probability of burial.

\section{Biomass Consumed at Kills}

Not considering the effect of prey mass, total biomass estimated to have been consumed by a mountain lion from a documented kill was related to four variables in a model that explained $15 \%$ of total variance and almost certainly was not by chance alone $(F=4.87, \mathrm{df}=7 / 196, p<0.0001)$. Consumed mass increased with elevation and with a kill versus an instance of scavenging, and averaged greatest during fall-winter (96 kg [95\% 
$\mathrm{CI}=64-145])$, especially compared to during the monsoons (56 kg [34-92]). Consumed mass was also related to sex-age class (Figure 3.9), and was greatest for mature males (95 kg [57-159]) and young females (96 kg [60-154]), especially compared to mature females (44 kg [28-70]). Sexage class and scavenging had the greatest effects in this model.

Estimated rate of consumption $(\mathrm{kg} / \mathrm{hr})$ was also related to four explanatory variables in a model that explained $19 \%$ of total variance, almost certainly not by chance alone $(F=7.35$, df $=$ $6 / 184, p<0.0001)$. Rate of consumption increased with increasing elevation and decreased with increasing forest cover and when a carcass was buried versus not. As with total consumed mass, rate of consumption was related to sex-age class (Figure 3.9), and greatest for mature males (2.1 $\mathrm{kg} / \mathrm{hr}$ [1.6-2.8]), especially compared to mature females (0.9 kg/hr [0.7-1.2]). Elevation, sex-age class, and forest cover all had strong effects in this model.

\section{Discussion}

Although the number of activity sites we sampled is already comparatively large, the small number of sampled individuals precludes our reaching definitive conclusions at this time about mountain lions in the Flagstaff Uplands. Even so, some intriguing patterns emerged from this preliminary analysis, well supported by the data. These patterns pertained to the effects of season and time of day, weather, site vegetation and physical features, type and mass of prey, and mountain lion sex-age class. Moreover, these effects pertained to a number of mountain lion behaviors, many of which have not previously been rigorously investigated, including kill intervals, timing of kills, time spent at kills, handling of kills, and estimated rates of consumption. Many of these patterns are germane to managing for human safety, as elaborated in Chapter 4.

\section{Kill Rates and Timing of Kills}

As previously reported by Mattson et al. (2005), dusk and to a lesser extent night were times of peak success for mountain lions preying on larger ungulates in our study area. Extensive movements by our marked lions during dusk (see Chapter 2) suggest that this greater success was at least partly intentional rather than simply fortuitous. Beier et al. (1995) and Anderson and Lindzey (2003) also observed that most kills in their study areas occurred at night, between 1800 and 0200 hours. This begs the question, though, why predatory success in our study area was appreciably greater or, similarly, why lions were apparently making a greater effort at dusk compared to dawn? More straight-forward, initiation of inactive periods during early morning by lions in our study area, typically sustained through most of the day (see Chapter 2), is consistent with our expectation that mountain lions will avoid daytime heat and favor activity during darker times of day when prospective prey are presumably more vulnerable.

Considering both small and large prey, kill rates documented so far for mountain lions in our study area (5.4-7.9 dys, depending on sex-age class) are slightly lower than kill rates of large prey documented for mountain lions elsewhere. Murphy et al. (1992) and Ruth (2004) reported kill rates from the Yellowstone ecosystem mostly in the range of once every six to nine or 11 days, with primary differences between maternal females and other lions. Shaw (1977), Beier et al. (1995), and Anderson and Lindzey (2003) reported similar results from northern Arizona, southern California, and southeastern Wyoming. However, small (2-30 kg wet weight) prey were apparently not a significant factor in these other studies, or at least not overtly considered in calculation of kill rates. Considering only large prey, our results (one kill every 6.0-9.2 dys) align remarkably well with previous research, and are lower than rates predicted by Ackerman et al. (1986) on the basis of energetics - around once every eight-nine days for adult males and once every 16 days for adult females.

Seasonal differences in predatory activity and apparent predatory success were only partly consistent with our prior expectations. The short average interval between kills during the spring drought is consistent with prey comparatively concentrated, presumably near water, and in poor physical condition as a result of prolonged poor forage conditions (Logan and Sweanor 2001). Longer kill intervals during the monsoons are consistent with expected reductions in predatory success plausibly arising from greater dispersal and improved condition of prey. However, the long intervals between kills during fall-winter were opposite of what we had expected, with prey 
presumably concentrated on spatially-restricted winter ranges and in increasingly poor condition. And, indeed, the increased frequency of mule deer kills during winter, in association with sites offering abundant winter deer browse such as cliffrose and mountain mahogany, is consistent with this expectation. In any case, the lower fallwinter kill rates were somewhat offset for lions by their consumption of greater mass, on average, from kills that did occur.

\section{Kill Composition and Scavenging}

The composition of mountain lion kills reported here is consistent with the composition reported by Mattson et al. (2005) and much like the composition of mountain lion kills documented in central Idaho, the Montana Rocky Mountain East Front, and northern Yellowstone - other areas with substantial numbers of both elk and deer (Hornocker 1970, Williams et al. 1995, Husseman et al. 2003, Ruth 2004). Elk comprised 50 to 73\% of all kills in these more northern study areas, which overlaps the $52 \%$ documented in our study area. So far, mountain lions in our study have apparently strongly selected for elk $<1$-yr-old, which comprised $67 \%$ of all elk kills, proportionately more than were documented in central Idaho (51\%; Husseman et al. 2003) and Yellowstone (50-53\%; Ruth 2004). This apparent tendency to select for smaller age classes among intrinsically larger-bodied prey, such as elk, is consistent with the near exclusive focus of mountain lion predation on moose (Alces alces) calves and juveniles observed by Ross and Jolkotzy (1996) in Alberta.

Kills of elk $<1$-yr-old by mountain lions in our study area were consistent with what we expected both by probable vulnerability and abundance of elk calves. Calving among elk in temperate regions of North America most commonly begins near mid-May and peaks near the beginning of June (Taber et al. 1982). Predation on elk calves by mountain lions in our study area peaked during mid- to late-July, presumably at a time when elk calves had reached maximum numbers and were still quite vulnerable (Geist 1982). The steady decline in proportional frequency of elk calves among lion kills thereafter presumably reflected reduced vulnerability of calves with increasing mobility and vigor. Given that elk calves were the single largest category of lion kills, this presumed decline in vulnerability and more certain decline in frequency among lion kills may partly explain reduced kill rates and increased movements of lions that we observed during fall and winter. The large number of elk calf kills following the 2005 elk calving season probably reflected the exceptionally large calf crop (Arizona Game and Fish Department 2005b) that followed an exceptionally wet winter (187\% of average at Flagstaff's Pulliam Airport, September through mid-April), in what has otherwise been an extended multi-year drought.

Differences in prey selection between mountain lion sexes have only rarely been documented. Anderson and Lindzey (2003) observed a tendency for adult males to kill more bull elk and for adult females to kill more does, whereas Pierce et al. (2000) observed that, compared to male mountain lions, females killed more young deer. We found that, compared to females, males killed virtually no small prey and many more elk. This result is consistent with the expectation that larger-bodied mountain lions of whatever sex would be killing larger-bodied prey, and fits similar range-wide population-level patterns (Iriarte et al. 1990). Our results clearly point to the potential importance of smaller (2-30 $\mathrm{kg}$ ) prey to especially female mountain lions in our study area, and highlight potential implications of the widespread bias against documenting small prey to our understanding of mountain lion ecology (Ackerman et al. 1984).

Most of the documented kills of small (2-30 $\mathrm{kg}$ ) prey in our study area were mesocarnivores, particularly coyotes. In fact, we have so far documented more kills of mescocarnivores $(n=$ 27) than have been reported during other studies regardless of duration, intensity and number of collared animals, including studies with $>200$ investigated kills (Murphy et al. 1992, Ross and Jalkotzy 1996, Logan and Sweanor 2001, Ruth 2004). In contrast to speculations by Boyd and O’Gara (1985), we found little indication that mountain lions in our study area were killing coyotes to protect kills of ungulates. All but three of the mesocarnivores were mostly consumed, and only three were associated in time and space with another kill. Our results are more consistent with Logan and Sweanor (2001), who speculated that mountain lions killed coyotes to protect kittens and more broadly to reduce competition for food. We also speculate that female lions were killing mesocarnivores simply as an immediate source of energy. 
We documented seven instances of scavenging, which lends weight to a growing body of evidence that mountain lions are not exclusively predators. Bauer et al. (2005), Logan and Sweanor (2001) and Ross and Jalkotzy (1996) previously recorded 20,16, and four instances of scavenging, respectively, involving primarily mule deer and moose. All of our cases involved adult elk, which were the largest-bodied ungulates in our study area, consistent with the likelihood that, if scavenging were to happen, it would involve a carcass with greater edible biomass (Mattson 1997). This documentation of scavenging raises the possibility that we and others have misclassified incidents of scavenging as predations (Bauer et al. 2005). Although this may be true, we suspect our error rate has been small primarily because of our often close follow-up on mountain lion activity and our reliance on confirmatory evidence such as signs of struggle to identify predations.

\section{Effects of Prey Mass and Competing Scavengers}

Our results suggest that prey mass may affect mountain lion behaviors in complex ways, and that optimal prey mass may not be a simple function of what lions are capable of killing. Estimated percentages of edibles consumed by lions declined as prey mass increased, whereas relocation and burial of kills reached maximum probabilities at intermediate prey masses, in the range of 50-130 kg (110-290 lbs.). Moreover, absolute time spent on a kill did not increase monotonically with prey mass, as might be expected, but rather also peaked at an intermediate mass, around $115 \mathrm{~kg}$ (250 lbs.). Our results suggest that mountain lions in our study area were perhaps both less able and less motivated to secure large carcasses by relocating and burying them, and that they often profited little from the added mass obtained by risking the killing of large prey. Taken together, our results suggest that, although lions are capable of killing large ungulates, including fully adult male elk in the range of $270-360 \mathrm{~kg}$, optimal prey size is in the range of $50-150 \mathrm{~kg}$, the size of adult deer and calf elk, as much because of post-kill foraging efficiencies as risks of injury.

These speculations are consistent with the observed effect of ambient temperature on time spent at a kill and likelihood of burial. Burial reduced rates of consumption, which, as might be expected, suggests that burial served to preserve edible tissue (Goff 1992) and perhaps also engender a greater sense of security for the mountain lion. Probability of burial increased with increased ambient temperature. Again, this makes sense if burial is a strategy to both inhibit dissemination of odor and reduce loss of edibles to microbes and arthropods such as adult wasps (Vespidae), maggots (larvae of the family Calliphoridae), and carrion beetles (Silphidae), which would otherwise be accelerated with increased carcass temperature (Payne 1965, Tantawi et al. 1996). Controlling for the effect of carcass mass, the peak tenure of lions on kills at middling ambient temperatures $\left(15^{\circ} \mathrm{C}\right.$, roughly $60^{\circ} \mathrm{F}$ ) is consistent with accelerated loss of mass to especially arthropods and increased displacement or fear of displacement by large scavengers such as black bears (Ursus americanus) with warmer temperatures, as well as with potentially greater difficulty consuming frozen tissues at sub-freezing temperatures, which would be a factor during winter in our study area.

Our interpretation of the tendency for duration of consumption to decline with greater prey size and warmer ambient temperatures is consistent with previous theorizing by Hornocker (1970) and Ruth (2004). Hornocker (1970) speculated that warm weather would accelerate decomposition and thereby reduce efficiency of carcass use, whereas Ruth (2004) noted the potential for greater competition with scavengers at large kills, if for no other reasons than the difficulty of moving a large carcass to a more secure location and adequately burying it. Murphy et al. (1998) documented the loss of substantial prey biomass by mountain lions in Glacier and Yellowstone National Parks to bears that had displaced them from their kills.

The strong positive relation between time spent at a kill and precipitation, controlling for the effect of carcass mass, has not been previously observed nor previously subject to speculation. This relation is, again, consistent with a potentially major effect of competition with microbes and arthropods on behavior of mountain lions at kills. Precipitation has been shown to retard decomposition and other carcass depletion from microbes and arthropods (Payne 1965, Tantawi et al. 1996), which would logically prolong consumption of a kill by a lion. The effects of precipitation on decomposition can be neutralized by forest cover, although forest cover can at the 
same time also retard decomposition by reducing carcass temperature (Isiche et al. 1992, Tessmer and Meek 1996). Indeed, this latter effect is consistent with the reduced rates of consumption observed for lions in areas with greater forest cover, potentially also linked to the greater odds of carcass burial that we observed at forested kill sites, which would, alone, prolong lion use of a carcass.

Elevation was correlated with numerous mountain lion behaviors in our study area, including positive relations with percentage of edibles consumed, total biomass consumed, and rate of consumption, and negative relations with total time spent at a kill, probabilities of both relocating and burying a carcass, and likelihood of killing a mesocarnivore. In other words, mountain lions in our study area were apparently much more efficient at appropriating edibles from a kill at high compared to low elevations, and without resorting to extensive securing of the carcass. This suggests, in turn, that competition from microbes and arthropods may have been a lesser factor at high compared to low elevations, consistent with observations of diminished arthropod activity on carrion with increasing elevation in Colorado (DeJong and Chadwick 1999). We were somewhat surprised that elevation emerged as a strong correlate in so many models given that we had controlled for proximal ambient temperatures through application of an elevational lapse rate. If elevation effects were, indeed, a surrogate for arthropod activity on carrion, then proximal temperature would not logically serve as a control because arthropod activity is typically keyed more to the abundance and diversity of local arthropod communities than to site and carcass temperatures (Gill 2005).

\section{The Strategy of Mature Males}

We close this chapter by commenting on what is probably one of the most compelling results from this research so far - the marked differences in predatory and feeding behaviors by mature males compared to all other sex-age classes. All else equal, mature males spent the least time on a kill, consumed the least percentage of edibles, and were least likely to bury a carcass, yet, despite all this, consumed, on average, the greatest biomass at the greatest rate. As we noted before, they were also more likely than any other sex-age class to kill elk, especially elk calves, and least likely to kill small prey, especially mesocarnivores. Overall, these behaviors are logically interpreted as a time minimizing strategy; in other words, maximizing intake of energy in the minimum time possible.

As a corollary, mature males were likely adopting a time-minimizing approach to feeding to maximize reproductive opportunities. What they likely gained was the opportunity to travel through and monitor much larger areas than would otherwise be the case. Such movements would allow not only monitoring of potentially reproductive females, but also defense against incursions by competing males (Logan and Sweanor 2001). This interpretation is consistent with the greater movements of mature males documented here (Chapter 2) and in many other studies (cf., Logan and Sweanor 2001). This interpretation is also consistent with the observed decline in kill rate by mature males during the time of hypothesized greatest mating activity (FebruaryJuly), at the same time that kill rates of all other sex-age classes did not appreciably change. This decrease in kill rate raises the interesting possibility that males have a seasonal mating strategy cued to female availability, despite having the physiological capacity to reproduce year-round. 


\title{
Chapter 4
}

\section{Managing for Human Safety in Mountain Lion Range}

\author{
David Mattson
}

\section{Introduction}

Mountain lions (Puma concolor) are the smallest of only four felids that have a welldocumented history of killing people - the other cats being African and Asiatic lions (Panthera leo), leopards (Panthera pardus), and tigers (Panthera tigris). Of these species, mountain lions are responsible for the fewest recorded deaths, not anywhere near the numbers of people killed by tigers in India, which have been between 30 and 1300 per year since the 1920s (Løe 2002). Even so, any predation on a human by a large carnivore commands the attention of people in Canada and the U.S., and is sometimes cause for stronglyexpressed demands on managers to provide safety and exact retribution (Deurbrock and Miller 2001, Etling 2001). Concerns about threats posed by mountain lions have been fueled by a marked increase in numbers of attacks on people especially since the 1970s, to around 3-4/yr during the last two decades (Beier 1991, Fitzhugh et al. 2003; Figure 4.1). Numbers of attacks have stabilized since the early 1990s and declined during the last six years (Figure 4.1). Although there have been comparatively few attacks by lions on humans in Utah, New Mexico, Arizona, and Nevada, especially in contrast to California, Colorado, and British Columbia (Figure 4.2), encounters with lions that were perceived to be threatening by the involved humans have increased even in interior southwestern states, especially since the 1990s (e.g., Wakeling 2003, Barber 2005).

In this chapter I review what we know, deduce, and speculate about factors that govern risk of mountain lions attacking humans, to provide a basis for design of management to reduce risk to socially acceptable levels. I begin by describing a way to usefully frame risk and partition factors governing its' different facets, and then analyze existing relevant literature and available data to provide insight into the nature and relative importance of landscape features and
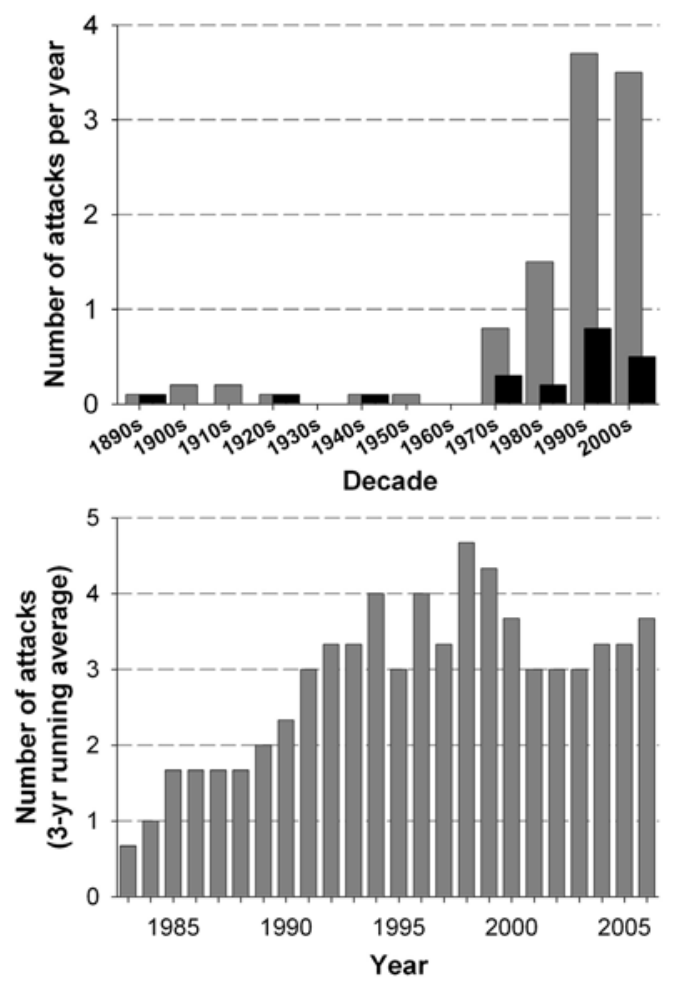

Figure 4.1. Annual number of attacks on humans by mountain lions (light bar, top) and number of resulting human fatalities (dark bar, top), averaged per decade, and a 3-yr running average of number of attacks, by year (bottom), for Canada and the U.S. Data are from Beier (1991), Etling (2001) and online from http://www.cougarinfo.com.

human and mountain lion behaviors and physical attributes associated with encounters and attacks. I used data that were previously published by Beier (1991), Etling (2001), and Fitzhugh et al. (2003), or were publicly available online in a compilation of attacks and other close encounters at http://www.cougarinfo.com. I emphasized empirical results, but also gave due consideration to published recommendations grounded in experience, anecdote, and general knowledge of feline behavior. I employed weight-of-evidence to reach conclusions rather than emphasizing either 
proof or disproof of a particular effect (i.e., I did not minimize either type I or type II errors). This

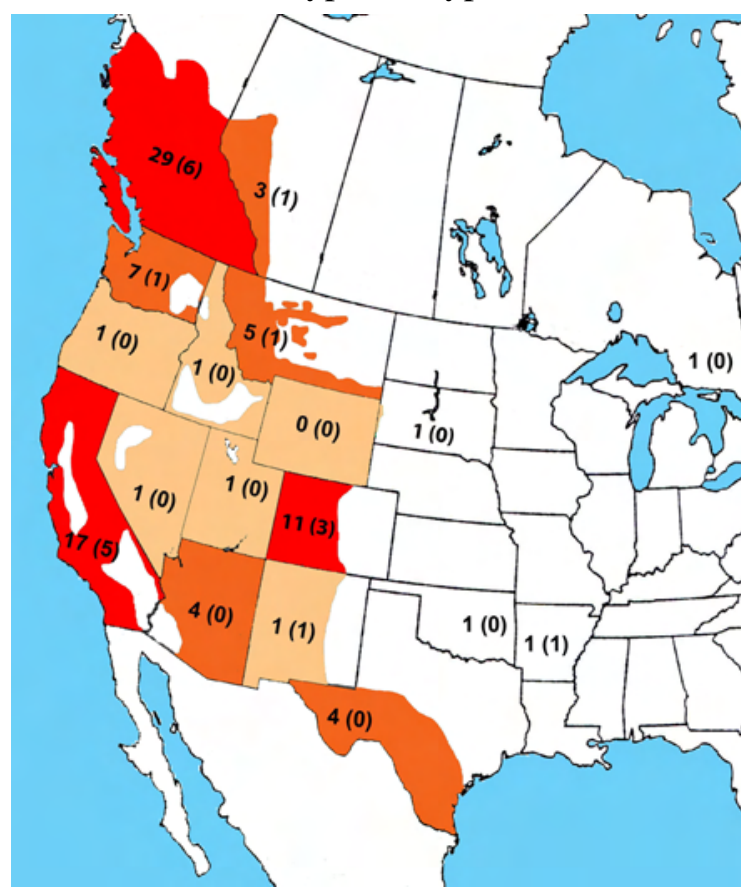

Figure 4.2. Number of attacks on humans by mountain lions and number of resulting human fatalities (in parentheses to right) since 1890, by state and province for Canada and the U.S. Data are from Beier (1991), Etling (2001) and online

approach to uncertainty is consistent with likelihood theory and well-suited to identifying models of how the world works that are, of all feasible candidates, best supported by the available information (Smith et al. 2002).

\section{Partitioning Risk of Mountain Lion Attack}

Of all possible outcomes of a humanmountain lion encounter, wildlife and public lands managers are most concerned about human death. Human injury, almost always a consequence of any physical contact with a lion, is of second greatest concern. Of third greatest concern are encounters perceived to be threatening by the involved humans, and also possible precursors to later attacks. Of least concern are benign encounters (Arizona Game and Fish Department 2005a). These outcomes are not only given different management priority, they are also associated with different probabilistic transitions governed by different causal factors. More specifically, human death is the logical outcome of:
1) the probability that a mountain lion will encounter a human (probability of an encounter);

2) the probability that an encounter will trigger curiosity and other similar lion behaviors that will be perceived as threatening by the involved human or, indeed, be aggressive (probability of an aggressive response given an encounter);

3) the probability that initial responses by the lion will result in an attack (probability of an attack given an aggressive response); and

4) the probability that an attack will be fatal (probability of death given an attack).

Managers or people involved in an encounter can affect the odds of a fatal or injurious outcome at each one of these transitions. Managers plausibly have greatest influence over risk at transition (1), through area-specific management of mountain lion populations or human activity, and some degree of influence over all other transitions, through activities such as education and interventions to remove or otherwise modify the behaviors of known lions that are perceived to pose an unacceptable threat. Humans involved in encounters also have influence over all transitions, but most importantly transitions (2)-(4), associated with an unfolding interaction with a lion. Given information, involved humans can also affect their baseline exposure (transition [1]) by deciding whether or not to use areas known to be frequented by mountain lions. I have structured the main part of this chapter that follows around these transitions, beginning each related section with conceptual considerations, followed by relevant information, empirical where possible, focused on the Flagstaff Uplands and other similar areas.

\section{Probability of an Encounter}

Encounters between humans and mountain lions, benign or otherwise, more-or-less equate to the notion of exposure used in risk management (Pritchard 2000). Without exposure to mountain lions, there would be no risk of human injury or death. This proviso is important to making meaning of oft-quoted statistics regarding comparative risks posed by different factors in the human environment. For example, coyotes (Canis lupus) and venomous snakes have killed substantially more people than have mountain lions (Conover et al. 1995), yet people are undoubtedly 
exposed much more often to these comparatively numerous and widespread animals. Put simply, risk of attack by lions is most usefully judged in terms of odds for those humans who are out and about in areas occupied by mountain lions (Fitzhugh 1988). Those who hold a negativistic worldview (in the parlance of Kellert [1996]) are overtly fearful of wildlife, and sometimes advocate for managing risk by eliminating exposure through eradication of animals such as mountain lions (Kellert 1996). This is an extreme view, but highlights the potential importance of managing exposure as part of reducing risk of human injury or death, more plausibly through affecting human activities. Such a strategy would be most feasible where managers and the public had access to detailed information about spatial and temporal distributions of especially predatory mountain lion activities. Local mountain lion densities and landscape features that predict distributions of mountain lion activity would be important factors for assessing likely human exposure. Such parameters are amongst the easiest to specify in management of risk given that they are grounded in data typically collected from radio-telemetry studies, the core of most wildlife research.

Despite the dramatic increase in numbers of mountain lion attacks on humans since 1970 (Figure 4.1), it remains unclear whether per capita risk is any higher now compared to in the past for a human who ventures into lion range. Absolute numbers of lion attacks could increase for several reasons, including increased numbers of lions and humans in lion range, and increases in predisposing behaviors by both species. Increased numbers of mountain lions would lead to increased exposure of humans to risk, unless modified by factors such as lions increasingly avoiding people. A number of wildlife managers have concluded that mountain lion populations increased in most of the western U.S. since the 1970s (for example, see the State Reports in Proceedings of Mountain Lion Workshops and DeVos and McKinney [2005]). Increases in lion range and associated numbers are most certain to the east, especially in the Great Plains (Riley and Malecki 2001, Tischendorff 2003, Kintigh 2005). Otherwise, the basis for judgments about state-wide lion population trends is generally uncertain evidence such as harvest and depredation trends and sex-age composition of harvested lions (Logan and Sweanor 2001, Cougar Management Guidelines Working Group 2005, DeVos and McKinney 2005). More certainly, decadinal U.S. censuses show that human numbers have increased dramatically in states occupied by mountain lions, two to five-fold since the 1950s in Arizona, New Mexico, and Utah. There has also been a similar, less dramatic, increase in numbers of people recreating on U.S. Forest Service lands (http://www.srs.fs.usda.gov/trends/Nsre). Torres et al. (1996) concluded that increased human safety incidents in California, principally depredation on pets, was attributable more to the spread of humans into lion habitat than to increases in lion populations. Whatever these broad-scale patterns, area-specific drivers of exposure, and of risk, are likely to be unique, requiring management based on case-specific details.

\section{Temporal Dimensions of Exposure}

Managers of risk are assisted by natural temporal partitioning of humans and mountain lions. Each species favors different diel periods for daily activity. Mountain lions tend to be active during night (see Chapters 2 and 3) and humans during day, especially when recreating or otherwise active in wildlands. A priori, the greatest likely period of overlap between lions and people is at dusk, which is also the period of greatest predation by lions on large prey in the Flagstaff Uplands (Figure 4.3). With this context, it is interesting to note that historical attacks on people by mountain lions peaked during daylight and dusk hours (Figure 4.3). The daylight peak no doubt reflected much greater activity by humans in lion habitat during this time of day, especially compared to dawn and night. The large number of attacks at dusk is plausibly interpreted as arising from overlap between continued human activities initiated during daytime and predatory activities initiated by lions with fading daylight. We don't have comprehensive information on diel activity of humans in mountain lion range, but the patterns documented here are consistent with per capita risk being greatest for humans at dusk.

Levels of human activity also potentially affect seasonal distributions of mountain lion attacks. Most attacks have occurred during spring and summer, and the fewest during fall and winter (Figure 4.4). Interestingly, the attacks that did occur during winter were more likely to be fatal compared to attacks during any other time of year. The summertime part of peak attacks matches spring through fall peaks in numbers of mountain lion sightings, or “encounters,” observed in 
Montana and in state and national parks of the
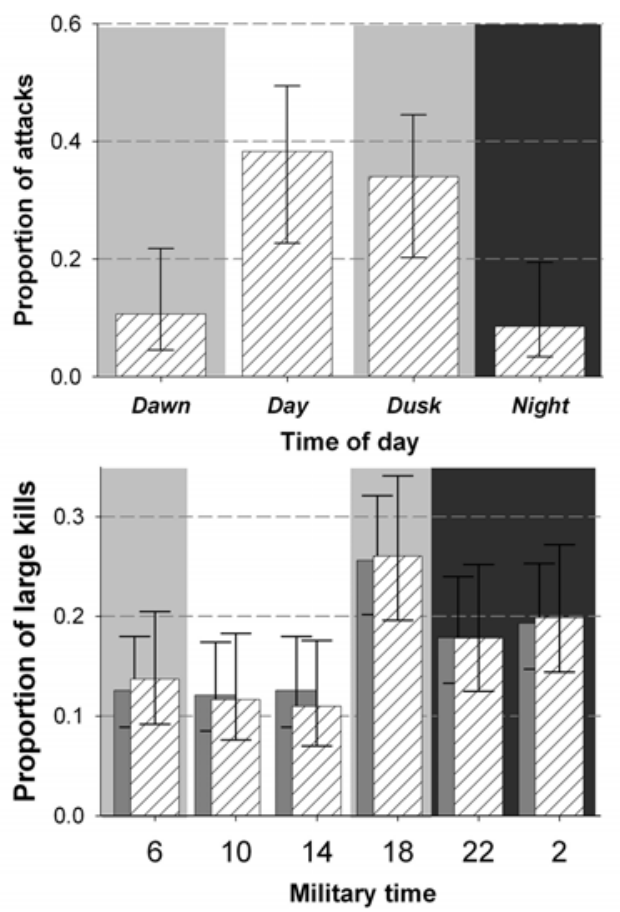

Figure 4.3. Proportional distribution (with 95\% Cls) of attacks by mountain lions on humans in Canada and the U.S. during 1890-2006, by time of day (top), and proportional distribution of kills of large prey by mountain lions in the Flagstaff Uplands during 2003-2006 by 4-hour intervals denoted by modal military time (bottom, see Chapter 3).

Redwood Basin of California (Riley and Aune 1997, Holm 2003), and is consistent with the notion that more people see and are attacked by lions during summer simply because more people are out in lion habitat (Beier 1991). However, this explanation does not adequately address the pronounced ebb in attacks during fall, when substantial numbers of humans are still likely out in mountain lion range, or the dearth of mountain lion observations during winter among year-round residents of a Colorado community near good lion habitat (Anderson 1993). Nor is the invocation of human activity to explain more frequent springsummer attacks entirely consistent with the peak in mountain lions sighting observed along the Colorado Rocky Mountain Front during winter, in presumed association with winter concentrations of mule deer (Odocoileus hemionus) near human residential areas (Halfpenny et al. 1993). As we learn more about mountain lion ecology and behaviors near people, I suspect that the

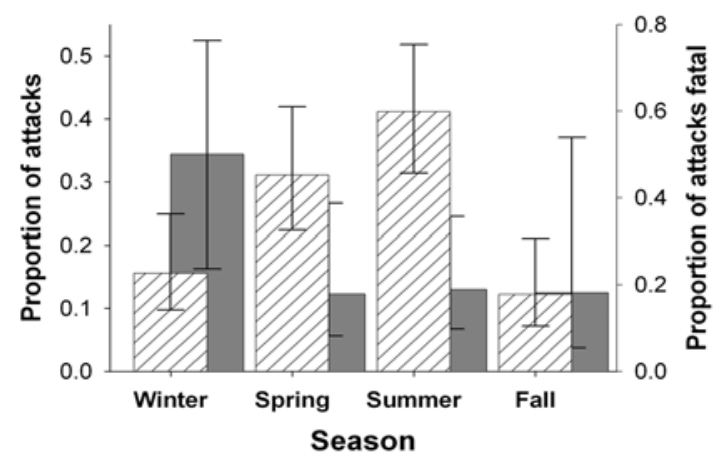

Figure 4.4. Proportional distribution of attacks by mountain lions on humans in Canada and the U.S. during 1890-2006, by season (with 95\% Cls). Open bars with cross-hatches are attacks and dark bars behind are proportion of attacks that are fatal, by season.

explanation for seasonal patterns of encounters with humans will become more complex.

\section{Spatial Dimensions of Exposure}

Little has been done to systematically investigate the spatial dimensions of human exposure to mountain lions and related incidences of lion attacks. Of the few investigations, Halfpenny et al. (1993) and Shuey (2005) not surprisingly observed that encounters between humans and lions along the east front of the Colorado Rockies were concentrated during winter along the urban-wildland fringe facing the mountain front, which constituted high-quality mule deer winter range. In general, the plausible expectation is for human exposure to be greatest in areas where mountain lion populations are near carrying capacity and, at a finer grain, where habitat features attract lions. As discussed in more detail in Chapter 2, mountain lions apparently use landscapes so as to optimize prey density and prevalence of features that provide ambush cover (Riley and Malecki 2001). Mountain lions have been consistently shown to select for shrubby or timbered habitat, rugged terrain, and areas with favored mule deer browse species (Chapter 2; Logan and Irwin 1985, Koehler and Hornocker 1991, Laing and Lindzey 1993, Williams et al. 1995, Riley and Malecki 2001, Husseman et al. 2003). Throughout the West, as in the Flagstaff Uplands of Arizona (Chapter 2), the Rocky 
Mountain Front of Colorado, and the Wasatch Front of Utah, humans have favored settling in valleys or flatlands immediately adjacent to mountain massifs or other terrains that constitute prime mountain lion habitats. Regardless of trends in lion populations, habitat preferences of humans alone have almost certainly increased human exposure to mountain lions.

\section{Probability of an Aggressive Response Given an Encounter}

We probably know the least about factors that turn a benign encounter into one of intent curiosity or non-contact aggression by the involved mountain lion. Other than the work of Sweanor et al. (2005), we have virtually no data on benign encounters, in contrast to those deemed problematic by the involved human, including no information on conditioning factors that might be at play. Nor has any systematic research been conducted under non-field controlled conditions covering lion responses to humans. Insight is further muddied by the fact that judgments regarding curiosity or aggression of the involved lions are colored by the fear, knowledge and other vagaries of involved people. We are largely left with often limited anecdote and generalized notions about feline behavior.

Fitzhugh (1988), citing Leyhausen (1979), speculated that mountain lions treat other animals as either conspecifics or prey, and that, when engaged with an unknown type, will gather information to make a provisional determination one way or the other. Fitzhugh (1988) did not make an obvious allowance for lions treating humans uniquely. If so, by deduction, lions not being pursued by a human will react to an encounter one of five modal ways: (1) depart without any obvious engagement because a human is readily judged to be a "conspecific" or because of paramount distractions, in which case the involved human may or may not be aware of the lion, but, if aware, likely not feel threatened; (2) follow or otherwise observe the human, but while purposefully remaining hidden, in which case the human will not likely know the lion is present, but if aware, likely feel threatened; (3) remain in place or approach the involved human fully visible while exhibiting intense curiosity (e.g., staring; Fitzhugh 1988, Fitzhugh and Feljine 1997), in which case the involved human will very likely feel threatened, (4) remain in place or approach the involved human exhibiting defensive aggressive behavior (e.g., hissing, growling, or charging; Sweanor et al. 2005), in which case the involved human will almost certainly feel threatened, or (5) approach in a predatory manner (e.g., crouched, with tail sweeping), either hidden or in view, in which case virtually anyone involved would feel endangered if aware of the lion's approach. Fitzhugh (1988) and Fitzhugh and Feljine (1997), again referencing Leyhausen (1979) and individuals who train mountain lions, judged modalities 1 and 2 to be a minimal threat to human safety, modalities 3 and 4 to be a "substantial" threat, and modality 5 to be a "serious" to "extreme" threat. Sweanor et al. (2005) found that defensive aggression against humans (modality 4) was almost exclusively exhibited at ranges of $<50$ $\mathrm{m}$ and by female lions in apparent defense of kittens. That said, much can be speculated and little is reliably known regarding factors that govern transitions between each of these modalities, other than what we can back-cast from factors associated with actual attacks (see following sections).

Again, referencing Leyhausen (1979) and mountain lion trainers, Fitzhugh (1998) and Fitzhugh and Feljine (1997) speculated that the transition from uncertainty regarding a novel animal to responding as if it were prey could be virtually instantaneous if the otherwise unknown creature were about the size of normal prey and moving rapidly away. As we speculate in Chapter 3 , optimal prey for most mountain lions, at least in the Flagstaff Uplands, is likely in the range of 100300 lbs., the size of most adult humans. If Fitzhugh and Feljine are correct, then, a priori, a jogging, running, or skiing human, not immediately typed as “non-prey” by a nearby lion, may have little chance to respond to an uncertain or otherwise curious lion but, rather, would be dealing with an overt predator at the virtual onset of an encounter (see following sections).

We know very little about just how intrinsically curious mountain lions are, or how fixed their prey images might be. If mountain lions were prone to curiosity about anything a bit out of the ordinary, and employed highly malleable prey images that readily encompassed anything novel, then one might expect modalities (1) and (2) to be relatively uncommon or fleeting, and modalities (3) and (4) to be commonplace, followed by an attack. However, the scarcity of well-documented attacks by lions on humans (only 
about 90 since 1890 in Canada and the U.S.), despite what must be considerable opportunity, argues strongly against an exceptionally high degree of curiosity or highly flexible prey images. Another possibly complementary explanation might be that mountain lions do, indeed, differentiate humans from other creatures and transmit this distinction among generations, presumably matrilineally.

To my knowledge, there are only three published estimates of rates at which sightings of lions or other encounters known to the involved human transitioned into something more aggressive or threatening, including $11 \%$ from the Redwoods Basin of California (Holm 2003) and $3 \%$ from a residential area along the Front Range of Colorado (Anderson 1993). The most reliable estimate is 6\% reported by Sweanor et al. (2005) based on approaches to radio-marked lions initiated by researchers in a wilderness study area. These rates are almost certainly high when considering all types of human-lion encounters, including encounters in urban-wildland contact zones where the lion was aware of the human, but the human unaware of the lion. If we ever develop means of documenting all types of encounters, I suspect that we will find there are numerous cases where the lion chose to immediately depart, was merely curious, or otherwise behaviorally neutral, consistent with the results of Sweanor et al. (2005).

\section{Probability of an Attack Given an Aggressive Response}

Much of what can be said here is germane to modalities of encounters discussed in the preceding section. Factors affecting the transition from noncontact aggression to an attack probably similarly affect whether a mountain lion transitions from being curious to aggressive (i.e., predatory). And, although data on transitions from aggressive approaches to attacks are comparatively scant, they are more numerous than data on transitions from awareness or curiosity to aggression, if for no other reason than the involved people are more likely to report or otherwise document the former types of incidents compared to the latter. In general, the basic notion is that if you encounter a mountain lion, you do not want to superficially look and act like prey, or if engaged with a lion that is deliberating the situation, you want to dominate the lion or otherwise convince it that you pose a
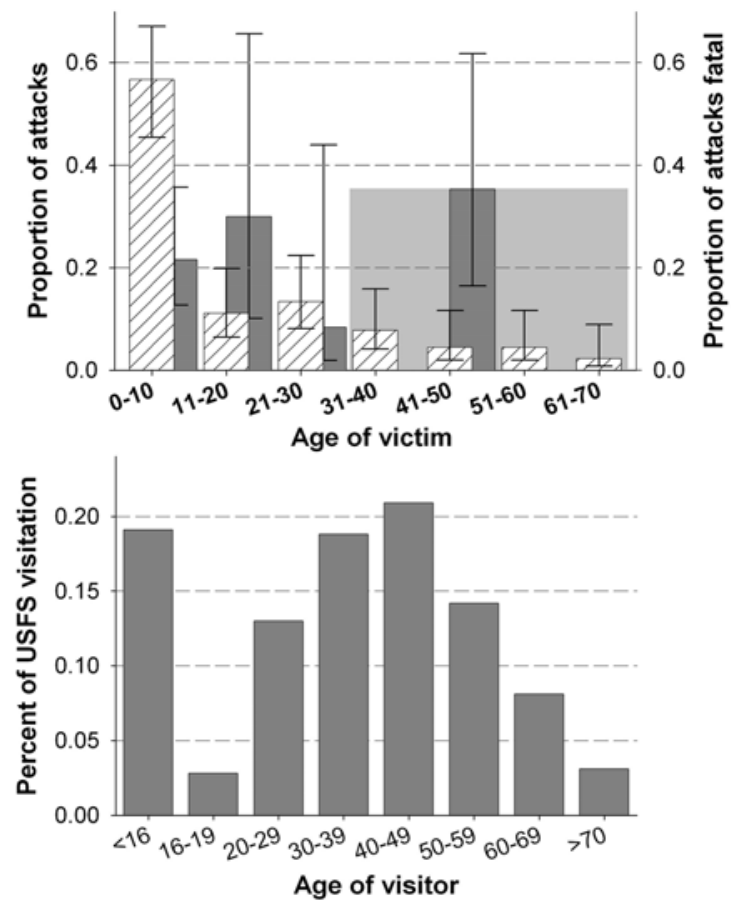

Figure 4.5. Proportional distribution of human victims of mountain lion attacks, by age (with 95\% $\mathrm{Cl}$, top, cross-hatched bars), and proportion of those attacks that were fatal (top, dark bars behind), for Canada and the U.S., 1890-2006. Proportional distribution of visitors to USFS jurisdictions in the U.S., by age (bottom).

potential risk (Fitzhugh and Feljine 1997, Sweanor et al. 2005).

There is good evidence to suggest that physical attributes and behaviors of humans involved in threatening encounters with mountain lions strongly influence whether the encounter turns into an attack. A large percent (nearly 60\%) of human victims during 1890-2006 were $\leq 10$-yrsold (Figure 4.5). Whether this can be interpreted as evidence of high risk for young children depends on the relative commonness of differentaged people active in mountain lion range. Although these specific data do not exist, the U.S. Forest Service (USFS) does provide statistics on ages of visitors to USFS jurisdictions (http://www.srs.fs.usda.gov/trends/Nsre), which, in a broad sense, can be applied to the question. These USFS statistics show a peak in visitors $<16$ yrs old (Figure 4.5), but this peak is proportionately much smaller relative to numbers of visitors between 20 and 70 yrs old, compared to numbers of victims of mountain lion attacks who were $\leq 10$-yrs-old relative to numbers of older victims (Figure 4.5). This result in consistent with conclusions reached earlier by Beier (1991), Etling 
(2001), and Fitzhugh et al. (2003) - that children are, indeed, at much greater risk of being attacked with any given level of exposure to mountain lions. As might be expected by predator body sizes, this proclivity of mountain lions to attack children versus adults is similar to that of leopards and intermediate between higher proportional rates for coyotes and lower proportional rates for tigers and Asiatic and African lions (Løe 2002).

The presence of children plausibly interacts with group size to determine whether a menacing mountain lion attacks or not. Proportionately, the largest number of mountain lion attacks has been on lone juvenile and adult humans ( $\geq 10$ yrs old; Figure 4.6). However, for groups of two or more people, very few attacks occurred when these groups were exclusively comprised of adults, and when groups were attacked, virtually all victims were children. For lack of information on the relative frequency of groups of different size and age composition in mountain lion range, it is not possible to reach definitive conclusions regarding the risk incurred by each group type. Even so, lone adults are probably much more common than lone

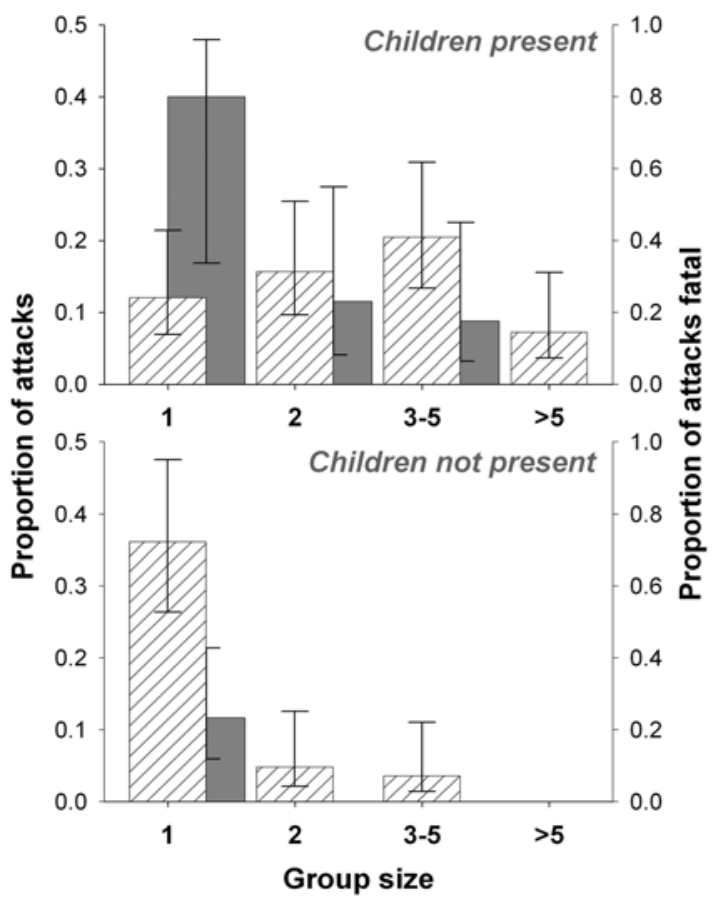

Figure 4.6. Proportional distribution of attacks (open cross-hatched bars in front) and fatalities as a fraction of attacks (dark bars behind), with 95\% Cls, by group size, for groups including children (top) and for groups not including children (bottom), for Canada and the U.S., 1890-2006. children in mountain lion range, often involved in some activity such as jogging (see below). Similarly, groups with children are probably not that much more numerous compared to groups comprised exclusively of adults, certainly not enough to explain the disparity in numbers of attacks on children in groups. As previously noted by Kadesky et al. (1998) and Fitzhugh et al. (2003), groups probably do not afford much protection for children from a mountain lion attack, especially when the group is comprised wholly or mostly of children. The only advantages are apparently in preventing fatalities (see next section).

The available data suggest that human behaviors at the onset of encounters had substantial effects on the likelihood that encounters known to the involved humans turned into an attack. People who were either running (including jogging),

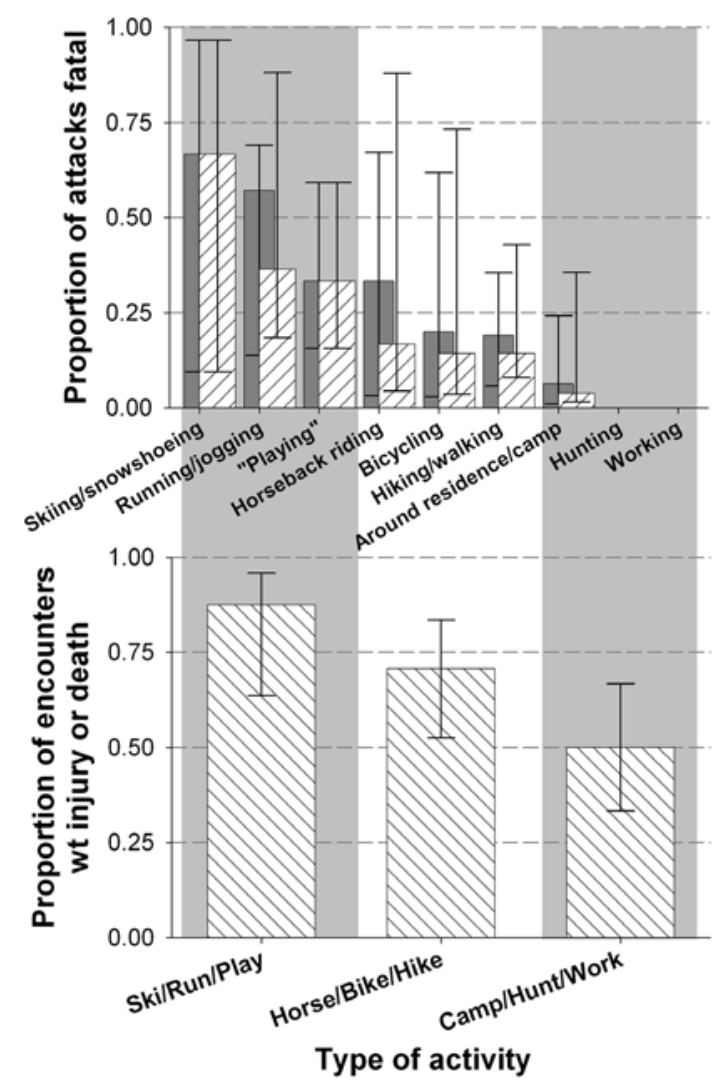

Figure 4.7. Proportions (with $95 \%$ Cls) of mountain lion attacks on humans that were fatal (top) and proportions of known \& reported encounters with mountain lions that turned into an attack (bottom), as a function of human activities, for Canada and the U.S., 1890-2006. Open bars with cross-hatches (top) are proportions of encounters, including nonattacks, that turned fatal whereas the dark bars behind are proportions of attacks, only, that were fatal. 
"playing," or skiing or snowshoeing were much more likely to be attacked during an encounter compared to people who encountered a lion while around camp or their home, or while working or hunting (Figure 4.7). People on horseback, bicycling, or hiking apparently experienced intermediate risk of attack. These patterns are, for the most part, consistent with predictions by Fitzhugh (1988) and Fitzhugh and Feljine (1997) (see previous section) that, compared to sedentary humans, individuals moving rapidly away from or laterally to mountain lions would more likely trigger a predatory response.

Given a threatening encounter, there is evidence from general observations of felines and from mountain lion attacks that human responses can influence outcomes. Fitzhugh (1988), Beier (1991), Fitzhugh and Feljine (1997), Etling (2001), Fitzhugh et al. (2003), and Sweanor et al. (2005) all recommend that humans involved in encounters not run away, which would presumably stimulate a predatory response, and, instead, respond in an assertive, even aggressive manner. In particular, they recommend that the involved people stand their ground and attempt to look large, especially by holding something over their head. These recommendations are partly based on documented outcomes of encounters (e.g., Sweanor et al. 2005), and partly on observations by Leyhausen (1979) and others regarding cats, which appear fearful when approached by large objects from above. There are mixed recommendations regarding eye contact, an aggressive approach, and throwing things. Conrad (1992) recommends not attempting to make eye contact, but then maintaining eye contact once made. Etling (2001), by contrast, recommends initiating eye contact as a means of asserting dominance. Throwing things at the lion is generally recommended, but only if objects can be obtained without bending down; that is, without appearing prey-like (Beier 1991, Fitzhugh et al. 2003).

The efficacy of sustained noise is perhaps best supported by the available data. Fitzhugh et al. (2003) found that loud sustained noise (typically yelling), of all noises, most often precipitated the departure of a potentially threatening lion (61\% of the time; Figure 4.8$)$. The field observations reported by Sweanor et al. (2005) support the efficacy of noise. By contrast, the single sharp report of a warning gunshot had little apparent effect (only 17\% of animals departed). These results are consistent with the

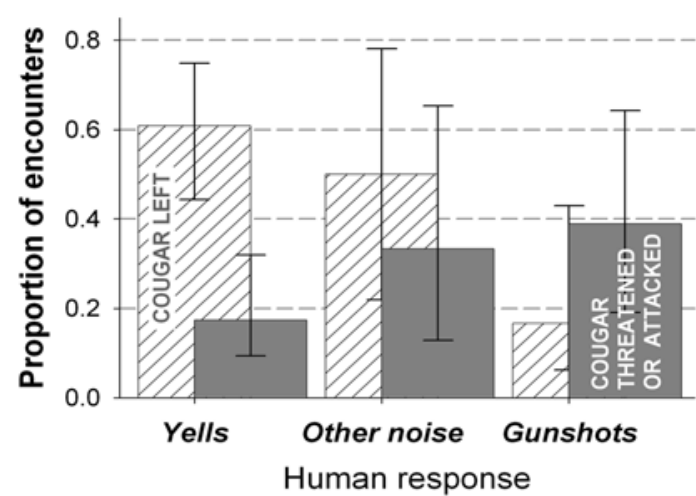

Figure 4.8. Reactions of mountain lions to different kinds of noise created by humans during close or otherwise threatening encounters (proportions with $95 \% \mathrm{Cl}$ ), differentiating departure of the mountain lion (open hatched bars behind) versus continued threatening approach or attack (dark bars in front). Results are regraphed from Fitzhugh et al. (2003), $n$ $=76$.

finding by Sanders and Halfpenny (1993) that lions were averted from attacking in $43 \%$ of cases by the involved people yelling and throwing objects. Given these results, devices such as air-horns may be amongst the best non-lethal deterrents for people to carry in mountain lion range, useful in situations where there is time to affect the behavior of a curious or otherwise deliberating lion (Etling 2001).

Not all lions are apparently equally likely to confront a human or, having done so, attack. Data from Beier (1991), Etling (2001), and fttp: IIwww.cougarinfo.com, suggest that, although there is no great disparity in sex of lions involved in encounters with humans (see also Aune 1993), females are more likely to attack if involved (Figure 4.9). Otherwise, of animals that were aged, young mountain lions (generally $\leq 2$-yrs old) were responsible for $73 \%$ of attacks, and, where body condition was reported, the majority (65\%) of involved animals were considered to be "poor," which is probably in excess of the norm for a mountain lion population. In short, young animals in poor condition were probably the most likely to attack, although not necessarily kill, a human. This is consistent with conclusions by Beier (1991) and Løe (2002), but somewhat at variance with observations by Aune (1993), Riley and Aune (1997), and Mansfield and Charlton (1998). These last three authors reported that depredating lions tended to be in fair to excellent condition, although the animals that they considered were involved in 

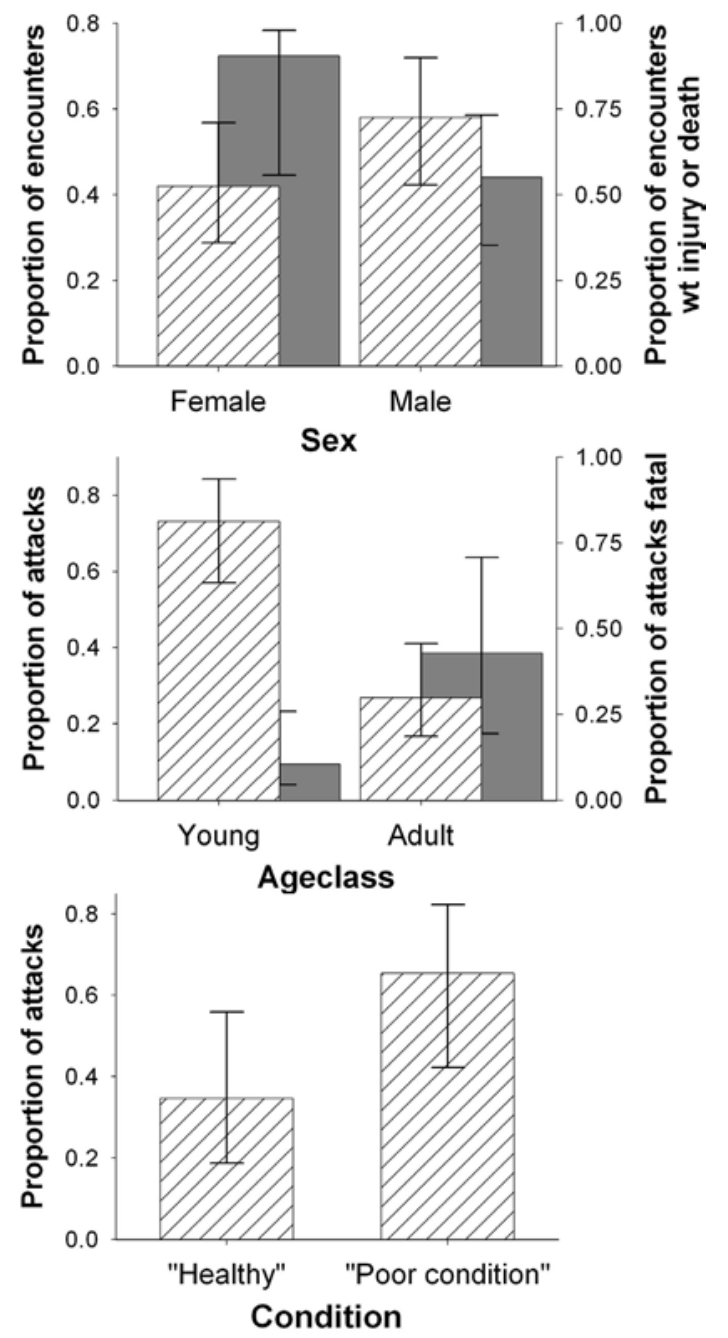

involved in most attacks, it is not surprising that they would be selecting for children rather than adults. The second complementary explanation invokes the possibility that stature rather than mass is a primary trigger of lion attacks. Humans are unique in their bipedal stance amongst potential prey in mountain lion range, and human children ages 8-10 average $130-140 \mathrm{~cm}$ (51-55inches) tall, which is in the range of heights for adult mule deer and elk calves - preferred prey of mountain lions, at least in the Flagstaff Uplands of Arizona.

Several researchers and managers have expressed the opinion that habituation of lions to humans increases odds of attack (Fitzhugh 1988, Halfpenny et al. 1993, Løe 2002). Habituation has been confirmed as a major risk factor in managing for human safety around bears (Herrero 1985). Habitation is the conditioning of an animal to the presence of humans, almost always entailing loss of fear. This notion is relevant to judging risks in situations where a lion has been repeatedly sighted not exhibiting obvious fear of nearby humans. Under such circumstances, judgment of risks intersects with speculations by Fitzhugh (1988) and Fitzhugh and Feljine (1997), that lions treat humans as either prey or virtual conspecifics. Framed this way, loss of fear could signal that a lion is, indeed, viewing humans as non-threatening conspecifics rather than as prey. However, the implicit concern is that increased exposure of a lion to people increases the odds that, at some point, the lion switches its' typing of humans. We currently know little that is reliable about risks entailed by habituation, and future research may

Figure 4.9. Proportional characteristics (with $95 \%$ Cls) of mountain lions involved in encounters, attacks, or human fatalities by sex (top), age-class (middle), and physical condition (bottom), for Canada and the U.S., 1890-2006. Open bars with cross-hatches at top are for lions involved in encounters, with and without attacks, and dark bars behind are for proportions of encounters that resulted in injury or death. Open bars with crosshatches at middle are for lions involved in attacks and dark bars behind are for proportion of those attacks that were fatal.

livestock depredation as well as public safety incidents.

The apparent selection of children, rather than adults, for attack by mountain lions is at variance with our speculations in Chapter 3 that lions select for prey in the range of $50-130 \mathrm{~kg}$ (110-290 lbs), the mass of most human adults. This discrepancy can be explained in two ways. First, small mountain lions tend to kill smaller prey (see Chapter 3), and given that young lions are uncover nuances in how habituation affects responses of lions to humans. That said, a precautionary approach would meanwhile treat obviously habituated mountain lions as a threat.

\section{Probability of Death Given an Attack}

Even though only 19 people are known to have been killed by mountain lions between 1890 and 2006, of all transitions, we have perhaps the best understanding of factors associated with human death. Virtually all serious attacks and related human fatalities have been documented, recently in great detail. In most cases the perpetrating lion has also been killed and characterized. Under such circumstances, with a near census of events, the role of statistical 
inference is minor, except as it relates to the "population" of attacks yet to happen in the future.

The proportion of mountain lion attacks on humans that were fatal exhibited an interesting pattern as a function of victim age, realizing that all conclusions here are compromised by a (fortunately) very small sample size. Fatalities were proportionally highest for victims 31-70 yrs old (35\%), and progressively lower for victims 1120 yrs old (30\%), 1-10 yrs old (22\%), and, finally, 21-30 yrs old (8\%; Figure 4.5). Victims 21-30 yrs old, at the usual physical prime for humans, were able to fight off most attacks, typically with greater success than juvenile humans 11-20 yrs old (Etling 2001). The comparatively low death rate of young children in contrast to juveniles was attributable to interventions by adults (Kadesky et al. 1998, Etling 2001). Most attacks on children occurred while they were in groups that included adults, who often drove off the attacking lion. However, when alone, the death rate for children, given an attack, was an alarming $80 \%$ (Figure 4.6). These results highlight the importance of fighting back when attacked by a mountain lion, and the related importance of physical prowess under such circumstances (Beier 1991, Conrad 1992, Etling 2001). These results similarly emphasize that, whereas group size and the presence of adults may not prevent a lion from attacking a child, subsequent speedy intervention by the attendant adults can prevent death.

The presence of a dog seems to reduce the odds of death when a human is attacked. During 1890-2006, only 7\% (95\% CIs $=2.1-33.9)$ of people who were attacked when accompanied by a dog died compared to 28\% (19.9-38.0) of people who were unaccompanied. This is consistent with case-specific reports of dogs harassing an attacking lion sufficient to drive the lion away or to allow for arrival of human rescuers (Etling 2001). Aside from this apparent benefit of dogs, much has been speculated about the role of dogs in precipitating aggression by lions that would have not otherwise happened. There is no doubt that mountain lions will kill free-ranging dogs, as well as dogs in their owner's yard (Aune 1993, Davies 1993, Torres et al. 1996). Killings of domesticated canids are consistent with our finding in the Flagstaff Uplands that mountain lions can kill substantial numbers of coyotes (Canis latrans), most likely for food (Chapter 3). However, looking at the data, there was virtually no difference in percentages of encounters where a mountain lion attacked a human with (70\%) or without (72\%) a dog present, suggesting that dogs were not a precipitating factor, while potentially providing a benefit for those people who were attacked.

This still begs the question of whether an attack by a lion on a dog automatically poses a threat to a nearby human. Typical of scenarios reported to me, a dog running free on a trail is chased back to its accompanying owner by a lion hot on its tail. Not unnaturally, owners feel concern for the welfare of their pets and a certain amount of threat to themselves. People have intervened to protect a pet and been injured in the process (Etling 2001); but none have died. I speculate that, in most cases, an attack by a lion on a dog is simply that, and not an attack on an accompanying human. The apparent ability of a lion to focus on single prey in the midst of other animals is consistent with attacks on children in groups of adults and fawns or calves in herds of deer or elk.

Not surprisingly, human activity at the time of an attack seems to strongly influence whether the outcome is deadly. During 1890-2006, not only were people involved in "playing," running, or active snow sports more likely to be attacked without warning, the outcome was more often fatal (Figure 4.7). By contrast, people moving more slowly and often deliberately, such as when hunting, working, or around camp or a residence, were rarely killed when attacked. For hunters, this was often because they shot and killed the attacking lion (Fitzhugh et al. 2003). Otherwise, these results are consistent with the expectation that prey-like movements by humans will trigger more aggressive and perhaps instantaneously predatory responses from an observing mountain lion (Fitzhugh 1988, Fitzhugh and Feljine 1997).

Given an attack, some mountain lions are more deadly to the victim. In particular, $43 \%$ of attacks by adult lions resulted in the human victim's death, compared to $11 \%$ of attacks by young lions (Figure 4.9). This range of lethalities is comparable to that of leopards, but much lower than the $50-90 \%$ range observed for attacks on humans by African lions (Treves and NaughtonTreves 1999). Not surprisingly, larger and more experienced felids seem to be more effective at killing humans once they've judged them to be prey. In contrast to young mountain lions, adults rarely attack humans, but the attacks that do occur are often on lone humans that are jogging or skiing - moving in ways that resemble movements of 
native prey (Etling 2001). These sorts of presumably spontaneous attacks by adult lions are intrinsically hard to anticipate or manage, except at the level of people's overall exposure to high quality lion habitat. On the other hand, these results suggest that, where time is available for a considered management response, adult lions that exhibit threatening behaviors should be taken very seriously.

\section{Conclusions}

I focus here on conclusions relevant to managing for human safety on recreational trails or around human facilities in backcountry areas typical of USFS and U.S. National Park Service jurisdictions on the Colorado Plateau, and along the urban-wildland interface typical of cities such as Payson, Sedona, and Flagstaff, Arizona. Most conclusions regarding risks of mountain lions attacking humans are necessarily tentative, simply because we have so few data. Not only have attacks been rare, record-keeping has also been sparse, especially regarding incidents or encounters not resulting in human injury or death. Even so, some conclusions are well-supported by not only the available data, but also by what we otherwise know of mountain lion, feline, and human behaviors. For example, I can say with a fair degree of confidence that a small adult or child running or jogging alone at dusk in wooded rugged terrain, in an area used by a young mountain lion in poor condition, will maximize what are otherwise the slim odds of being attacked by a lion.

As others have done before me, I present here a laundry list of tactics and strategies that managers could use to increase human safety in mountain lion range. I emphasize non-lethal approaches primarily because lethal ones, involving removal of lions, are common-place and comparatively rote. I also do not stray far from the empirical and conceptual basis I present in this chapter. I have noticed that a number of educational materials seem to reiterate the exact same safety recommendations, several of which have only a very tenuous basis, apparently validated primarily through frequent repetition. That said, some recommendations with a weak basis in fact can be legitimized by the precautionary principle, applied to provision human safety.

I do not cover here diagnostics regarding level of risk implicit to different mountain lion behaviors during an encounter with a human. The basis for these diagnostics is almost wholly anecdote or generalized conclusions from observing other felines. This is not to say that making judgments regarding the implications of lion behaviors is unimportant to management. In some ways it is critically important. Rather, I have little basis in published or other inter-subjective information for assessing the merits of existing assertions. Sources such as Fitzhugh and Feljine (1997) and Cougar Management Guidelines Working Group (2005) do a good job of outlining current understandings of risks associated with different mountain lion behaviors.

I structure my following recommendations according to whether the focus is on planning spatial aspects of visitor facilities or residential developments, managing exposure of humans who are at high risk of lion attacks, or educating people to successfully manage threatening encounters with lions:

\section{Planning for Safe Development}

Urban and federal lands planners have the opportunity to build human facilities, especially those providing over-night or permanent residence, in areas where likelihoods of mountain lion activity are low and quality lion habitat far removed. Such an accommodation is to some degree natural given that mountain lions select for rugged terrain, which is not well-suited for building most human facilities. Given that highquality habitat for mountain lion prey often also constitutes high-quality habitat for mountain lions, avoidance of areas where predicted levels of lion activity are high typically has the added benefit of preserving quality habitat for species such as mule deer and elk (Cervis elaphus). Of course, planning for such an outcome is in large measure contingent on having a reliable map of predicted mountain lion activity, such as we present in Chapter 2 for the Flagstaff Uplands.

Unfortunately, managers and planners are confronted with a legacy of choices that has placed human facilities and resident or visiting humans in potential harms way. Such is the case for most Colorado Plateau towns and cities, where a number of residential areas are located immediately adjacent to prime mule deer or elk winter range associated with rugged terrain. Moreover, there is a speculated dynamic where profuse planting of shrubs and liberal watering of private and public 
lawns creates habitat that is attractive to mountain lion prey, and hence mountain lions, within peripheral urban or visitor areas (Halfpenny et al. 1993, Baron 2004).

Under such circumstances, the common recommendation is to reduce plantings of palatable shrubs, reduce the extent and watering of grassy areas, and directly manage deer and elk to reduce their numbers in and near people (Baron 2004, Cougar Management Guidelines Working Group 2005). The basic idea is to manage attractants of mountain lion prey, which, in turn, attract mountain lions. This all seems to make selfevident sense. Interestingly, though, a strong empirical basis for these phenomena and for the purported efficacy of ameliorative management does not exist. Managers must invoke first principles to justify following such recommendations for managing residential areas, which is often a reasonable basis for management in the face of uncertainty coupled with cause to act.

\section{Proximal Management of High-Risk Exposure}

There is little doubt that children and people of all sizes when alone and moving like native prey are at greatest risk of being peremptorily attacked by mountain lions. It is also quite likely that dusk constitutes a high-risk time of day. Given these tenets, there are several tactics that wildland and wildlife managers could use to potentially substantially reduce risk in areas known to be frequented by mountain lions.

a) Trails (and other facilities) could be closed during seasons of peak lion activity;

b) trails could be closed before dusk and reopened at dawn;

c) children could be prohibited from using the area, even in the company of adults (i.e., adult use areas only);

d) adults could be required to keep children in their immediate vicinity;

e) non-motorized users could be required to travel in groups of at least two; and

f) jogging and trail running could be prohibited.

Managers could, to the extent deemed desirable, mix and match any of these recommendations, for example, prohibiting trail running and jogging at dusk during times of year when mountain lion activity was most common. Alternatively, a non- prohibitive approach could be taken, emphasizing information and education about risks and options that would provide users of high-risk areas a more informed basis for their choices.

Contrary to recommendations made elsewhere, I found little justification for being particularly concerned about dogs near people in the backcountry of lion range, or risks of having dogs off leash. There are, perhaps, many good reasons relevant to other values for prohibiting dogs or requiring that they be restrained, but safety from lions does not provide a compelling justification at this point in time. People with dogs were not more likely to be attacked than people without, and dogs possibly helped prevent some attacks from being fatal. I also found little to convince me that attacks on dogs by lions were necessarily an immediate threat to nearby humans, except to the extent that the humans tried to intervene. An attack on a dog could signal a progression of mountain lion behavior that might ultimately put a human at risk, but this is a different consideration from whether dogs, as such, increase risks for nearby humans.

Regarding tactical management of lions themselves, there seem to be limited options, or the justifications for intervention are highly uncertain. The clearest case for intervention and possible removal is when young lions in poor condition are observed being aggressive or intently curious about humans. Likewise, an adult mountain lion known to have closely followed or stalked a human, or exhibit a predatory stance near people, should not be treated lightly given the high death rate attributable to attacks by larger older lions. The risk posed by an adult mountain lion is classically difficult to judge and manage, in that the odds are likely quite low, although largely unknown, whereas the outcome is potentially severe. Moreover, cogent management response is complicated in most real-life situations because reliable determinations of lion age and condition are not possible from information provided by most people involved in encounters (Beier 1991).

Perhaps the most difficult type of attack to prevent is one triggered by a human acting like prey under circumstances that trigger an instantaneous, perhaps instinctive, predatory response by a lion. As noted before, these types of attacks are likely to occur at a very low rate wherever numerous humans are active for sustained periods near mountain lions. The only practical tactics for lowering odds of this kind of 
attack are those designed to minimize exposure. This entails managing to minimize temporal and spatial overlap, including the means outlined at the beginning of this section.

Non-lethal options for managing known potentially problematic lions are largely of unknown efficacy. Limited results from capturing and relocating lions suggest that many die afterwards, and a few simply return (Ross and Jalkotzy 1995, Ruth et al. 1998). Even so, relocation does allow for the possibility of at least a few animals surviving elsewhere (ideally $>480$ $\mathrm{km}$ away to prevent return; Ruth et al. 1998), as opposed to the unequivocally certain verdicts of lethal control or disposal in a zoo. Otherwise, to my knowledge, aversive conditioning has not been systematically attempted with mountain lions.

Such a tactic may work under certain circumstances, but the current state of knowledge makes employing this method in management risky for any humans subsequently exposed to a “treated” animal (Beier 1991, Cougar Management Guidelines Working Group 2005). Hazing, that is, simply trying to scare a lion away without necessarily changing fundamental behavioral traits, is another tactic that has only anecdotal justification and unclear results (Cougar Management Guidelines Working Group 2005).

\section{Management of Threatening Encounters}

It is at this level of managing encounters that risk of falling prey to oft-repeated truisms is perhaps greatest, if for no other reason than there are so many in circulation. One can go to the literature and track lineages of recommendations that, at root, have justification in only one reference or in anecdote, generalizations, and deduction. This does not axiomatically make such recommendations unhelpful or inefficacious. Rather, these circumstances merely recommend that managers be judicious and clear about uncertainties that entail risk of being wrong. Under such circumstances it is also often appropriate to adopt a precautionary approach acting so that, if proven wrong, additional risk is not placed on people in a crisis situation with a mountain lion.

Of all responses to a potentially threatening mountain lion, the efficacy of standing ground and making loud sustained noise is best supported by currently available information. Although not tested, this result suggests that an air horn might be the best non-lethal device for backcountry users to carry for deterring mountain lions. By contrast, anecdotal results from use of pepper spray on lions are mixed and not very reassuring, despite the popularity of this deterrent for use on bears. Otherwise, recommendations regarding the desirability of making eye contact, of looming large by spreading a coat or holding an object over one's head, or even of throwing objects at a threatening lion, are all highly plausible, but more in the nature of oft-repeated truisms rather than well-substantiated tactics.

Insofar as children are concerned, certainly they should not be allowed to wander away, even a few yards, from a group of any sort while in mountain lion habitat, realizing that in a few attacks the lion literally grabbed a child away from the hand of an adult (Etling 2001). It has often been recommended that, when confronting a lion, children be put behind an adult, or even lifted off the ground (Etling 2001, Cougar Management Guideline Working Group 2005). Again, the efficacy here is more surmised than verified, but such an action would more likely be precautionary than not.

\section{Analysis and Research Opportunities}

Additional research is needed for managing human safety in mountain lion range to the extent that managers are willing, or not, to make decisions based on the current state of knowledge. Much of this knowledge is derived from anecdote, informed speculation, and scant analyses of scant data. This is not said with the intent of belittling historical efforts to understand lions and the threats they pose to humans. Rather, the current weak state of knowledge is very likely the result of overall very few mountain lion attacks and related human fatalities, a comparatively only recent burgeoning of attacks, an historical proclivity to deal with perceived risks simply by killing or otherwise removing implicated lions (Papouchis 2004, Clark and Munno 2005), and related underattention to comprehensive record-keeping and analyses of encounters between humans and lions. Researchers have been left to do what they can with minimal time, resources, and data.

As suggested many places in this chapter, there are a number of measures that could be taken and topics that could be investigated to substantially increase the richness and reliability of 
our collective basis for managing human safety in mountain lion range. Opportunities potentially reside in analysis of existing data, better record keeping, field studies, and controlled experimental investigations:

Analysis of Existing Data: There are potentially ample opportunities to analyze existing data on human-mountain lion conflicts and mountain lion movements and habitat selection to improve the current basis of management. Shuey (2005) made a laudable first cut at explaining the spatial distribution of human-mountain lion conflict along the Front Range of Colorado. However, much more could be done with this data set and with others in other states to more comprehensively diagnose landscape features that drive conflict. Even more insight could be gained by coupling information on distributions of humans, models that predict distributions of lions, and spatial data on human-mountain lion encounters to specify and explain spatial elements of exposure and other facets of risk. More generally, much insight could be gained by pooling the considerable data collected any more by each state on mountain lion encounters or "incidents" and subjecting these data to rigorous analysis. Even a state-by-state effort of this sort would no doubt yield considerable insight.

Record Keeping: Historically, little attention has been given to keeping standardized records on encounters of all sorts between humans and mountain lions, detailed enough to control for biases that potentially plague any data based on self-reporting by the general public (cf., Green 1991). Such record keeping is a non-trivial task, but virtually essential to gaining reliable insight into factors that drive the probability of an otherwise benign encounter turning into one of aggression, or of an encounter typified by noncontact aggression turning into an attack. Ideally, such record-keeping would be done in a way that is standardized among management jurisdictions, and constructed in such a way so as to anticipate relevant questions and control as much as possible for bias.

Field Studies: Given the current availability of GPS and satellite technologies, it is possible now more than ever to design field studies organized around deliberate approaches to or other placements of people nearby radio-marked mountain lions. Both near- and long-term responses of lions could be readily monitored. Even with current technologies, such studies are costly and logistically difficult. However, they are doable and potentially compatible with studies undertaken to address more general ecological questions.

Controlled Experimental Studies: This is perhaps where the greatest opportunities can be found for gaining rapid insight into issues of import to managing for human safety. As has been done with bears, the efficacy of deterrents such as pepper spray and air-horns could be efficiently tested. A surer assessment of the risks implicit to different mountain lion behaviors, postures, or expressions could be produced comparatively rapidly. Responses of lions to different human behaviors, both at the initiation of an encounter and with an encounter's progression, could also be efficiently determined. Coupled with results of field studies, as described above, results of experimental studies such as these could provide a reliable and robust basis for education outreach and for judgment of risk and appropriate reaction to management situations. 


\section{References Cited}

Ackerman, B.B., Lindzey, F.G., and Hemker, T.P. 1984. Cougar food habits in southern Utah. Journal of Wildlife Management 48: 147-155.

Ackerman, B.B., Lindzey, F.G., and Hemker, T.P. 1986. Predictive energetics model for cougar. Pages 333352 in S.D. Miller and D.D. Everett, editors. Cats of the world: Biology, conservation and management. National Wildlife Federation, Washington, D.C.

Akenson, J.J., Nowak, M.C., Henjum, M.G., and Witmer, G.W. 2003. Characteristics of mountain lion bed, cache and kill sites in northeastern Oregon. Pages 111-118 in S.A. Becker, D.D. Bjornlie, F.G. Lindzey, and D.S. Moody, editors. Proceedings of the seventh mountain lion workshop. Wyoming Game and Fish Department, Lander, Wyoming.

Alexander, S.M., and Waters, N.M. 2000. The effect of highway transportation corridors on wildlife: A case study of Banff National Park. Transportation Research Part C 8: 307-320.

Anderson, A.E. 1981. Morphological and physiological characteristics. Pages 27-97 in O.C. Wallmo, editor. Mule and black-tailed deer of North America. University of Nebraska Press, Lincoln.

Anderson, A.E. 1983. A critical review of literature on puma (Felis concolor). Colorado Division of Wildlife Special Report 54, Ft. Collins, Colorado.

Anderson, A.E. 1993. Frequency of mountain lion sightings by residents and employees of a housing development. Page 19 in C.S. Braun, editor. Mountain lion-human interaction symposium and workshop. Colorado Division of Wildlife, Denver, Colorado.

Anderson, C.R., Jr., and Lindzey, F.G. 2003. Estimating cougar predation rates from GPS location clusters, Journal of Wildlife Management 67: 307-316.

Arizona Game and Fish Department. 2001. Wildlife 2006: The Arizona Game and Fish Department wildlife management strategic plan for the years 2001-2006. Arizona Game and Fish Department, Phoenix, Arizona.

Arizona Game and Fish Department. 2005a. Action plan for minimizing and responding to lion/human interaction. Arizona Game and Fish Department, Phoenix, Arizona.
Arizona Game and Fish Department. 2005b. Regional elk management operational plans. Arizona Game and Fish Department, Phoenix, Arizona.

Aune, K.E. 1993. Increasing mountain lion populations and human-mountain lion interactions in Montana. Pages 86-94 in C.S. Braun, editor. Mountain lionhuman interaction symposium and workshop. Colorado Division of Wildlife, Denver, Colorado.

Ballard, W.B., Lutz, D., Keegan, T.W., Carpenter, L.H., and DeVos, J.C., Jr. 2001. Deer-predator relationships: A review of recent North American studies with emphasis on mule and black-tailed deer. Wildlife Society Bulletin 29: 99-115.

Barber, S.P. 2005. Arizona mountain lion status report. Mountain Lion Workshop 8: 65-69.

Baron, D. 2004. The beast in the garden: A modern parable of man and nature. W.W. Norton, New York, New York.

Barrett, M.W. 1984. Movements, habitat use, and predation on pronghorn fawns in Alberta. Journal of Wildlife Management 48: 542-550.

Bauer, J.W., Logan, K.A., Sweanor, L.L., and Boyce, W.M. 2005. Scavenging behavior in puma. The Southwestern Naturalist 50: 466-471.

Beier, P. 1991. Cougar attacks on humans in the United States and Canada. Wildlife Society Bulletin 19: 403412.

Beier, P. 1993. Determining minimum habitat areas and habitat corridors for cougars. Conservation Biology 7: $94-108$.

Beier, P. 1995. Dispersal of juvenile cougars in fragmented habitat. Journal of Wildlife Management 59: 228-237.

Beier, P., and Barrett, R.H. 1993. The cougar in the Santa Ana Mountain Range, California. Orange County Cooperative Mountain Lion Study Final Report.

Beier, P., Choate, D., and Barrett, R.H. 1995. Movement patterns of mountain lions during different behaviors. Journal of Mammalogy 76: 1056-1070. 
Boyd, D., and O’Gara, B. 1985. Cougar predation on coyotes. The Murrelet 66:17.

Bubenik, A.B. 1982. Physiology. Pages 125-179 in J.W. Thomas and D.E. Toweill, editors. Elk of North America: ecology and management. Stackpole Books, Harrisburg, PA.

Burnham, K.P., and Anderson, D.R. 1998. Model selection and inference: A practical informationtheoretic approach. Springer, New York, New York.

Burt, W.H., and Grossenheider, R.P. 1976. A field guide to the mammals: North America north of Mexico. Third edition. Houghton Mifflin, Boston, MA.

Cain, J.W., III, Krausman, T.R., Jansen, B.D., Morgart, J.R. 2005. Influence of topography and GPS fix interval on GPS collar performance. Wildlife Society Bulletin 33: 926-934.

Clark, T.W., and Munno, L. 2005. Mountain lion management: Resolving public conflict. Pages 71-98 in T.W. Clark, M.B. Rutherford, and D. Casey, editors. Coexisting with large carnivores: Lessons from Greater Yellowstone. Island Press, Washington, D.C.

Clevenger, A.P., and Waltho, N. 2000. Factors influencing the effectiveness of wildlife underpasses in Banff National Park, Alberta, Canada. Conservation Biology 14: 47-56.

Clevenger, A.P., and Waltho, N. 2005. Performance indices to identify attributes of highway crossing structures facilitating movement of large mammals. Biological Conservation 121: 453-464.

Conover, M.R., Pitt, W.C., Kessler, K.K., DuBow, T.J., and Sanborn, W.A. 1995. Review of human injuries, illnesses and economic losses caused by wildlife in the United States. Wildlife Society Bulletin 23: 407414.

Conrad, L. 1992. Cougar attack: A case report of a fatality. Journal of Wilderness Medicine 3: 387-396.

Cooper, A.B., and Millspaugh, J.J. 1999. The application of discrete choice models to wildlife resource selection studies. Ecology 80: 566-575.

Cougar Management Guidelines Working Group. 2005. Cougar management guidelines. $1^{\text {st }}$ edition. WildFutures, Bainbridge Island, Washington.
Davies, R.B. 1993. Lion damage to pets in urban Colorado Springs, Colorado. Pages 79-80 in C.S. Braun, editor. Mountain lion-human interaction symposium and workshop. Colorado Division of Wildlife, Denver, Colorado.

Decision Research. 2004. Arizona statewide polling results. Unpublished memorandum. Decision Research, San Diego, California.

DeJong, G.D., and Chadwick, J.W. 1999. Decomposition and arthropod succession on exposed rabbit carrion during summer at high altitudes in Colorado, USA. Journal of Medical Entomology 36: 833-845.

D’Eon, R.G., Serrouya, R., Smith, G., and Kochanny, C.O. 2002. GPS error and bias in mountainous terrain. Wildlife Society Bulletin 30: 430-439.

D’Eon, R.G., and Delparte, D. 2005. Effects of radiocollar position and orientation on GPS radio-collar performance, and the implications of PDOP for data screening. Journal of Applied Ecology 42: 383-388.

Ernest, H.B., Boyce, W.M., Bleich, V.C., May, B., Stiver, S.J., and Torres, S.G. 2003. Genetic structure of mountain lion (Puma concolor) populations n California. Conservation Genetics 4: 353-366.

Deurbrock, J., and Miller, D. 2001. Cat attacks: True stories and hard lessons from cougar country. Sasquatch Books, Seattle, Washington.

DeVos, J.C., Jr., and McKinney, T. 2005. Recent trends in North American mountain lion populations: A hypothesis. Pages 297-307 in C. van Riper III and D.J. Mattson, editors. The Colorado Plateau II: Biophysical, socioeconomic, and cultural research. University of Arizona Press, Tucson, Arizona.

Dickson, B.G., and P. Beier. 2002. Home-range and habitat selection by adult cougars in southern California. Journal of Wildlife Management 66: 1235-1245.

Dickson, B.G., J.S. Jenness, and P. Beier. 2005. Influence of vegetation, topography, and roads on cougar movement in southern California. Journal of Wildlife Management 69: 264-276.

Etling, K. 2001. Cougar attacks: Encounters of the worst kind. The Lyons Press, Guilford, Connecticut. 
Fitzhugh, E.L. 1988. Managing with potential for lion attacks against humans. Pages 74-77 in R.H. Smith. editor. Proceedings of the third mountain lion workshop. Arizona Game and Fish Department, Phoenix, Arizona.

Fitzhugh, E.L., and Fjelline, D.P. 1997. Puma behaviors during encounters with humans and appropriate human responses. Pages 26-28 in W.D. Padley, editor. Proceedings of the fifth mountain lion workshop. Southern California Chapter of The Wildlife Society, San Diego, California.

Fitzhugh, E.L., Schmid-Holmes, S., Kenyon, M.W., and Etling, K. 2003. Lessening the impact of a puma attack on a human. Pages 89-103 in S.A. Becker, D.D. Bjornlie, F.G. Lindzey, and D.S. Moody, editors. Proceedings of the seventh mountain lion workshop. Wyoming Game and Fish Department, Lander, Wyoming.

Frair, J., Nielsen, S.E., Merrill, E.H., Lele, S.R., Boyce, M.S., Munro, R.H.M., Stenhouse, G.B., and Beyer, H.L. 2004. Removing GPS collar bias in habitat selection studies. Journal of Applied Ecology 41: 201-212.

Geist, V. 1982. Adaptive behavioral strategies. Pages 219-277 in J.W. Thomas and D.E. Toweill, editors. Elk of North America: Ecology and management. Stackpole Books, Harrisburg, PA.

Gill, G.J. 2005. Decomposition and arthropod succession on above ground pig carrion in rural Manitoba. Canadian Police Research Centre Technical Report TR-06-2006, Ottawa, Ontario.

Gloyne, C.C., and Clevenger, A.P. 2001. Cougar Puma concolor use of wildlife crossing structures on the Trans-Canada highway in Banff National Park, Alberta. Wildlife Biology 7: 117-124.

Goff, M.L. 1992. Problems in estimation of postmortem interval resulting from wrapping of the corpse: a case study from Hawaii. Journal of Agricultural Entomology 9: 237-243.

Green, K.A. 1991. Development of a data base for analysis of information about lion sightings and lion-human interactions. Page 18 in C.S. Braun, editor. Mountain lion-human interaction symposium and workshop. Colorado Division of Wildlife, Denver, Colorado.
Halfpenny, J.C., Sanders, M.R., and McGrath, K.A. 1993. Human-lion interactions in Boulder County, Colorado: Past, present, and future. Pages 10-16 in C.S. Braun, editor. Mountain lion-human interaction symposium and workshop. Colorado Division of Wildlife, Denver, Colorado.

Hayes, C.L., Rubin, E.S., Jorgensen, M.C., Botta, R.A., and Boyce, W.M. 2000. Mountain lion predation of bighorn sheep in the Peninsular Ranges, California. Journal of Wildlife Management 64: 954-959.

Holm, G.W. 2003. What does ten years (1993-2002) of mountain lion observation data reveal about mountain lion-human interactions within Redwood National and State Parks? Page 165 in S.A. Becker, D.D. Bjornlie, F.G. Lindzey, and D.S. Moody, editors. Proceedings of the seventh mountain lion workshop. Wyoming Game and Fish Department, Lander, Wyoming.

Herrero, S. 1985. Bear attacks: Their causes and avoidance. Nick Lyons Books, New York, New York.

Hornocker, M.G. 1970. An analysis of mountain lion predation upon mule deer and elk in the Idaho Primitive Area. Wildlife Monograph 21: 1-39.

Hosmer, D.W. and Lemeshow, S. 2000. Applied logistic regression. Second edition. Wiley and Sons, New York.

Husseman, J.S., Murray, D.L., Power, G., Mack, C., Wenger, C.R., and Quigley, H. 2003. Assessing differential prey selection patterns between two sympatric large carnivores. Oikos 101: 591-601.

Iriarte, J.A., Franklin, W.L., Johnson, W.E., and Redford, K.H. 1990. Biogeographic variation of food habits and body size of the American puma. Oecologia 85: 185-190.

Isiche, J., Hillerton, J.E., and Nowell, F. 1992. Colonization of the mouse cadaver by flies in southern England. Medical and Veterinary Entomology 6: 168-170.

Kadesky, K.M., Manarey, C., Blair, G.K., Murphy, J.J., III, Verchere, C., and Atkinson, K. 1998. Cougar attacks on children: Injury patterns and treatments. Journal of Pediatric Surgery 33: 863-865.

Katnik, D.D., and Wielgus, R.B. 2005. Landscape proportions versus monte carlo simulated home ranges for estimating habitat availability. Journal of Wildlife Management 69: 20-32. 
Keating, K.A., and Cherry, S. 2004. Use and interpretation of logistic regression in habitat selection studies. Journal of Wildlife Management 68: 774-789.

Kellert, S.R. 1996. The value of life: Biological diversity and human society. Island Press, Washington, D.C.

Kintigh, M. 2005. South Dakota mountain lion status report. Mountain Lion Workshop 8: 34-37.

Koehler, G.M., and Hornocker, M.G. 1991. Seasonal resource use among mountain lions, bobcats, and coyotes. Journal of Mammalogy 72: 391-396.

Kunkel, K.E., Ruth, T.K., Pletscher, D.H., and Hornocker, M.G. 1999. Winter prey selection by wolves and cougars in and near Glacier National Park, Montana. Journal of Wildlife Management 63: 901-910.

Laing, S.P., and Lindzey, F.G. 1993. Cougar habitat selection in south-central Utah. Pages 27-37 in C.S. Braun, editor. Mountain lion-human interaction symposium and workshop. Colorado Division of Wildlife, Denver, Colorado.

Laliberte, A.S., and Ripple, W.J. 2004. Range contractions in North American carnivores and ungulates, BioScience 54: 123-137.

Laundré, J.W., and Hernández, L. 2003. Winter hunting habitat of puma Puma concolor in northwestern Utah and southern Idaho, USA. Wildlife Biology 9: 123-129.

Leyhausen, P. 1979. Cat behaviour: The predatory and social behaviour of domestic and wild cats. Garland Press, New York, New York.

Løe, J. 2002. Large carnivore related deaths: A conservation issue. M.Sc. Thesis, Norwegian University of Science and Technology, Trondheim, Norway.

Logan, K.A., and Irwin, L.L. 1985. Mountain lion habitats in the Bighorn Mountains, Wyoming. Wildlife Society Bulletin 13: 257-262.

Logan, K.A., and L.L. Sweanor. 2000. Puma. Pages 347-377 in S. Demaris and P.R. Krausman, editors. Ecology and management of large mammals in North America. Prentice Hall, Upper Saddle River, NJ.

Logan, K.A., and Sweanor, L.L. 2001. Desert puma: Evolutionary ecology and conservation of an enduring carnivore. Island Press, Washington, D.C.
Maehr, D.S., and Caddick, G.B. 1995. Demographics and genetic introgression in the Florida panther. Conservation Biology 9: 1295-1298.

Mansfield, T.M., and Charlton, K.G. 1998. Trends in mountain lion depredation and public safety incidents in California. Pages 118-120 in R.O. Baker and A.C. Crabb, editors. Proceedings of the $18^{\text {th }}$ Vertebrate Pest Conference.

Mattson, D.J. 1997. Use of ungulates by Yellowstone grizzly bears Ursus arctos. Biological Conservation 81: 161-177.

Mattson, D., Hart, J., and Arundel, T. 2005. Cougar predation in the Flagstaff Uplands: preliminary results from July 2003-May 2005. Mountain Lion Workshop 8: 158-169.

McRae, B.H., Beier, P., DeWald, L.E., Huynh, L.Y., and Keim, P. 2005. Habitat barriers limit gene flow and illuminate historical events in a wide-ranging carnivore, the American puma. Molecular Ecology 114: $1965-1977$.

Meinke, C.W., Golightly, R.T., Quigley, H.B., Ellingson, J., and Hofstra, T. 2004. Mountain lion habitat use relative to human activities in the Redwood Basin of northwest California. Abstract. American Society of Mammalogists Annual Meeting, 2004.

Murphy, K.M., G.S. Felzien, and S.E. Relyea. 1992. The ecology of the mountain lion (Felis concolor missoulensis) in the northern Yellowstone ecosystem. Cumulative Progress Report No. 5. Wildlife Research Institute, Moscow, ID.

Murphy, K.M., Felzien, G.S., Hornocker, M.G., and Ruth, T.K. 1998. Encounter competition between bears and cougars: some ecological implications. Ursus 10: 55-60.

Nielsen, S.E., Boyce, M.S., Stenhouse, G.B., and Munro, R.H.M. 2002. Modeling grizzly bear habitats in the Yellowhead Ecosystem of Alberta: Taking autocorrelation seriously. Ursus 13: 45-56.

Ockenfels, R.A. 1994. Mountain lion predation on pronghorn in central Arizona. Southwestern Naturalist 39: 305-306.

Papouchis, C.M. 2004. Conserving mountain lions in a changing landscape. Pages 219-239 in N. Fascione, A. Delach, and M.E. Smith, editors. People and predators: From conflict to coexistence. Island Press, Washington, D.C. 
Payne, J.A. 1965. A summer carrion study on the baby pig Sus scrofa L. Ecology 46: 592-602.

Perry, G.L., and DeVos, J.C., Jr. 2005. A case study of mountain lion-human interaction in southeastern Arizona. Mountain Lion Workshop 8: 104-113.

Pierce, B.M., Bleich, V.C., and Bowyer, R.T. 2000. Selection of mule deer by mountain lions and coyotes: effects of hunting style, body size, and reproductive status. Journal of Mammalogy 81: 462472.

Pritchard, P. 2000. Environmental risk management. Earthscan Publications, London, United Kingdom.

Riley, S.J., and Aune, K.E. 1997. Mountain lion-human and mountain lion-livestock incidents in Montana. Page 91 in W.D. Padley, editor. Proceedings of the fifth mountain lion workshop. Southern California Chapter of The Wildlife Society, San Diego, California.

Riley, S.J., and Malecki, R.A. 2001. A landscape analysis of cougar distribution and abundance in Montana, USA. Environmental Management 28: 317-323.

Riley, S.J., DeGloria, S.D., and Elliot, R. 1999. A terrain ruggedness index that quantifies topographic heterogeneity. Intermountain Journal of Sciences 5: 23-27.

Riley, S.J., Nesslage, G.M., and Maurer, B.A. 2004. Dynamics of early wolf and cougar eradication efforts in Montana: Implications for conservation. Biological Conservation 119: 575-579.

Ripple, W.J., and Beschta, R.L. 2006. Linking a cougar decline, trophic cascade, and catastrophic regime shift in Zion National Park. Biological Conservation 133: 397-408.

Robinnette, W.L., Gashwiler, J.S., and Morris, O.W. 1959. Food habits of the cougar in Utah and Nevada. Journal of Wildlife Management 23: 261-273.

Robinson, H.S., Wielgus, R.B., and Gwilliam, J.C. 2002. Cougar predation and population growth of sympatric mule deer and white-tailed deer. Canadian Journal of Zoology 80: 556-568.

Rodgers, A.R., Carr, A.P., Smith, L., and Kie, J.G. 2005. HRT: Home range tools for ArcGIS. Ontario Ministry of Natural Resources, Centre for Northern Forest Ecosystem Research, Thunder Bay, Ontario, Canada.
Rominger, E.M., Whitlaw, H.A., Weybright, D.L., Dunn, W.C., and Ballard, W.B. 2004. The influence of mountain lion predation on bighorn sheep translocations. Journal of Wildlife Management 68: 412-426.

Ross, P.I., and Jalkotzy, M.G. 1992. Characteristics of a hunted population of cougars in southwestern Alberta. Journal of Wildlife Management 56: 417426.

Ross, P.I., and Jalkotzy, M.G. 1995. Fates of translocated cougars, Felis concolor, in Alberta. Canadian Field-Naturalist 109: 475-476.

Ross, P.I., and Jalkotzy, M.G. 1996. Cougar predation on moose in southwestern Alberta. Alces 32: 1-8.

Ruth, T.K. 2004. Ghost of the Rockies: the Yellowstone cougar project. Pages 13-24 in R.J. Anderson, editor. Yellowstone Science 12. Yellowstone National Park, Wyoming.

Ruth, T.K., Logan, K.A., Sweanor, L.L., Hornocker, M.G., and Temple, L.J. 1998. Evaluating cougar translocation in New Mexico. Journal of Wildlife Management 62: 1264-1275.

Sanders, M.R., and Halfpenny, J.C. 1993. Human-lion interactions in Boulder County, Colorado. Page 17 in C.S. Braun, editor. Mountain lion-human interaction symposium and workshop. Colorado Division of Wildlife, Denver, Colorado.

Schubert, D.J. 2004. Arizona mountain lion information. http://lions.adlaz.org/azsum1.html.

Seidensticker, J.C., IV, Hornocker, M.G., Wiles, W.V., and Messick, J.P. 1973. Mountain lion social organization in the Idaho Primitive Area. Wildlife Monographs 35: 1-60.

Shaw, H.G. 1977. Impact of mountain lion on mule deer and cattle in northwestern Arizona. Pages 17-32 in R.C. Phillips and C. Jonkel, editors. Proceedings of the 1975 predator symposium. Montana Forest and Range Conservation Experiment Station, University of Montana, Missoula.

Shuey, M.L. 2005. Land-cover characteristics of cougar/human interactions in and around an urban landscape. Mountain Lion Workshop 8: 117-126.

Sinclair, E.A., Swenson, E.L., Wolfe, M.L., Choate, D.C., Bates, B., and Crandall, K.A. 2001. Gene flow estimates in Utah imply management beyond Utah. Animal Conservation 4: 257-264. 
Smith, E.P., Lipkovich, I., and Ye, K. 2002. Weight-ofevidence (WOE): Quantitative estimation of probability of impairment for individual and multiple lines of evidence. Human and Ecological Risk Assessment 8: 1585-1596.

Spalding, D.J., and Lesowski, J. 1971. Winter food of the cougar in south-central British Columbia. Journal of Wildlife Management 35: 378-381.

Sweanor. L.L., Logan, K.A., and Hornocker, M.G. 2005. Puma responses to close approaches by researchers. Wildlife Society Bulletin 33: 905-913.

Taber, R.D., Raedeke, K., and McCaughran, D.A. 1982. Population characteristics. Pages 279-298 in J.W. Thomas and D.E. Toweill, editors. Elk of North America: ecology and management. Stackpole Books, Harrisburg, PA.

Tantawi, T.I., El-Kady, E.M., Greenberg, B., and ElGhaffar, H.A. 1996. Arthropod succession on exposed rabbit carrion in Alexandria, Egypt. Journal of Medical Entomology 33: 566-580.

Tessmer, J.W., and Meek, C.L. 1996. Dispersal and distribution of Calliphoridae (Diptera) immatures from animal carcasses in southern Louisiana. Journal of Medical Entomology 33: 665-669.

Tischendorf, J.W. 2003. Cryptic cougars - perspectives on the puma in the eastern, midwestern, and Great Plains regions of North America. Pages 71-86 in S.A. Becker, D.D. Bjornlie, F.G. Lindzey, and D.S. Moody, editors. Proceedings of the seventh mountain lion workshop. Wyoming Game and Fish Department, Lander, Wyoming.

Torres, S.G., Mansfield, T.M., Foley, J.E., Lupo, T., and Brinkhaus, A. 1996. Mountain lion and human activity in California: Testing speculations. Wildlife Society Bulletin 24: 451-460.

Treves, A., Naughton-Treves, L. 1999. Risk and opportunity for humans coexisting with large carnivores. Journal of Human Evolution 36: 275282.

Van Dyke, F.G., Brocke, R.H., Shaw, H.G., Ackerman, B.B., Hemker, T.P., and Lindzey, F.G. 1986. Reactions of mountain lions to logging and human activity. Journal of Wildlife Management 50: 95102.
Wakeling, B.F. 2003. Status of mountain lions in Arizona. Pages 1-5 in S.A. Becker, D.D. Bjornlie, F.G. Lindzey, and D.S. Moody, editors.

Proceedings of the seventh mountain lion workshop. Wyoming Game and Fish Department, Lander, Wyoming.

Weisberg, S. 1985. Applied linear regression. Second edition. John Wiley, New York, New York.

Williams, J.S., McCarthy, J.J., and Picton, H.D. 1995. Cougar habitat use and food habits on the Montana Rocky Mountain Front. Intermountain Journal of Sciences 1: 16-28. 


\section{Acknowledgments}

Paul Whitefield (NPS), Mark Sogge (USGS), Denny Fenn (USGS, retired), Ron Hiebert (NPS) and Melanie Lambert (Summerlee Foundation) provided critically important support for our study. Paul Beier (NAU), Stephanie Nichols-Young (Wiburforce Foundation), Mary and Jesse Johnson (Johnson Family Foundation), Rick Miller (AZGF), Karen Murray (Grand Canyon Trust), Dave Bergman (USDA Wildlife Services), Steve Mitchelson (NPS), Richard Ockenfels (AZGF), and Ron Sieg (AZGF) offered much appreciated support and encouragement. Sam Dieringer (USDA Wildlife Services) and his hounds provided extraordinary and otherwise much appreciated capture services. Scott Sprague (AZGF) located lost mountain lions for us. Mike and Diane Miller were volunteers extraordinaire. We greatly valued all of our volunteers, including Zachary and Sky Bischoff-Mattson, Susan Bischoff, Brandon Holton, Trevor Streng, Jesse Millen-Johnson, David Allen, Margaret Carr, Samantha McClure, John Broecher, Bill Martin, Jamie and Dick McNeil, Chris and Michael Finney, Tim Melnick, and Adam Glover. Financial support for this study has been provided by the USGS Park-Oriented Biological Support program, the USGS Colorado Plateau Research Station, the NPS Cooperative Conservation Initiative, the Summerlee Foundation, the Wilburforce Foundation, the USGS Southwest Biological Science Center, the USGS Fire Research Program, and the Johnson Family Foundation. Material and other in-kind support has been provided by USDA Wildlife Services, The Grand Canyon Trust, Northern Arizona University, Arizona Game and Fish Department, and the NPS Flagstaff Area National Monuments. The use of trade, product, or firm names in this publication is for descriptive purposes only and does not imply endorsement by the U.S. Government. 


\section{Appendix 1. Summary of Outreach}

\section{Public presentations, informational meetings, and other public outreach or academic service accomplished during January 2003-July 2006 as part of this project.}

\section{Presentations}

1. "A conceptual model and appraisal of existing research related to interactions between humans and pumas," by D. Mattson, J. Hart, P. Beier, \& J. Millen-Johnson at $7^{\text {th }}$ Mountain Lion Workshop, sponsored by Wyoming Game \& Fish Department and The Wildlife Society, Jackson, WY, May 2003.

2. "Cougars of the Flagstaff Uplands," by J. Hart and D. Mattson for Science in the Park, sponsored by Flagstaff Festival of Science, Flagstaff, AZ, September 2003.

3. "A conceptual model and appraisal of research related to interactions between humans and pumas,” by D. Mattson, J. Hart \& P. Beier for $7^{\text {th }}$ Biennial Conference of Research on the Colorado Plateau, sponsored by the $7^{\text {th }}$ Biennial Conference Committee, Flagstaff, AZ, November 2003.

4. “Cougars of the Flagstaff Uplands research project," by D. Mattson, J. Hart \& T. Arundel for 2004 Western Region Center Director's Meeting, sponsored by USGS BRD Western Region, Flagstaff, AZ, June 2004.

5. “Cougars of the Flagstaff Uplands: an introduction and results of the 2003-2004 field season,” by J. Hart, D. Mattson \& T. Arundel for 2004 State Meeting of the Arizona Wildlife Services Program, sponsored by USDA Wildlife Services, Hawley Lake, AZ, July 2004.

6. "Cougars of the Flagstaff Uplands: an introduction and results of the 2003-2004 field season," by D. Mattson, J. Hart \& T. Arundel for 2004 Flagstaff Field Center Open House, sponsored by the USGS Flagstaff Field Center, Flagstaff, AZ, July 2004.

7. “Cougars of the Flagstaff Uplands: an introduction and results of the 2003-2004 field season,” by D. Mattson, J. Hart \& T. Arundel for August Staff Meeting, Region 2 Arizona Game \& Fish Department, sponsored by Region 1, Arizona Game \& Fish Department, Flagstaff, AZ, August 2004.

8. “Cougars on the edge... of Flagstaff," by D. Mattson, J. Hart and T. Arundel for Northern Arizona University Forestry Seminar Series, sponsored by NAU School of Forestry, Flagstaff, AZ, September 2004.

9. “Cougars of the Flagstaff Uplands: an introduction and results of the 2003-2004 field season,” by D. Mattson, J. Hart \& T. Arundel for Flagstaff Science Center September All Hands Meeting, sponsored by USGS Flagstaff Science Center, Flagstaff, AZ, September 2004.

10. “Cougars of the Flagstaff Uplands,” by J. Hart \& D. Mattson for Science in the Park, sponsored by Flagstaff Festival of Science, Flagstaff, AZ, September 2004.

11. “Cougars of the Flagstaff Uplands," by J. Hart, D. Mattson \& T. Arundel for Community Forest Forum, Flagstaff City Hall, sponsored by the Greater Flagstaff Forests Partnership, Flagstaff, AZ, October 2004.

12. "Cougars of the Flagstaff Uplands: an introduction and results of the 2003-2004 field season,” by J. Hart, D. Mattson \& T. Arundel for Forest Management (FOR323W), Northern Arizona University School of Forestry, Flagstaff, AZ, February 2005. 
13. "A multi-park design for investigating cougar-related risks to humans in the Southwest," by D.J. Mattson, J. Hart, T. Arundel, E. Garding, H.S. Kim, and E. Leslie, for 2005 George Wright Society Biennial Conference on Parks, Protected Areas and Cultural Sites, sponsored by the George Wright Society, Philadelphia, PA, March 2005.

14. "Cougars of the Flagstaff uplands: cougar-informed spatial frames for analyzing habitat selection,” by D.J. Mattson, T. Arundel and J. Hart, for $8^{\text {th }}$ Mountain Lion Workshop, sponsored by the Washington Department of Fish \& Wildlife, Leavenworth, WA, May 2005.

15. “Cougars of the Flagstaff uplands: results of 2003-2004 predation studies,” by D.J. Mattson, J. Hart and T. Arundel, for $8^{\text {th }}$ Mountain Lion Workshop, sponsored by the Washington Department of Fish \& Wildlife, Leavenworth, WA, May 2005.

16. "Development of an agent-based model for cougars in Arizona," by T.R. Arundel, D.J. Mattson, and J. Hart, for ESRI 2005 User Conference, San Diego, CA, June 2005.

17. “Conflict over carnivores: a window on natural resources governance,” by D.J. Mattson for conference on Governance and Decision-Making in Mountain Areas, sponsored by Parks Canada and The Banff Centre, Banff, AB, Canada, June 2005.

18. "Cougars of the Flagstaff Uplands," by J. Hart for Science in the Park, sponsored by The Flagstaff Festival of Science, Flagstaff, AZ, September 2005.

19. “(We are) living with cougars in the Flagstaff Uplands,” by D.J. Mattson, sponsored by the Phoenix Zoo and Sierra Club, Flagstaff, AZ, September 2005.

20. “Safety in Red Rock’s Lion Country,” by D.J. Mattson for the USFS Red Rocks Ranger District Monthly Safety Meeting, sponsored by the USFS Red Rocks Ranger District, Sedona, AZ, October 2005.

21. "Conflict over cougars: A window on the institution of wildlife management," by D. Mattson for Foundations of Natural Resources Policy and Management (F\&ES 891b), Yale School of Forestry and Environmental Studies, New Haven, CT, October 2005.

22. "Human dimensions of mountain lion management: Value orientations and policy preferences of Northern Arizona residents,” by E.J. Ruther, D.M. Ostergren, and D.J. Mattson for $8^{\text {th }}$ Biennial Conference of Research on the Colorado Plateau, sponsored by the $8^{\text {th }}$ Biennial Conference Committee, Flagstaff, AZ, November 2005.

23. "Predation by cougars in the Flagstaff Uplands 2003-2005," by D. Mattson, J. Hart and T. Arundel for $8^{\text {th }}$ Biennial Conference of Research on the Colorado Plateau, sponsored by the $8^{\text {th }}$ Biennial Conference Committee, Flagstaff, AZ, November 2005.

24. “Cougars of the Colorado Plateau: A multi-park investigation,” by D. Mattson, J. Hart, T. Arundel, R. Stevens, E. Garding, RV Ward, J. Bradybaugh, and E. Leslie, for $4^{\text {th }}$ Annual Southwest Biological Science Center All-Employees Meeting, sponsored by the USGS Southwest Biological Science Center, Flagstaff, AZ, November 2005.

25. “Cougars of the Colorado Plateau: A multi-park investigation,” by D. Mattson, J. Hart, T. Arundel, R. Stevens, and J. Bradybaugh, for Zion National Park staff, sponsored by Zion National Park, UT, December 2005. 
26. “Cougars of the Colorado Plateau: A multi-park investigation,” by D. Mattson, J. Hart, T. Arundel, R. Stevens, and J. Bradybaugh, for public venue, sponsored by Zion National Park, Springdale, UT, December 2005.

27. “Cougars of the Colorado Plateau: A multi-park investigation,” by D. Mattson, J. Hart, T. Arundel, R. Stevens, E. Garding, RV Ward, J. Bradybaugh, and E. Leslie, for $1^{\text {st }}$ Meeting of the Colorado Plateau Mountain Lion Working Group, sponsored by the USGS Southwest Biological Science Center, Flagstaff, AZ, January 2006.

28. “Cougars of the Flagstaff Uplands: Preliminary results 2003-2005,” by D. Mattson, J. Hart, and T. Arundel, for $1^{\text {st }}$ Meeting of the Colorado Plateau Mountain Lion Working Group, sponsored by the USGS Southwest Biological Science Center, Flagstaff, AZ, January 2006.

29. "Living with large fierce creatures: Cougars at the Arizona urban-wildland interface," by D. Mattson for the Environmental Studies Colloquium, sponsored by Prescott College, Prescott, AZ, April 2006.

30. "Cougar studies at the Southwest Biological Science Center," by D. Mattson, J. Hart and T. Arundel, for the Flagstaff Leadership Program, sponsored by the USGS Flagstaff Science Center and Flagstaff Leadership Program, Flagstaff, AZ, May 2006.

31. “Cougars of the Flagstaff Uplands,” by D. Mattson, J. Hart and T. Arundel, for Flagstaff Area National Monuments staff, sponsored by the NPS Flagstaff Area National Monuments, Flagstaff, AZ, May 2006.

32. "Lions in the mountains: Co-existence and the nature of pumas," by D. Mattson for the First Sunday Program, sponsored by Red Rock State Park, Sedona, AZ, June 2006.

33. "Lions in the mountains: Co-existence and the nature of pumas," by D. Mattson for the Willow Bend Environmental Center Summer Speaker Series, sponsored by the Willow Bend Environmental Center, Flagstaff, AZ, July 2006.

\section{Posters and Other Printed Informational Material}

1. "Monitoring cougar movements near the Flagstaff urban interface," POSTER and presentation by J. Hart and D. Mattson for Cougars and Human Safety Trailhead Workshop, sponsored by the US Forest Service and Arizona Department of Game \& Fish, Flagstaff, AZ, December 2002.

2. Mattson, D.J., J. Hart \& T. Arundel. (2002). Cougars of the Flagstaff uplands. USGS Southwest Biological Science Center, Flagstaff, AZ. 2pp. (RESEARCH BRIEFING).

3. "Monitoring cougar movements near the Flagstaff urban interface," POSTER by J. Hart and D. Mattson for Cougars and Human Safety Trailhead Workshop, sponsored by the US Forest Service and Arizona Department of Game \& Fish, Flagstaff, AZ, December 2002.

4. "Spatial analysis of puma (Puma concolor) habitat use relative to topographic roughness in northern Arizona," POSTER by T.R. Arundel, S.T. Arundel, D. Mattson \& J Hart for $7^{\text {th }}$ Biennial Conference of Research on the Colorado Plateau, sponsored by the $7^{\text {th }}$ Biennial Conference Committee, Flagstaff, AZ, November 2003.

5. "Kills by cougars in the Flagstaff uplands of northern Arizona” POSTER by D. Mattson, J. Hart, \& T. Arundel for 2004 Western Region Center Director's Meeting, sponsored by USGS BRD Western Region, Flagstaff, AZ, June 2004. 
6. Mattson, D.J., J. Hart \& T. Arundel. (2004). Kills by cougars in the Flagstaff Uplands of northern Arizona July2003-May 2004. USGS Southwest Biological Science Center, Flagstaff, AZ. 1pp. (FACT SHEET)

7. "Cougar-informed spatial frames and control for autocorrelation in analyses of habitat selection," POSTER by D. Mattson, T. Arundel, \& J. Hart for $8^{\text {th }}$ Mountain Lion Workshop, sponsored by Washington Department of Fish \& Wildlife, Leavenworth, WA, May 2005.

8. Mattson, D.J., T. Arundel \& J. Hart. (2005). Preliminary analysis of habitat selection by cougars in the Flagstaff uplands. USGS Southwest Biological Science Center, Flagstaff, AZ. 1pp. (FACT SHEET)

9. Mattson, D., Hart, J. and Arundel, T. (2005). Kills by cougars in the Flagstaff uplands of northern Arizona, July 2003-February 2005. USGS Southwest Biological Science Center, Flagstaff, AZ. 1pp. (RESEARCH BRIEFING).

10. Mattson, D., Arundel, T., and Hart, J. (2005). Preliminary analysis of habitat selection by cougars in the Flagstaff uplands of northern Arizona. USGS Southwest Biological Science Center, Flagstaff, AZ. 1pp. (RESEARCH BRIEFING).

\section{Reviews of Management Materials}

1. Review of the draft report Analysis of Scientific Publications Related to the Florida Panther for U.S. Fish \& Wildlife Service and Florida Fish \& Wildlife Commission, 2003.

2. Review of Cougar Management Guidelines for North America, for the authors and for Wild Futures, Earth Island Institute, Bainbridge Island, WA, 2004-2005.

\section{Published Abstracts and Papers}

1. Mattson, D.J., J.V. Hart, P. Beier \& J. Millen-Johnson. (2003). A conceptual model and appraisal of existing research related to interactions between humans and pumas. Page 104 in S.A. Becker, D.D. Bjornlie, F.G. Lindzey \& D.S. Moody, editors. Proceedings of the Seventh Mountain Lion Workshop. Wyoming Game \& Fish Department, Lander, WY. (ABSTRACT)

2. Mattson, D., J. Hart, \& T. Arundel. (2005). Cougar predation in the Flagstaff Uplands: preliminary results from July 2003-May 2005. Pages 158-169 in R. Beausoleil \& D. Martorello, editors. Proceedings of the $8^{\text {th }}$ Mountain Lion Workshop. Washington Department of Fish \& Game Department, Olympia, WA.

\section{Mentoring and Training}

Volunteers (listing those who made substantial contributions)

Grand Canyon Trust: Karen Murray, Bill Martin, Jamie and Dick McNeil, Chris and Michael Finney, and Adam Glover.

Northern Arizona University: Samantha McClure, John Broecher, Brandon Holton, Trevor Streng, and Tim Melnick.

USGS: Mike and Diane Miller, Zachary and Sky Bischoff-Mattson, Susan Bischoff, Jesse Millen-Johnson, David Allen, and Margaret Carr. 


\section{Preceptorships and Graduate Committees}

1. D. Mattson, Preceptor, 2003, Intern program for Jesse Millen-Johnson involving field work for the Flagstaff area cougar project, Bates College, Lewiston, ME.

2. D. Mattson, Committee Member, 2002-2005, Master's program for Elizabeth Ruther, Conflict and cohabitation: a survey of northern Arizona ponderosa pine ecosystem residents assessing nature views and cougar perceptions, Environmental Sciences \& Policy, Northern Arizona University, Flagstaff, AZ.

3. D. Mattson, Preceptor, 2004, Winter Study Project for Margaret Carr and David Allen, Where the wild things are: a study of cougar response to the presence of humans, Winter Studies Program (SPEC 99), Williams College, Williamsburg, MA.

4. D. Mattson, Faculty Advisor, 2004-2005, Senior Project for Trevor Streng, Cougar biology in northern Arizona, Center for Environmental Studies \& Education, Northern Arizona University, Flagstaff, AZ. 